\title{
LIDERAZGO DEL SECTOR PRIVADO EN LA CONSERVACIÓN DEL MEDIO AMBIENTE**
}

\begin{abstract}
Actualmente hay catorce millones de hectáreas protegidas por el Estado chileno a través del SNASP (Sistema Nacional de Áreas Silvestres Protegidas), lo que ha permitido conservar un área importante del patrimonio ambiental terrestre del país. Adicionalmente, hay cerca de 1,5 millones de hectáreas bajo regímenes de protección privada. ¿Cómo se puede incrementar ese patrimonio, en manos privadas? ¿Qué herramientas se están usando en países de similar nivel de desarrollo para proteger áreas privadas ambientalmente significativas? ¿Qué experiencias existen de alianzas entre el sector público y privado para proteger áreas relevantes?

Por otro lado, ¿qué y cuánto estamos protegiendo de nuestros más de 4.200 kilómetros de costa, con qué herramientas? ¿Es posible combinar protección de los recursos marinos y su explotación económica sustentable?

En estas páginas se recogen ponencias que sugieren respuestas a estas interrogantes. Ellas fueron presentadas en el seminario "El liderazgo del sector privado en la conservación del medio ambiente” realizado en el Centro de Estudios Públicos (CEP) el 26 de marzo de 2008, Santiago, con el patrocinio de la Wildlife Conservation Society (WCS), el Center for Environmental Markets de Goldman Sachs y el CEP.
\end{abstract}

* Ponencias presentadas en el seminario "El liderazgo del sector privado en la conservación del medio ambiente" que se realizó el 26 de marzo de 2008 en el Centro de Estudios Públicos, Santiago, con el copatrocinio de la Wildlife Conservation Society (WCS), el Center for Environmental Markets de Goldman Sachs y el Centro de Estudios Públicos (CEP).

Estudios Públicos agradece a Leonel Sierralta por la edición de los textos.

Estudios Públicos, 112 (primavera 2008). 
Introducción.

\section{Palabras inaugurales}

Eliodoro Matte ....................................................................................... 175

Mark Tercek ..................................................................................... 178

\section{El contexto internacional}

Compensación para la biodiversidad: Desafíos y oportunidades Ray Victurine.....

Conservación privada y comunal en el Perú

Jorge Caillaux Z.

El gran experimento conservacionista: Parque Adirondack

Ross S. Whaley

\section{El contexto nacional}

La experiencia de la Fundación Lahuén

Sergio Vergara Larraín

El océano y la conservación en Chile: Los eternos olvidados

Juan Carlos Castilla

Plantaciones forestales y sustentabilidad

Fernando Raga y Aldo Cerda

Instrumentos no tradicionales para la protección de los recursos naturales en Chile

Ricardo Katz, Gabriel del Fávero, Leonel Sierralta, Javier Vergara, Guillermo González y Gonzalo Moyano 


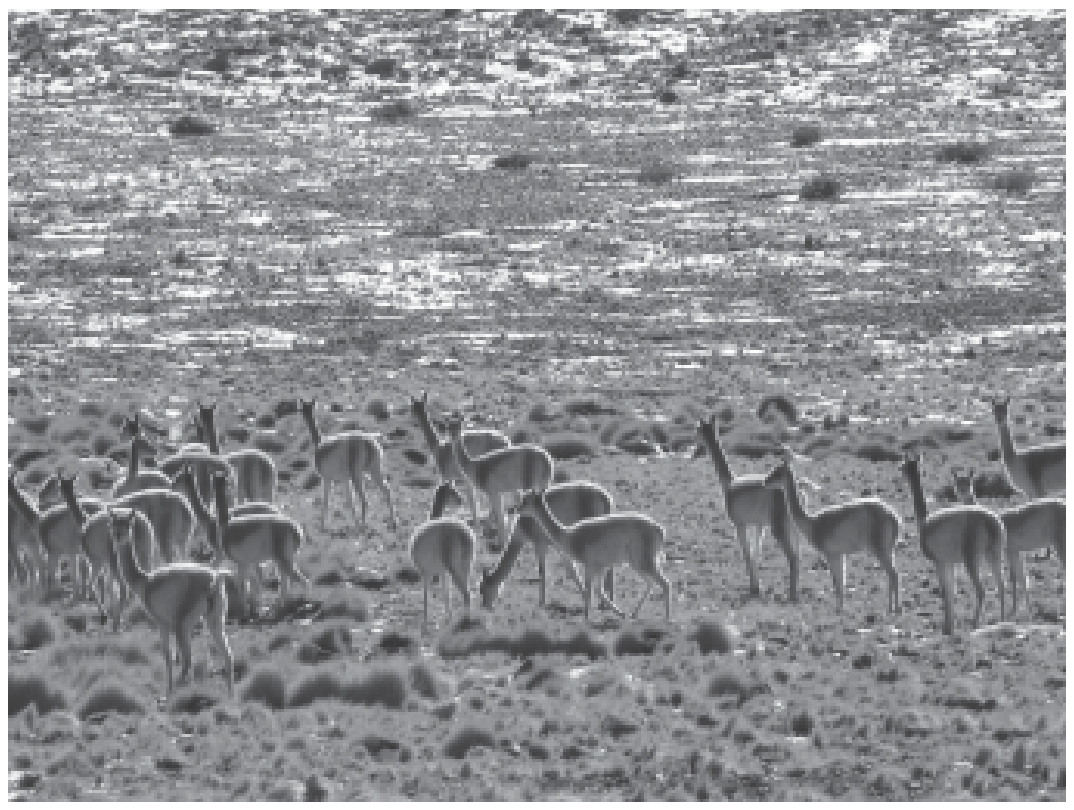

Rebaño de vicuñas, II Región, Chile. (C) GAC.

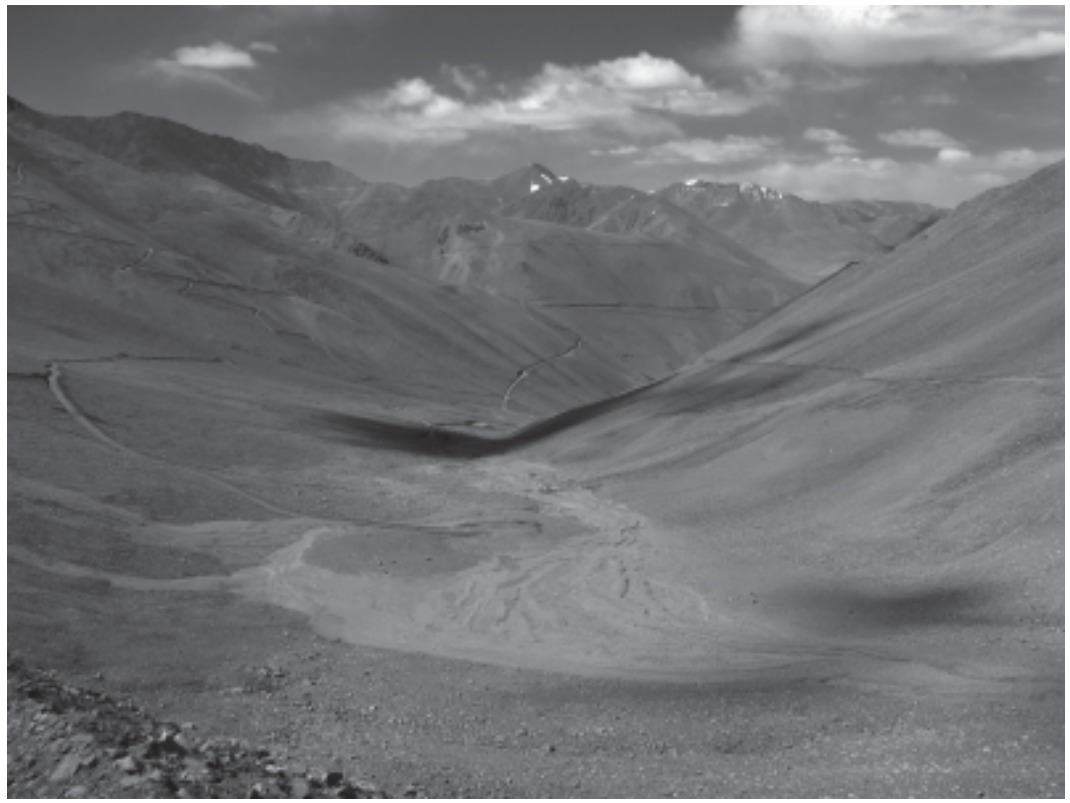

Cordillera de la III Región, Chile. (c) GAC. 


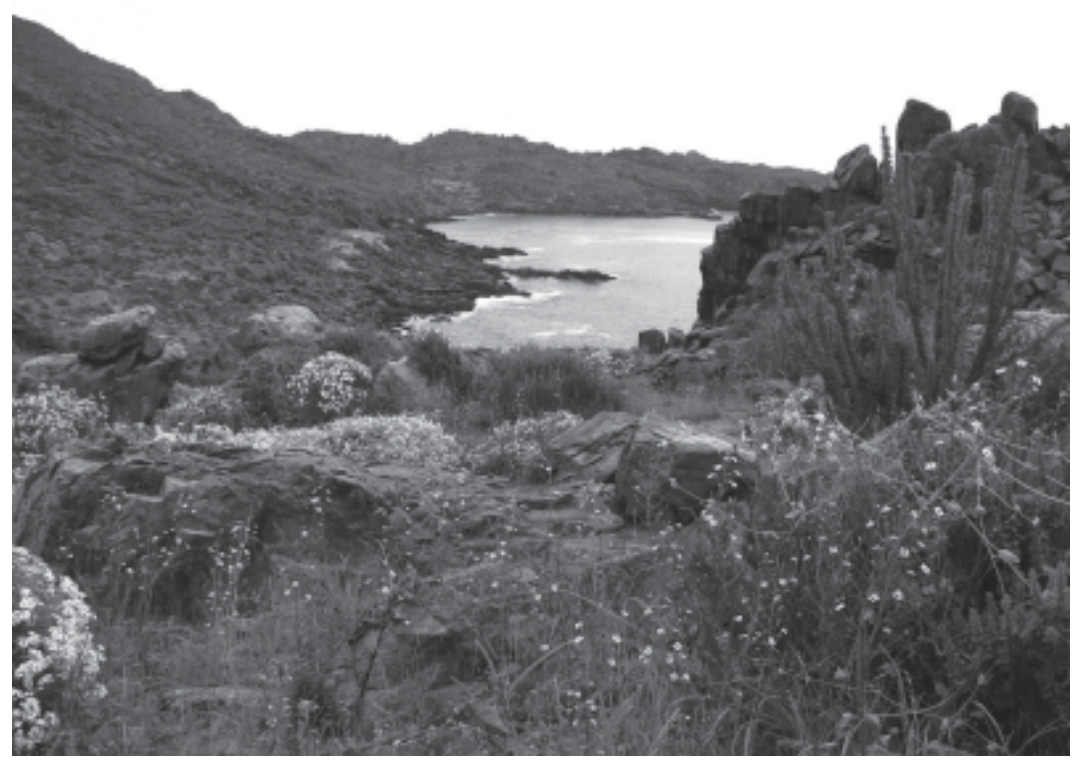

Cruz Grande, IV Región, Chile. (c) GAC.

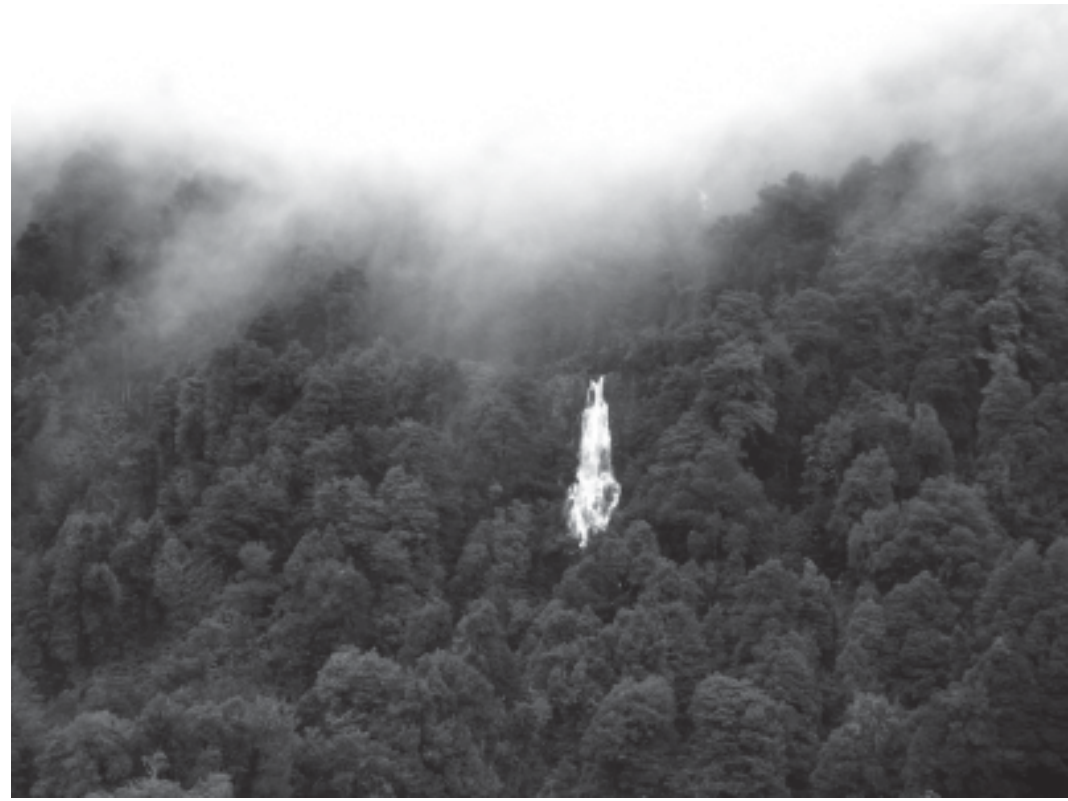

Bosque valdiviano, Región de los Ríos, Chile. @ GAC. 


\section{Introducción}

En estas páginas se reúne un conjunto de ponencias relacionadas con el rol del sector privado en la conservación. Las ocho ponencias, que aquí se entregan en su versión extensa, fueron presentadas en el auditorio del Centro de Estudios Públicos el 26 de marzo del 2008, en el contexto del Seminario "El liderazgo del sector privado en la conservación del medio ambiente" con el copatrocinio de la Wildlife Conservation Society (WCS), el Center for Environmental Markets de Goldman Sachs y el Centro de Estudios Públicos (CEP).

El tema ambiental, en su sentido global, ha evolucionado en Chile desde la generación de la legislación ambiental a comienzos de los años 90 hasta la instalación del mismo en la gestión diaria de las empresas, en conjunto con el desarrollo de un elaborado sistema de gestión pública que involucra a una buena parte de la administración estatal. Ese avance en la gestión ha estado centrado en el control de la contaminación y en el desarrollo de un sistema de evaluación de los impactos ambientales de los proyectos de inversión. Paralelamente, se ha instalado una nueva institucionalidad pública en esas materias.

Ese desarrollo legislativo, de gestión e institucional no ha sido equivalente en materias relacionadas con los Recursos Naturales, en especial con respecto a la conservación de áreas relevantes de ecosistemas naturales. En efecto, la urgencia de contar con una legislación ambiental que permitiera el control y manejo de los desechos de la producción, dejó en el olvido la gestión y promoción de los recursos naturales. Transcurrieron dieciocho años entre la promulgación de la Ley de Pesca de comienzos de los 90 y la promulgación de la Ley de Bosque Nativo, a mediados del 2008. Por otra parte, la ley que regula y moderniza la gestión de las áreas silvestres del Estado y de la institucionalidad que la gestiona, fue promulgada en 1984, sin contar con un reglamento aún que le permita funcionar.

¿Por qué debatir estos temas en el CEP? En primer lugar porque se trata de un tema ambiental relevante que tiene implicancias en la gestión pública. En segundo lugar, porque detectamos un creciente interés en el desarrollo de áreas protegidas privadas, que no cuentan con apoyos tributarios o subsidios para su creación. Nuevamente, el emprendimiento privado pasa por alto las barreras burocráticas y encuentra las soluciones a sus requerimientos. Ambas razones explican la discusión de ellos en el CEP.

Los catorce millones de hectáreas protegidas por el Estado en el Sistema Nacional de Áreas Silvestres Protegidas del Estado han permitido conservar un importante componente del patrimonio ambiental terrestre chi- 
leno. Adicionalmente, y sin sistemas de apoyo o incentivo estatal, un conjunto relativamente pequeño de privados mantiene casi 1,5 millones de hectáreas adicionales bajo regímenes de protección. ¿Cómo se puede incrementar ese patrimonio, en manos privadas? ¿Qué herramientas se están usando en los países de nivel similar de desarrollo al nuestro para proteger áreas privadas ambientalmente relevantes? Por otra parte, ¿qué experiencias existen de desarrollo de alianzas entre el sector público y el privado para proteger áreas relevantes? A su vez, ¿qué podemos hacer por incorporar áreas relevantes patrimonialmente y que están en manos privadas usando las herramientas legales vigentes? En otro eje de discusión podemos preguntarnos respecto a la conservación de áreas marinas. ¿Qué y cuánto estamos protegiendo de nuestros más de 4.200 kilómetros de costa? ¿Qué herramientas estamos usando para proteger esos ecosistemas? ¿Es posible combinar protección de los recursos marinos y explotación económica sustentable de ellos?

Las ponencias que siguen proponen y sugieren respuestas a esas interrogantes.

Leonel Sierralta Comisión de Medio Ambiente, Centro de Estudios Públicos 


\title{
I. PALABRAS INAUGURALES
}

\author{
Eliodoro Matte \\ Presidente del Centro de Estudios Públicos
}

Me es muy grato recibirlos hoy en el Centro de Estudios Públicos. Agradezco en especial a Wild Conservation Society (WCS) y a Goldman Sachs la oportunidad de organizar en conjunto este interesante seminario. Para el CEP, los temas que nos convocan esta mañana han sido motivo de muchas investigaciones, publicaciones y seminarios, que concitaron nuestro interés muy tempranamente. Ya hacia fines de la década de los 80 el CEP constituyó la Comisión de Medio Ambiente, que continúa en funciones hasta hoy y que tuvo activa participación en la elaboración de la Ley de Bases promulgada en 1994 y en los sucesivos debates sobre la institucionalidad medioambiental, sobre las normas, los reglamentos y tantas otras materias que nuestro país ha ido adoptando paulatinamente.

El asunto que nos reúne esta mañana está lleno de desafíos enteramente nuevos para los Estados, las empresas y los países en general. La naturaleza, cuya fuerza atemorizó a la humanidad por milenios, llenando a los hombres de miedo y asombro, depende hoy del cuidado de los hombres. La naturaleza es vulnerable y es, quizás, nuestra tecnología la que despierta miedo y asombro.

La especie humana sólo puede sobrevivir en un ambiente natural determinado. Nuestro futuro depende de la conservación de esas condiciones de vida. Esa labor de conservación en nuestro tiempo sólo será posible si la tecnología y las políticas públicas, en sentido amplio, son puestas por el ser humano al servicio de la conservación.

El desafío presente es conciliar el desarrollo económico, que nuestros pueblos buscan y requieren, con la conservación de nuestro hábitat, sin el cual la vida humana y el propio desarrollo se volverían imposibles o ilusorios.

Hoy se oyen muchas voces que claman por cambiar el modelo de desarrollo que mayoritariamente ha adoptado el mundo; algunos creen que es imposible continuar por esta senda ya que los daños que se están produciendo en el medio ambiente tendrá consecuencias impredecibles. Otros tienen gran confianza en que la creatividad de la mente humana, en especial cuando los derechos de propiedad están bien asignados y las señales de precio son las adecuadas, permitirá crear mecanismos que restablecerán un equilibrio entre el hombre y la naturaleza. 
Para los países subdesarrollados, la disyuntiva es aún más complicada, ya que por qué se les va a impedir a sus pueblos las oportunidades que los países desarrollados tuvieron hace cien años atrás y que le ha permitido a su población tener altos indicadores de desarrollo humano. Este no es solo un dilema técnico sino que ético.

Hay una pluralidad de formas para abordar la tarea del cuidado del medio ambiente y la conservación de áreas naturales. La responsabilidad es tan enorme que requiere de la colaboración de todos, cada cual desde su función propia. El Estado, las empresas privadas y los particulares pueden y deben desarrollar actividades convergentes. En este seminario nos ocuparemos de algunas de ellas.

Una de las dificultades que implica la conservación es el volumen de los recursos que requiere y los plazos, pues el financiamiento ha de ser continuo. Las experiencias de Wildlife Conservation Society y del Center for Environmental Markets de Goldman Sachs son, en esta materia, sumamente interesantes. Están abriendo nuevos caminos a la participación del sector privado en la tarea de la conservación a través de mecanismos de financiamiento atractivos y modernos.

Por ejemplo, las experiencias de compra de bonos de carbono o los swaps de deuda por naturaleza (debt-for-nature swaps) que liberan recursos de los países que tienen deuda externa, para dedicarlos al financiamiento de la conservación, constituyen modalidades ingeniosas de fomento de la conservación.

En nuestro país no hay ventajas tributarias ni de otro orden que incentiven la mantención de áreas de conservación. Veremos qué ha ocurrido sin ellas en la definición de áreas privadas de conservación. Cada día son más las empresas y personas que se ocupan de mantener parques naturales. A riesgo de omitir a muchas, no puedo dejar de mencionar el Parque Karukinka de WCS donado por Goldman Sachs, el Parque Pumalín que ha impulsado Douglas Tompkins, el Parque Tantauco, creado por el empresario y político Sebastián Piñera, el Parque Oncol de Celulosa Arauco y el Parque Jorque Alessandri de Forestal Mininco y tantos otros. Se estima que en total hay un millón quinientas mil hectáreas de áreas protegidas privadas que se suman a los catorce millones de hectáreas del SNASPE (Sistema Nacional de Áreas Silvestres Protegidas del Estado) que incluye Parques Nacionales, Reservas Nacionales y Monumentos Nacionales. Esto hace que más del 20\% del territorio nacional está bajo protección, siendo Chile uno de los países con mayor protección del mundo.

El sector productivo forestal chileno mantiene más de cuatrocientas mil hectáreas de patrimonio protegido, mayoritariamente de bosque nativo, 
aunque también áreas de humedales y matorrales de altura, ciertamente valiosos. Este esfuerzo de protección no sólo es valioso por las hectáreas protegidas en sí mismas, sino también por el valor ambiental de dichas superficies, las que actúan como corredores ecológicos y como reservas de biodiversidad para la recolonización de áreas aledañas. Lo anterior ha sido posible, ya que el desarrollo de plantaciones de pinos y eucaliptos intensivas, han permitido satisfacer en casi un ciento por ciento la demanda por madera quitando presión a la explotación del bosque nativo. Y este desarrollo, aunque en ciertas zonas del país no lo parezca, ha sido bastante equilibrado ya que en Chile hay 2 millones de hectáreas de plantaciones, versus 13,4 millones de hectáreas de bosque nativo.

Chile tiene el privilegio de tener bosques nativos dotados de una amplísima biodiversidad, algo que asombra a los científicos de otras latitudes. Mantener esa riqueza y pluralidad de formas de vida — ya extintas en muchísimos otros países - es un deber de nosotros los chilenos. Las generaciones jóvenes de ahora y las generaciones futuras serán severas a la hora de juzgarnos en este aspecto. La acelerada extinción de especies representa una amenaza no sólo a los ecosistemas sino que a los seres humanos. No podemos apostar desaprensivamente a que la vida humana en libertad y progreso sea posible en el contexto de una biodiversidad severamente reducida.

Sin embargo, no sólo las empresas se han comprometido en esta tarea. También asociaciones de personas naturales que aportan pequeños capitales para la formación de fundaciones que compran y gestionan áreas de conservación. Éste es un camino muy promisorio que permitiría, con los estímulos adecuados, incrementar fuertemente los recursos protegidos.

Esta mañana también examinaremos casos de exitosa colaboración pública-privada, como el del Adirondack Park, en Nueva York.

Nos aproximaremos, asimismo, a la labor de conservación que han generado indirectamente herramientas económicas. Es lo que ha sucedido en Chile, por ejemplo, con las concesiones marinas para la pesca artesanal. Los propios pescadores, al ejercer derechos de propiedad sobre áreas concesionadas, se han transformado en actores interesados en la conservación de los recursos y del hábitat que los sustenta.

Tres investigadores del CEP harán una serie de sugerencias respecto a instrumentos no tradicionales para la protección de recursos naturales. Una de las proposiciones consiste en que el Estado seleccione áreas que deben protegerse y luego licite fondos cuya gestión quedaría a cargo de los particulares. 
Estos desafíos requieren un Estado confiable, ágil, moderno, transparente y descentralizado. A su vez, muchas de estas iniciativas deberán ser encaradas desde las regiones. Sin excelencia técnica, seguridad jurídica de las áreas bajo protección, estabilidad e imparcialidad de las regulaciones que se dicten, estos proyectos no fructificarán.

Lo que necesitamos es una "alianza por la vida” para usar la expresión de Edward Wilson. Que nuestras reflexiones de hoy nos encaminen en ese propósito.

Muchas gracias.

\section{Mark Tercek}

\section{Director general de Goldman Sachs}

Buenos días. A nombre de Goldman Sachs, quiero aprovechar esta oportunidad para agradecer al Centro de Estudios Públicos (CEP) y a su presidente, el señor Eliodoro Matte, por ser los anfitriones de este evento y por copatrocinar este seminario en conjunto con la institución que represento y con nuestros amigos y socios en el proyecto Karukinka en Tierra del Fuego, la Wildlife Conservation Society, liderada por el señor Steve Sanderson. Finalmente, muchas gracias a todos los presentes en el evento del día de hoy por su interés y participación.

Para Goldman Sachs, Chile ocupa un importante lugar en el desarrollo de su estrategia medioambiental. Cuando adquirimos un portafolio de deuda insolvente en el curso normal de nuestros negocios, nos encontramos una garantía consistente en 283.290 hectáreas en Tierra del Fuego. La iniciativa de uno de los miembros de nuestro equipo al identificar este importante activo ecológico nos dio la oportunidad de evaluar cuidadosamente las opciones para su disposición. Tras varios estudios y evaluaciones meticulosas, llegamos a la conclusión de que el mejor uso posible para esa tierra era preservarla a perpetuidad, decisión a la que sólo pudimos llegar en conjunto con nuestro socio, Wildlife Conservation Society (WCS), una poderosa organización con experiencia en conservación a nivel global.

Como ustedes saben, esta decisión fue el nacimiento de lo que hoy es el proyecto Karukinka en Tierra del Fuego. Goldman Sachs tomó la decisión de proteger estas tierras a perpetuidad porque era lo correcto. Es un ejemplo de cómo nuestra gente, nuestro capital y nuestras ideas pueden producir cambios importantes en el mundo. Esperamos que sirva como modelo inspirador para que otros líderes del sector privado se conviertan en agentes del medio ambiente. 
La experiencia también abrió nuestras mentes a cómo los temas medioambientales se relacionan con nuestro negocio. En 2005 establecimos el Marco de Políticas Medioambientales de Goldman Sachs con el fin de representar la filosofía de que los mercados de capitales pueden y deben desempeñar un importante papel al momento de asumir los desafíos medioambientales del presente. Goldman Sachs cree que es necesario un medio ambiente saludable para el bienestar de la sociedad, nuestra gente y nuestro negocio, y es la base para una economía sustentable y fuerte.

Estamos trabajando para asegurar que nuestra gente, nuestro capital y nuestras ideas se empleen para encontrar soluciones efectivas basadas en el mercado para enfrentar el cambio climático, la degradación de los ecosistemas y otros temas medioambientales críticos.

Nuestro Grupo de Estrategia Ambiental es responsable de supervisar la implementación de nuestro Marco de Políticas Ambientales, a través de la coordinación de las iniciativas ambientales globales de la firma y la administración del Centro Goldman Sachs para Mercados Ambientales. A través de este último estamos asociados a organizaciones académicas y no gubernamentales para examinar y promover soluciones basadas en el mercado, para los desafíos del medio ambiente.

Aun cuando estamos comprometidos en el manejo de nuestra propia huella ambiental, a la vez estamos estableciendo una posición de liderazgo en el conocimiento de las muchas formas en que los asuntos ambientales afectan a los mercados globales.

Nuestros equipos de investigación de inversiones han establecido un enfoque riguroso para evaluar los criterios ambientales, sociales y de gobierno tanto para las industrias desarrolladas como para los sectores emergentes.

Hemos invertido más de US\$ 2 mil millones en proyectos de energías alternativas a través de una gama de tecnologías entre las que se incluyen la eólica, fotovoltaica, solar y geotérmica, cifra que excedió nuestro compromiso inicial de US\$ 1.000 millones, ya que representaba una atractiva oportunidad de negocios. Las inversiones se iniciaron con antelación a la reciente alza en el precio mundial de la energía.

Hemos estado realizando transacciones en créditos de carbono en el mercado europeo de emisiones de carbono desde sus comienzos y hemos expandido nuestras actividades, las que incluyen transacciones e inversiones en créditos para la reducción de emisiones para proyectos específicos y fijación de precios para el riesgo de emisión.

Un buen ejemplo de cómo nuestro compromiso con el medio ambiente ha significado importantes oportunidades de negocios tiene relación con una transacción completada en 2007. En esa ocasión Goldman Sachs se 
unió a un grupo de inversionistas que incluía a Kohlberg Kravis Roberts \& Co. (KKR) y al Texas Pacific Group (TPG) para adquirir la TXU Corporation, la generadora eléctrica más grande de Texas. La transacción en ese momento representó la mayor adquisición apalancada en la historia de EE.UU., por un valor total de US\$ 44 mil millones.

Nuestro equipo interdisciplinario de profesionales de la Banca de Inversión, del Grupo Financiero, de Productos Crediticios, de Commodities y de nuestro Centro de Mercados Ambientales colaboró en la ejecución de la transacción y el financiamiento asociado en medio de mercados turbulentos y un debate público de alto perfil. Goldman Sachs actuó como asesor financiero, lideró el financiamiento corporativo de mayor retorno en la historia y creó un innovador programa de manejo de riesgos de commodities para apoyar la adquisición.

La transacción fue notable por el rigor del debate ambientalista que la precedió y que finalmente configuró el resultado. Una fuerte y sostenida campaña de largo alcance fue clave para la creación del apoyo legislativo y público para la transacción. Gracias al liderazgo de KKR, TPG, Environmental Defense, el National Resources Defense Council (NRDC) y Goldman Sachs, entre otros, las partes involucradas llegaron a un acuerdo para limitar sustancialmente las emisiones de carbono futuras. Específicamente, el número de plantas a carbón planificadas fue reducido de once a tres. Además, con los nuevos propietarios, TXU duplicó su inversión en eficiencia energética, reforzó sus políticas ambientales y está haciendo importantes inversiones en energías alternativas.

En conclusión, lo que comenzó como una iniciativa inteligente de uno de los nuestros por hacer lo correcto, dio por resultado no sólo la preservación de las tierras de Karukinka en alianza con la Wildlife Conservation Society sino, además, el desarrollo de una nueva política medioambiental interna y una serie de atractivas oportunidades de negocios para la empresa sustentada en la premisa de que un medio ambiente sano es la base para una economía sustentable y fuerte.

Al recorrer este camino hemos llegado a comprender cuánto podemos aprender de la comunidad ambiental por medio de asociaciones constructivas e innovadoras como la que hemos construido con la Wildlife Conservation Society para Karukinka, aprendizaje que crea valor para los negocios y para el medio ambiente.

Una vez más agradezco la oportunidad de estar con ustedes hoy y de compartir brevemente nuestras ideas sobre este crucial desafío global. 


\title{
II. EL CONTEXTO INTERNACIONAL
}

\author{
COMPENSACIÓN PARA LA BIODIVERSIDAD: \\ DESAFÍOS Y OPORTUNIDADES
}

\section{Ray Victurine}

Los paisajes proporcionan un flujo de servicios del ecosistema que están íntimamente conectados con la conservación de la biodiversidad. Dichos servicios incluyen calidad de agua, polinización, estabilización del clima y fertilidad del suelo, todos ellos importantes activos fijos naturales que además tienen un impacto en la salud humana y entregan beneficios económicos. Los economistas han calculado que el valor neto anual que estos servicios representan para la economía global está dentro del rango de los 33 trillones de dólares ${ }^{1}$. La inmensa mayoría de estos servicios son bienes públicos globales y no se transan en los mercados. Aun cuando tienen un valor económico para los consumidores, se obtienen sin costo o no se les toma en cuenta en los cálculos económicos y financieros, por lo que los promotores inmobiliarios no tienen mayor incentivo monetario para asegurar su disponibilidad futura. Como resultado de esto, los ecosistemas se degradan y la sociedad pierde el valor de estos servicios.

La creciente demanda por recursos naturales para alimentar el crecimiento económico pone en peligro la biodiversidad y el capital natural. En el transcurso de los próximos veinte años, es probable que la demanda por energía primaria aumente más de 50\%, y se estima que la inversión en el desarrollo de nueva energía, extracción de minerales, recursos forestales y otras industrias con uso intensivo de recursos llegue a decenas de trillones de dólares. Gran parte de esta inversión tendrá lugar en tierras que albergan ecosistemas que son esenciales para mantener la vida. Es probable que en el proceso de determinación de prioridades en el uso de la tierra la protección al ecosistema esté en considerable desventaja frente a beneficios tangibles que también compiten, tales como las utilidades del sector privado, mayor recaudación tributaria y creación de empleo. Las medidas y políticas que hagan necesario que los inversionistas tomen en cuenta el valor de la biodiversidad y compensen por los impactos que produzcan en ella ofrecen

Ray Victurine. MS., Resource Economics, Texas A\&M University; BS, Georgetown University. Director del Programa para el Financiamiento de la Conservación de Wild Conservation Society (WCS).

${ }^{1}$ Constanza, Robert, et al.: “The Value of the World's Ecosystem Services and Natural Capital”, Nature, Vol. 387 (1997). 
una oportunidad para asegurar que los países puedan mantener importantes activos fijos naturales $\mathrm{y}$, a la vez, alcancen sus objetivos de desarrollo económico.

\section{Compensaciones a la biodiversidad}

Se ha definido a las compensaciones a la biodiversidad como "acciones de conservación diseñadas para indemnizar por el inevitable impacto que el desarrollo causa en la biodiversidad a fin de asegurar que no haya 'ninguna pérdida neta' sino, preferiblemente, una ganancia neta de biodiversidad"2. Las compensaciones a veces se diferencian de las medidas de 'conservación compensatorias'. Este último mecanismo proporciona cierta forma de reparación por los impactos que un proyecto puede tener sobre la biodiversidad, pero no da por resultado ‘ninguna pérdida neta' o una 'ganancia neta de biodiversidad’. Sin embargo, si los países tienen que conservar la biodiversidad será necesario desarrollar e implementar mecanismos para garantizar que no haya pérdida neta e incluso haya un aumento neto de la biodiversidad como parte de sus procesos de desarrollo.

Al tratar el manejo del ecosistema, la Convención sobre Diversidad Biológica ha declarado que los objetivos de manejo de la tierra, agua y recursos vivos son temas de decisión de la sociedad. En lo fundamental, las compensaciones involucran un trueque: las compensaciones se basan en la premisa de que se pueden dañar o destruir los sistemas naturales de un lugar dado si a cambio se conserva o restaura la biodiversidad en otro lugar. Las decisiones con respecto a estos trueques involucran que la sociedad esté de acuerdo sobre las prioridades de conservación así como sobre alguna forma de valorización que haga posible el diferenciar entre lo que puede o no puede dañarse, dónde puede o dónde no puede haber desarrollo, y qué se puede dar a cambio de qué otra cosa. Sin que estas prioridades y valores estén firmemente establecidos, los países están en riesgo de perder o dañar la biodiversidad y los servicios de los ecosistemas o pueden incluso terminar haciendo el trueque equivocado.

\section{El rol de las compensaciones}

Las medidas para compensar, equilibrar o contrarrestar los impactos negativos residuales sobre el medio ambiente natural se han incrementado

${ }^{2}$ Ten Kate, K., J. Bishop y R. Bayon: "Biodiversity Offsets: Views, Experience, and the Business Case”. IUCN, Gland, Suiza y Cambridge, Reino Unido, e Insight Investment, Londres, Reino Unido, 2004. 
en los últimos años. Estas medidas reflejan una creciente toma de conciencia y responsabilidad de parte de los promotores inmobiliarios y entes regulatorios acerca de la pérdida sin precedentes de biodiversidad y el crucial papel que desempeñan los sistemas vivos en apoyar el desarrollo sustentable. En la mayoría de los casos, las compensaciones a la biodiversidad existentes representan los esfuerzos voluntarios de las empresas que están motivadas por una gran variedad de asuntos, entre otros, a) los requisitos para financiamiento de bancos e instituciones tales como la International Finance Corporation; b) presiones de los accionistas y grupos de interés para invertir responsable y sustentablemente, y c) actuar como buenos ciudadanos corporativos y, de esa manera, asegurar sus permisos para operar en los países donde invierten.

Estos esfuerzos voluntarios son dignos de alabanza, pero involucran riesgos. Uno de los riesgos principales de los esfuerzos voluntarios, que no responden a algún mecanismo o procedimiento establecido, es que ni el promotor ni el gobierno pueden comprender qué se espera de la compensación y sobre qué base o usando cuáles criterios se evaluarán su aptitud y efectividad. En esas condiciones no se puede garantizar la calidad de las compensaciones. Las compensaciones voluntarias también pueden implementarse de manera poco sistemática, habiendo algunas compañías que optan por llevar a cabo compensaciones y otras que prescinden del proceso. Dadas estas condiciones, puede ser imposible el asegurar que no haya ninguna pérdida neta de biodiversidad. Y los gobiernos tampoco serán capaces de garantizar que las áreas prioritarias de biodiversidad estarán protegidas.

\section{Mecanismos de mercado}

Existe una necesidad de marcos de políticas de apoyo para las compensaciones a la biodiversidad a fin de ayudar a los promotores de desarrollos y a las autoridades a diseñar, ubicar e implementar las compensaciones en forma efectiva. Dichas políticas deberán estar acompañadas de alguna forma de regulación y de claros estándares viables que garanticen la compensación de la calidad y el logro efectivo de las metas de biodiversidad. La Tabla $\mathrm{N}^{\circ} 1$ esboza enfoques regulatorios potenciales que podrían asegurar el éxito de las compensaciones.

La efectiva reglamentación de las compensaciones ofrece a los gobiernos la oportunidad de realizar un intercambio positivo entre desarrollo y conservación de la biodiversidad. Una reglamentación con base amplia que lleve aparejado el desarrollo de oportunidades para la creación de bancos 


\begin{tabular}{lcc}
\hline Marco & Requisitos & $\begin{array}{c}\text { Problemas } \\
\text { involucrados }\end{array}$ \\
\hline
\end{tabular}

Compensaciones Necesarias para A ser conseguidas gatilladas (triggered offsets). cierto nivel de impacto.

Compensaciones agregadas (aggregated offsets).

Bancos
Requisitos determinados para todos los tipos de desarrollos en áreas o territorios específicos.

Las compensaciones son requisito para todos los proyectos que afecten la biodiversidad. por medio de regulaciones de EIA y requisitos, junto con estándares para el diseño e implementación de compensaciones.

Selección de sitios basada en nivel de planificación regional o territorial.

Involucra establecer bancos de biodiversidad y un sistema de mercado para que las empresas compren bonos de biodiversidad.
Necesita reglamentaciones y estándares claros.

Protección más eficiente de la biodiversidad.

Necesidad de planificación territorial y regulaciones claras.

Compensaciones más efectivas.

Mecanismo de mercado para proteger la biodiversidad.

Participación activa del sector privado.

Necesidad de regulaciones claras y sistemas e información apropiados.

de biodiversidad debería estimular la inversión activa del sector privado y su participación para alcanzar metas de conservación, aparte de dar mayores beneficios en términos de conservación al asegurar la protección de paisajes prioritarios. El mercado norteamericano regulado de la biodiversidad tiene un valor estimado de 1,5 billones de dólares anuales ${ }^{3}$, y en otros países se comienza a observar un crecimiento en los mercados para la protección de la biodiversidad. Operadores del sector privado con supervisión del gobierno están administrando estos bancos de biodiversidad con resultados positivos de conservación.

Con el aumento de las amenazas a la biodiversidad, los gobiernos deberán encontrar el equilibrio entre el manejo de sus activos fijos naturales contribuyendo a la salud y bienestar de sus habitantes y el atraer inversio-

\footnotetext{
${ }^{3}$ Ecosystem marketplace (www.ecosystemmarketplace.org).
} 
nes que les proporcionen beneficios económicos. La adopción de políticas claras sobre compensaciones a la biodiversidad y el trabajo conjunto con el sector privado para diseñar un programa de compensaciones efectivo hará que los gobiernos comiencen a lograr un cierto equilibrio entre el desarrollo y las metas de conservación de la biodiversidad. Con la creciente presión sobre la biodiversidad y los servicios de los ecosistemas, el lograr dicho equilibrio nunca será demasiado pronto.

Palabras clave: sector privado y conservación del medio ambiente; economía del medio ambiente; Convención sobre Diversidad Biológica. 


\section{CONSERVACIÓN PRIVADA Y COMUNAL EN EL PERÚ ${ }^{1}$}

\section{Jorge Caillaux}

El presente artículo describe la evolución de las iniciativas de conservación privada y comunal en el Perú y el marco legal que permite que éstas se desarrollen cada vez con mayor seguridad jurídica incluyendo las barreras que se han encontrado hasta el momento y los nuevos retos y oportunidades que se presentan para el futuro.

\section{Evolución de las iniciativas de conservación privada y comunal en el Perú}

La conservación de sitios en el Perú ha estado usualmente asociada a una tarea y responsabilidad directa del Estado a través de sus instituciones. El Sistema Nacional de Áreas Naturales Protegidas por el Estado $\left(\right.$ Sinanpe $^{2}$ ) conformado por 62 áreas naturales protegidas de nivel nacional, entre parques, reservas, santuarios y otras categorías, ha sido históricamente asumido como la cara visible de la conservación de sitios.

Si bien esta percepción es correcta, la participación de la sociedad civil ha sido vital a lo largo de los años para la gestión de éstas y otras áreas y ha quedado demostrado que la conservación privada cumple un rol fundamental no sólo para garantizar la conservación de los tesoros naturales de un país, sino también para articular la participación de la población local en la gestión de las mismas.

Jorge Caillaux Zazzali. Presidente de la Sociedad Peruana de Derecho Ambiental y Director del Grupo Drokasa, grupo empresarial peruano con inversiones en el sector agroindustrial y en el comercio de productos asociados. También es miembro honorario de la Comisión de Derecho Ambiental de la Unión Internacional para la Conservación de la Naturaleza (UICN).

${ }^{1}$ Este breve artículo se basa en la Iniciativa para la Conservación Privada y Comunal de la Sociedad Peruana de Derecho Ambiental (SPDA), que cuenta con una plataforma integral de actividades para optimizar, promover, difundir y revalorar la participación activa, responsable y organizada de la sociedad civil en la conservación de la biodiversidad empleando una serie de herramientas que la legislación peruana dispone para ello. La Iniciativa tiene como líneas de trabajo la difusión y capacitación a interesados, fortalecimiento de capacidades a la autoridad nacional, acompañamiento legal y técnico a usuarios, apoyo financiero a pequeños proyectos y monitoreo y evaluación de gestión de áreas. Más información en: www.conservacionprivada.org; www.spda.org.pe; comunicaciones@spda.org.pe.

${ }^{2}$ Actualmente el Sinanpe tiene a su cargo la gestión de casi el quince por ciento del territorio peruano, más de 18 millones de hectáreas. De acuerdo a la legislación el sistema es complementado por las áreas naturales protegidas de nivel regional y las áreas de conservación privada. 
Sin embargo y pese a ello, la participación privada o de la sociedad civil en la gestión de áreas protegidas y otros espacios públicos y privados no ha sido objeto de regulación específica, quedando más bien en el ámbito de la cooperación y de alianzas público-privadas surgidas en función de las circunstancias sin el debido reconocimiento y sin programas de promoción.

Felizmente la situación a nivel formal ha venido cambiando radicalmente en los últimos años y el Perú cuenta hoy con instrumentos legales establecidos y reglamentados que reconocen y promueven el papel de la sociedad civil en la conservación de sitios y recursos naturales del país. La legislación aprobada durante la última década en el Perú, tanto como resultado de la Ley de Áreas Naturales Protegidas (1997) como de la Ley Forestal y de Fauna Silvestre (2000), ha incorporado nuevos instrumentos que pretenden promover mayor inversión privada en la conservación de sitios. Dichos instrumentos contemplan la participación de la sociedad civil en el manejo de áreas, tanto si pertenecen al Sistema de Áreas Naturales Protegidas, como si están fuera de ellas y, en este último caso, tanto si son predios privados como públicos.

A la fecha, el gobierno peruano ha reconocido formalmente doce áreas de conservación privada, que significan 104.964 has. También se han firmado los primeros tres contratos de servidumbres ecológicas (88.29 has. en total). Paralelamente se han otorgado 16 concesiones para conservación sobre 423.094 has., así como 26 concesiones para ecoturismo, sobre 55.657 has. Estas cifras prueban que se ha iniciado un interesante proceso de reevaluación de las tierras privadas destinado a demostrar que la conservación de sitios no es una excentricidad o sueño lejano de algunos sino que es una oportunidad para poner en práctica actividades y negocios sostenibles, aportando, al mismo tiempo, a objetivos de conservación mayores relacionados con el reconocimiento de los servicios ambientales que proveen los ecosistemas.

\section{Las figuras legales usadas}

a. Áreas de conservación privada. Los propietarios individuales o comunales de predios que reúnan condiciones naturales con valores para la conservación por contener diversidad biológica o valores paisajísticos, pueden solicitar al Estado peruano el reconocimiento de sus predios como Áreas de Conservación Privada (ACP). El compromiso del propietario es presentar y ejecutar un plan de manejo que garantice la conservación del predio. A cambio recibe asistencia técnica del Estado, refuerza su titularidad 
sobre el predio y se beneficia porque facilita el acceso a fuentes de financiamiento proyectando a su vez una imagen de responsabilidad social reforzada por el reconocimiento oficial. A la fecha, no se han aprobado incentivos tributarios para promover la creación de áreas de conservación privada, pero el camino está allanado. La normatividad que permite esta figura está contenida en la Ley de Áreas Naturales Protegidas, Ley No. 26834 y en su Reglamento aprobado mediante Decreto Supremo No. 038-2001-AG y las disposiciones complementarias específicas sobre la materia.

b. Servidumbres ecológicas. Si bien no existe una categoría legal con esa denominación, las servidumbres son figuras legales contempladas en el Código Civil. De acuerdo al artículo $1035^{\circ}$ del Código Civil, cada propietario privado puede imponer gravámenes en beneficio de otro, que den derecho al dueño del predio dominante para practicar ciertos actos de uso del predio sirviente o para impedir al dueño de éste el ejercicio de alguno de sus derechos. Constituyen un derecho real. Los derechos reales son aquellos que se ejercen directamente sobre las cosas. Lo que prima en la relación jurídica es la cosa independientemente de quien sea su titular. Y la servidumbre tiene un carácter accesorio. La carga que se impone al predio sirviente se consagra a favor del predio dominante y no a favor de su propietario.

Vale la pena tener presente que, de acuerdo a la legislación peruana, no es necesario que estos predios sean de propietarios diferentes, ni que sean contiguos, se puede vincular a dos predios que se encuentran distantes entre sí. Una servidumbre ecológica, entonces, no sería otra cosa que la aplicación de las servidumbres tradicionales con un propósito específico vinculado a la conservación.

No existe en el Perú ninguna iniciativa destinada a modificar el Código Civil para regular de manera más clara y precisa — conforme a su verdadera naturaleza - las servidumbres ecológicas. En todo caso, la idea es desarrollar una nueva figura jurídica que no tenga las limitaciones de la servidumbre tradicional del Derecho Civil pero que adopte, entre otras características, su condición de carga permanente sobre el predio o la propiedad, salvo algunas excepciones.

c. Concesiones para conservación. Se otorgan a título gratuito, de preferencia sobre tierras que el Estado tiene identificadas y priorizadas como tierras de protección. En ellas se promueve, bajo planes de manejo y monitoreo del Estado, la investigación y usos alternativos de productos no 
maderables, así como la educación ambiental en ámbitos rurales. Se otorgan por un plazo máximo de cuarenta años, renovables.

De acuerdo con el Reglamento de la Ley Forestal y de Fauna Silvestre, los bosques en tierras de protección son aquellas superficies que por sus características bióticas y abióticas sirven fundamentalmente para preservar los suelos, mantener el equilibrio hídrico, conservar y proteger los bosques ribereños orientados al manejo de cuencas, la diversidad biológica y la conservación del ambiente. Dentro de estas áreas se promueven los usos indirectos como el ecoturismo, la recuperación de la flora y fauna silvestre en vías de extinción y el aprovechamiento de productos no maderables.

Las concesiones para conservación vienen generando mucho interés en Perú porque:

(i) Otorgan seguridad jurídica a la inversión que realizan las personas o instituciones interesadas en la conservación de la biodiversidad y valores asociados, complementando las estrategias de conservación de biodiversidad desde la sociedad civil, sin constituir un mayor gasto para el gobierno.

(ii) También constituyen una oportunidad para aquellas personas, poblaciones organizadas y/o instituciones con interés en conservar o proteger algunos elementos valores asociados a la diversidad biológica como, por ejemplo, cuencas hidrográficas, laderas y zonas altas para control de erosión y protección contra desastres naturales, así como otros servicios ambientales del bosque. En otras palabras, es una buena opción para otorgar derechos de ocupación formal del bosque, bajo una óptica de implementación del ordenamiento de la superficie forestal del Estado.

(iii) Constituye una buena herramienta para las instituciones que desean realizar trabajos a largo plazo y con importante inversión en investigación y monitoreo de la diversidad biológica.

(iv) En la medida que la deforestación evitada cada vez goza de mayor apoyo por parte de los gobiernos y también en los mercados de servicios ambientales alternativos al Protocolo de Kyoto, este instrumento abre la puerta para beneficiarse de dichos mercados emergentes con proyectos de cuarenta años y más.

d. Concesiones para ecoturismo. Se otorgan a título oneroso sobre tierras del Estado calificadas como de protección u otras con valores paisajísticos, sobre una extensión máxima de 10.000 ha. El plazo de la concesión es de hasta cuarenta años, renovables.

Las concesiones para ecoturismo confieren a su titular la facultad de aprovechar sosteniblemente el paisaje natural como recurso, en las condi- 
ciones y con las limitaciones que se establecen en la legislación específica y el correspondiente contrato.

El titular no puede hacer aprovechamiento de otros recursos naturales, como por ejemplo la flora o fauna que existen en el área concedida. Tampoco podrá realizar aprovechamiento de la madera que pueda existir en el área de la concesión, pues esto no sería congruente con su objeto y para ello existe el sistema de concesiones forestales con fines maderables.

El área de la concesión se define en base a los estudios técnicos que presente el concesionario como parte de su propuesta técnica, pudiendo alcanzar como máximo una superficie de diez mil (10.000) hectáreas.

Esta modalidad de concesión es muy ventajosa, pues sobre ella el titular puede imponer gravámenes e, incluso, ceder su posición contractual con la aprobación previa del Instituto Nacional de Recursos Naturales (Inrena). Es más, con la autorización expresa del Inrena, el concesionario puede desarrollar, directamente o a través de terceros, actividades económicas secundarias que maximizan la rentabilidad de la concesión.

Hasta la fecha se han otorgado 25 concesiones para ecoturismo sobre una superficie de 55.657 has.

\section{El valor agregado de la conservación privada y comunal}

Si bien el Perú mantiene aún un mayor porcentaje de tierras públicas vs. tierras privadas, estas últimas reúnen excelentes condiciones para trabajar de manera eficiente en conservación por las siguientes razones:

- $\quad$ Dependen en gran medida de la voluntad y capacidad de sus propietarios.

- $\quad$ Existen muchas propiedades ubicadas en zonas de alta diversidad biológica pertenecientes a comunidades indígenas o campesinas, ONG, empresarios, familias, etc.

- $\quad$ Con la voluntad del propietario se puede planificar un trabajo a largo plazo que trascienda, incluso, varias generaciones.

- $\quad$ Obtener un título de conservación privada permite fortalecer el derecho de propiedad y desarrollar proyectos rentables y convenientes para los propietarios y la comunidad local.

- $\quad$ El trabajo con propietarios privados permite además establecer claramente la corresponsabilidad entre el Estado y la sociedad civil por conservar el patrimonio natural de la Nación y construir una sociedad basada en una relación armoniosa con la naturaleza. 
De otro lado, el aumento progresivo y constante de las iniciativas privadas y comunales de conservación en el Perú nos muestra el interés de la sociedad civil por desarrollar estas actividades con seguridad jurídica. Asimismo, las diversas normas reglamentarias aprobadas evidencian que el Estado ha estado ocupado en consolidar el marco legal requerido para que éstas puedan implementarse de una manera adecuada. Pero las normas por sí solas no son suficientes, pues son parte de un proceso que ha incluido el desarrollo conceptual de las herramientas; la difusión de sus características, ventajas y desventajas, y la capacitación y el acompañamiento a las autoridades competentes e interesados.

A la fecha, se ha constituido una Red de Conservación Privada y Comunal a nivel nacional y también a nivel local; se ha llevado a cabo el Primer Foro Nacional de Conservación Privada y Comunal contando con la participación de más de 200 personas; herramientas de conservación privada han permitido consolidar corredores ecológicos en conjunto con áreas naturales protegidas de nivel nacional; predios que se encontraban dentro de la zona reservada Cordillera de Huayhuash han sido reconocidos como áreas de conservación privada constituyéndose las ACP en una alternativa para la categorización de zonas reservadas ${ }^{3}$ cuando las circunstancias lo permitan.

El avance y la evolución de la conservación privada en el Perú son tangibles, más de medio millón de hectáreas vienen siendo conservadas por empresas, comunidades, personas naturales y asociaciones sin fines de lucro. En el Lago Tres Chimbadas (ver: www.conservacionprivada.org) se ha implementado un acuerdo entre una empresa turística y la Comunidad Nativa de Infierno para la gestión de una concesión para ecoturismo. Los miembros de la comunidad ya están recibiendo beneficios y están capacitando a sus nuevas generaciones para que continúen con su proyecto ecoturístico en el futuro. Somos pues testigos de cómo los esfuerzos de personas de distintos lugares, culturas y edades van alimentando una cultura de conservación que se forja cada vez con más fuerza.

Por otro lado, obviamente se han multiplicado las amenazas. La política de promoción de las inversiones en hidrocarburos ha llevado a que tan sólo en tres años pasemos de tener un 15\% a más del 63\% de la Amazonía con derechos otorgados para el desarrollo de actividades de exploración y/o explotación de hidrocarburos. Consecuentemente, ello ha generado superpo-

${ }^{3}$ Las zonas reservadas gozan de un status transitorio como áreas naturales protegidas hasta que se lleven a cabo las investigaciones que permitan definir la categoría que les corresponde de acuerdo a sus características específicas. 


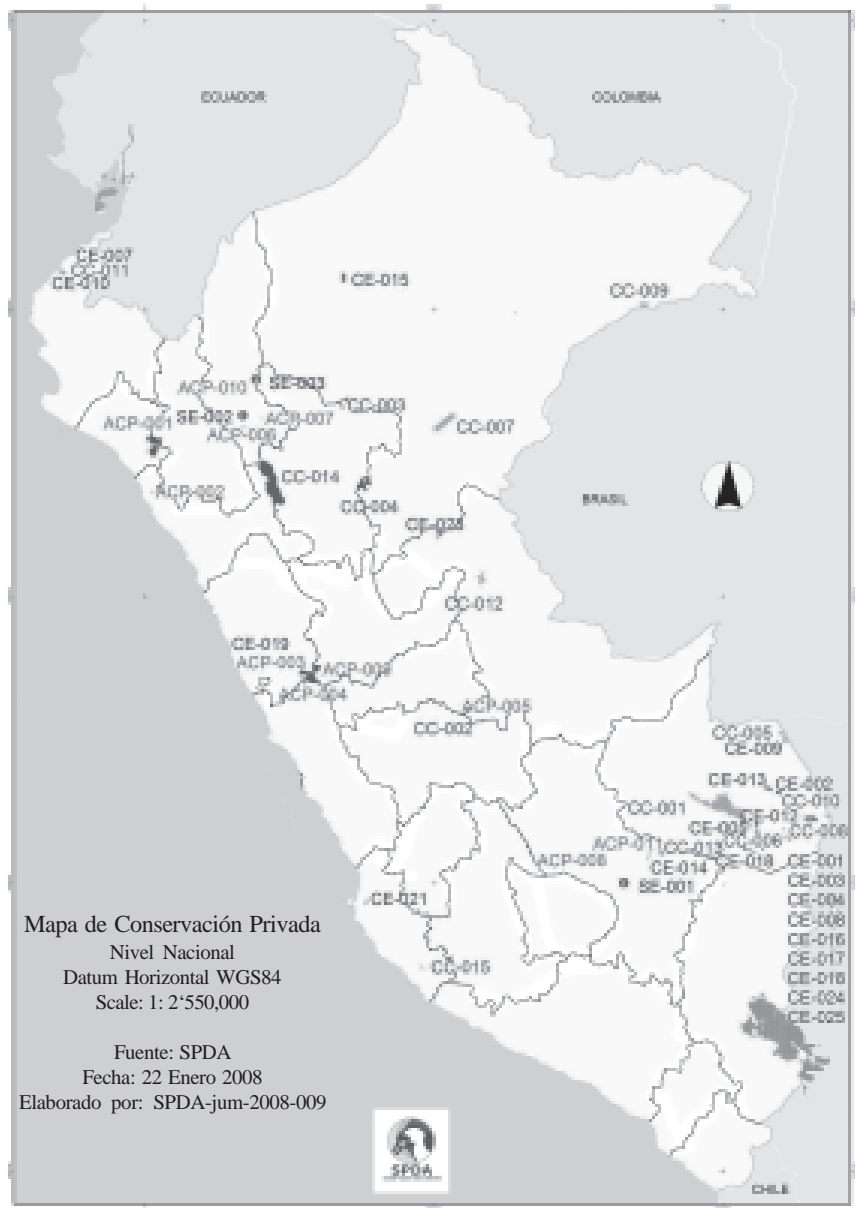

$\begin{array}{lll}\text { Áreas de conservación privadas } & \text { CE-006 } & \text { Inversiones Manguare } \\ & \text { CE-007 } & \text { Ismael Cisneros } \\ \text { ACP-001ACP Chaparri } & \text { CE-008 } & \text { Fernando Rosemberg } \\ \text { ACP-002ACP Bosque Natural El Cañoncillo } & \text { CE-009 } & \text { Sixto Delgado } \\ \text { ACP-003ACP Pacllón } & \text { CE-010 } & \text { Ricardo Pissani } \\ \text { ACP-004ACP Huayllapa } & \text { CE-011 } & \text { Lagartococha } \\ \text { ACP-005ACP Sagrada Familia } & \text { CE-012 } & \text { Madesos } \\ \text { ACP-006ACP Huiquilla } & \text { CE-013 } & \text { Jungle Odyssey } \\ \text { ACP-007ACP San Antonio } & \text { CE-014 } & \text { Martin Alejo Condori } \\ \text { ACP-008ACP Abra Malaga } & \text { CE-015 } & \text { Zafre } \\ \text { ACP-009ACP Jirishanca } & \text { CE-016 } & \text { Amtuset } \\ \text { ACP-010ACP Abra Patricia } & \text { CE-017 } & \text { CCNN Infierno } \\ \text { ACP-011ACP Bosque Nublado } & \text { CE-018 } & \text { Amaitus } \\ & \text { CE-019 } & \text { Inversiones Leniperú + } \\ \text { Concesiones para ecoturismo } & \text { CE-020 } & \text { Justiniano Zúñiga } \\ \text { CE-001 Tiburcio Huacho } & \text { CE-021 } & \text { Maveco Sand Tours SRL } \\ \text { CE-002 Tambopata Expeditions } & \text { CE-022 } & \text { Pantiacolla Tours } \\ \text { CE-003 Inka Terra } & \text { CE-023 } & \text { Juan Carlos Hidalgo } \\ \text { CE-004 Ecoamazonia Lodge } & \text { CE-024 } & \text { Abraham Aguirre } \\ \text { CE-005 Gilberto Vela } & \text { CE-025 } & \text { Rainforest Expeditions } \\ & & \end{array}$

Concesiones para conservación

CC-001 Acca

CC-002 Aprodes

CC-003 Paraíso de Yurilamas

CC-004 Aicon 1

CC-005 Conservación Internacional

CC-006 Picaflor Research Center

CC-007 Lotty Morey

CC-008 Amaru Mayu

CC-009 WCS

CC-010 Antonio Fernandini

CC-011 Carlos Berninzon

CC-012 Universidad Alas Peruanas

CC-013 CCNN Queros

CC-014 Ampa

CC-015 Asociación Civil Aves del Perú

\section{Servidumbre ecológica}

SE-001 SE Santa María

SE-002 Huyquilla y Municipalidad El Tingo SE-003 SE Ecoan 
siciones de derechos entre lotes de hidrocarburos y herramientas de conservación privada. En algunos casos, el aprovechamiento de hidrocarburos en una concesión para conservación o para ecoturismo puede resultar incompatible y ello exige una adecuada coordinación previa entre las autoridades para evitar atentar contra la seguridad jurídica de ambos inversionistas.

Finalmente, tenemos el "boom de los biocombustibles" que implica nuevas expectativas en los agricultores, autoridades y tomadores de decisión. A ello hay que sumarle la presencia de nuevas técnicas que permiten que la agricultura en la selva genere mayores beneficios que aquellos que generaba hace algunas décadas. De no tomarse medidas en el corto plazo, ello puede acarrear un mayor avance de la frontera agrícola en tanto la legislación vigente continúe incentivando perversamente al agricultor para que tale el bosque. Esto en la medida que el Estado únicamente titula aquellas áreas del bosque que han recibido "mejoras”, entendidas las mejoras como el cambio de uso de suelo para posibilitar la producción agrícola. Para algunos sectores del Estado, el bosque en pie sigue siendo improductivo.

Estamos, pues, ante la presencia de nuevos actores y de un escenario cada vez más competitivo. La conservación es una entre las distintas opciones y para su promoción es necesario establecer incentivos que atraigan tanto a las personas cuyos proyectos de vida están ligados a la conservación como a aquellas personas que ven una oportunidad de desarrollo económico.

Creemos sin embargo que el panorama es favorable. En las reuniones internacionales sobre cambio climático ya se habla de la importancia de la deforestación evitada y las experiencias de pago por servicios ambientales o compensación por servicios ecosistémicos son cada vez más frecuentes. El futuro de la conservación va a depender de nuestra capacidad de ver oportunidades en donde la mayoría sólo ve amenazas, de ser más eficientes y de ser capaces de mostrar los beneficios que genera invertir en conservación ${ }^{4}$. El reto está en nuestra capacidad de adaptarnos a un nuevo contexto con nuevos actores e intereses.

Palabras clave: iniciativas privadas y comunales de conservación del medio ambiente en Perú; energía; economía del medio ambiente.

${ }^{4}$ Un caso interesante está vinculado a la construcción de la Carretera Interoceánica Sur, en donde las herramientas de conservación privada han sido incluidas en el marco de una estrategia para mitigar los impactos ambientales de la carretera. 


\title{
EL GRAN EXPERIMENTO CONSERVACIONISTA PARQUE ADIRONDACK
}

\author{
Ross S. Whaley
}

Considero que el Parque Adirondack es el "gran experimento conservacionista”. En Estados Unidos, las leyes y políticas asociadas a dicho parque a menudo han sido las primeras en su tipo, siendo posteriormente copiadas por otros estados o por el gobierno federal.

Según Porter et al. ${ }^{1}$ :

[E]stas decisiones aportaron un caudal de conocimientos que son la base del concepto estadounidense de conservación. Moldeadas por una ambición visionaria, las decisiones fueron implementadas día a día y punto por punto por personas que entregaron no sólo talento y energía, sino además pasión. Las lecciones aprendidas por estas personas prepararon el terreno para una política de largo alcance que introdujo el tema de la conservación en el lenguaje cotidiano de los Estados Unidos y de su gobierno. La experiencia de Theodore Roosevelt en Adirondack aportó el impulso para el establecimiento del Servicio Nacional Forestal y los Parques Nacionales. Lo aprendido en Adirondack fue un antecedente para las leyes medioambientales de los años 60, entre las que se destaca la Wilderness Act (Ley de Zonas Naturales) de 1964. La Reserva Forestal de Adirondack fue la primera en demostrar el valor económico de preservar los ecosistemas naturales, el valor espiritual de la conservación de las tierras vírgenes, el valor ecológico de proteger un vasto y casi intacto ecosistema por medio de la incorporación de la gente a un parque, y el valor político de administrar los recursos naturales de una región para usos múltiples. Hoy en día, este inusual parque ofrece lecciones a los responsables de las políticas en todo el mundo que luchan por la protección del medio ambiente natural, a la vez que prestan atención a los problemas inmediatos de desarrollar comunidades pujantes y economías viables.

Ross S. Whaley. Destacado experto en manejo y desarrollo de recursos naturales. Fue director de Adirondack Park y presidente del State University College of Environmental Science (ESF), Siracusa, N.Y. entre los años 1984 y 1999. Entre otras importantes actividades profesionales y de servicio público ha sido, además, presidente de la Society of American Forestry y del Pinchot Institute of Conservation.

${ }^{1}$ Porter, William F., Jon D. Erickson y Ross Whaley: "Cornerstones of Conservation and Development: Voices from the Adirondack Park". En imprenta. 
El experimento prosigue hasta el día de hoy. Y el Parque Adirondack también continúa siendo un caso único entre los parques de los Estados Unidos. Haré una breve reseña de su historia, su historia natural, las instituciones reguladoras que lo controlan y sobre su potencial como modelo de desarrollo sustentable para las zonas naturales rurales.

En la actualidad, el parque se encuentra dividido casi por igual entre terrenos privados y estatales. Es inmensamente grande, aproximadamente del tamaño del estado de Vermont (USA), o 1,3 veces el tamaño de la Región de los Ríos de Chile. Tiene cerca de 132.000 residentes permanentes y otros 200.000 residentes temporales. Incluye 103 pueblos y aldeas.

\section{Un poco de historia}

Después de la guerra de independencia, a raíz de la cual los Estados Unidos se escindieron de Gran Bretaña, el estado de Nueva York reclamó para sí la propiedad de las tierras dentro de los límites estaduales. Luego el estado entregó estas tierras a particulares, principalmente para granjas. Las tierras en la región montañosa de Adirondack no eran aptas para la agricultura y sólo se destinó una pequeña parte de ellas al desarrollo de esta actividad. Sin embargo, a mediados del siglo diecinueve la industria de productos forestales adquirió gran parte de las tierras para producir madera a ser usada en la construcción en las ciudades que estaban creciendo: Nueva York, Filadelfia, Siracusa, etc. Debido a que el tipo de tala que se llevaba a cabo estaba destruyendo las cuencas que proveían de agua a la ciudad de Nueva York, y las inundaciones eran frecuentes, el estado de Nueva York decidió que el resto de las tierras forestales que aún no habían sido vendidas a particulares y compañías privadas permanecieran en manos del estado. En consecuencia, en 1885 se creó la Reserva Forestal, con el fin de establecer mejores prácticas forestales y así tener reservas perpetuas de madera y proteger las cuencas hidrográficas del lugar (esto antecedió por seis años a la Ley de Reservas Forestales de 1891). Sin embargo, en menos de una década, estas tierras pasaron a ser consideradas como lugares privilegiados de esparcimiento, especialmente por personas adineradas, las que comenzaron a comprar terrenos para la construcción de palaciegos "refugios” de verano. Así comenzó una controversia entre los que estaban a favor de la supresión de las talas en la Reserva Forestal y los que querían manejar los bosques para producción de madera. En rápida sucesión, en 1892 se aprobó una ley que trazó una línea alrededor de la Reserva Forestal y los terrenos particulares intermedios, todo lo cual pasó a llamarse Parque Adirondack. Dos años después, en 1894, se aprobó una enmienda constitu- 
cional prohibiendo la tala en la Reserva Forestal de propiedad del estado, declarándola “por siempre tierra virgen”.

Las tierras actualmente propiedad del Estado o las que se adquieran en adelante, que constituyan Reservas Forestales, como actualmente lo estipula la ley, deberán conservarse como áreas de bosque virgen, no podrán ser arrendadas, vendidas o dadas en trueque, o tomadas por ninguna corporación, pública o privada, ni su madera vendida, retirada o destruida ${ }^{2}$.

La declaración de estas tierras como "por siempre tierra virgen” antecedió en setenta años a la Ley de Zonas Naturales de los Estados Unidos (Wilderness Act) — una vez más, parte del experimento que a la larga fue copiado por el gobierno federal.

\section{Un poco de historia natural}

El Parque Adirondack constituye la más grande superficie de bosques templados protegidos del mundo. En Estados Unidos existen áreas con montañas más altas y estados donde se dice que hay más lagos, pero en ningún otro lugar de Estados Unidos puede encontrarse una combinación tan rica de montañas y lagos. Tiene cuarenta y seis picachos de más de 4.000 pies de altura (1.220 mts. aprox.); si se consideran los lagos pequeños o lagunas, la cifra es superior a once mil, aparte de miles de millas de arroyos y ríos. Algunas de las cumbres tienen vegetación del tipo alpino que no se presenta sino hasta más al norte, en Canadá. En la actualidad, es evidente el impacto que han tenido en vida silvestre los ya cien años de protección de la Reserva Federal. Muchos de los animales que alguna vez se extinguieron allí o fueron considerados especies en peligro han retornado. El castor, el martín pescador, el águila calva y el alce han regresado al parque.

El uso recreativo de los recursos naturales de la Reserva Forestal es un factor crítico en la economía del parque. La aldea de Lake Placid ha sido dos veces sede de las Olimpíadas de Invierno. Los deportes de nieve motorizados son un importante componente de la economía invernal en varios lugares del Parque. Varios millones de visitantes llegan durante el verano

2 "The lands of the State now owned or hereafter acquired, constituting the Forest Preserves, as now fixed by law, shall be forever kept as wild forest lands, they shall not be leased, sold or exchanged, or be taken by any corporation, public or private, nor shall the timber thereon be sold, removed or destroyed.” 
para pescar, hacer caminatas, escalar montañas, nadar o visitar sus dos extraordinarios museos, uno de ellos dedicado a la historia social y cultural del parque y el otro a la historia natural.

\section{Control de desarrollos en tierras de propiedad de privados y control del uso en la Reserva Forestal}

Aun cuando la Reserva Forestal había estado protegida de intervenciones desde fines del siglo XIX, la presión inmobiliaria sobre la tierra en manos privadas comenzó a crecer en la década de los 60. Dos factores explican este aumento en las presiones inmobiliarias: la subdivisión y venta de grandes propiedades privadas debido a la creciente carga tributaria de seguir conservando esas tierras, y el cada vez mayor mercado de casas de verano impulsado por el incremento en la renta disponible de muchas familias estadounidenses. Surgió así la preocupación de que un desarrollo inmobiliario descontrolado pudiese destruir el carácter especial del Parque Adirondack.

Nelson Rockefeller, en esa época gobernador del estado de Nueva York, estableció una Comisión de Estudios Temporal para tratar el asunto. Fruto de esta Comisión se creó la Agencia del Parque Adirondack (APA) en 1971. Ésta fue una política altamente controvertida, debido a que delegaba en una institución estatal los poderes que tradicionalmente se otorgaban a instancias de gobierno de menor jerarquía (condados y ciudades). La APA no sólo tenía poder regulador sobre las tierras privadas, sino que además se le otorgó autoridad sobre las actividades de planificación de la agencia estatal que administraba la Reserva Forestal, el Departamento de Conservación del Medio Ambiente (DEC, sigla en inglés). Esto también causó controversia ya que le otorgaba poder a una nueva y pequeña agencia gubernamental (APA) para dirigir las actividades de una agencia grande, establecida y desarrollada (DEC).

En sus primeros años la APA desarrolló y consiguió que el congreso estatal y el gobernador aprobaran un Plan de Uso y Desarrollo del Suelo del Parque Adirondack (Adirondack Park Land Use and Development Plan) para la regulación del desarrollo de las tierras privadas, y el Plan Maestro para las Tierras Estatales del Parque Adirondack (Adirondack Park State Land Master Plan), que regula las actividades en la Reserva Forestal. Según Porter et al.:

En muchos aspectos, los documentos de la Ley que creó la Agencia del Parque, el Plan Maestro y el Plan de Desarrollo 
están entre los más importantes en lo que respecta a conservación en Estados Unidos. Son los primeros en establecer una agenda de planificación regional que promueve la sustentabilidad de las tierras vírgenes y además la vitalidad económica. Estos documentos han demostrado ser tremendamente anticipatorios respecto a los desafíos claves que parques como el de Adirondack enfrentarían más adelante, y han resistido los cambios en la economía y las amenazas sociales y ecológicas al parque. En términos legales, estos documentos son largos y complejos, pero su esencia puede capturarse a partir de la descripción que hacen de la clasificación del uso del suelo y de sus pautas de manejo.

Plan de Uso y Desarrollo de Suelos del Parque Adirondack. La Ley que creó la Agencia del Parque de Adirondack requería que ésta preparara un plan de uso de suelos para todas las tierras del parque, a excepción de las pertenecientes al estado. Específicamente, el plan debía contener un mapa que mostrara una serie de categorías de usos aceptables de suelo. Para cada categoría, el plan debía tener un texto describiendo el tipo, carácter y extensión del uso permitido, y una descripción de cualquier limitación impuesta al desarrollo inmobiliario y su propósito. Las clases de suelos incluyen:

- $\quad$ Cabañas.

- $\quad$ Áreas de intensidad moderada de uso.

- $\quad$ Áreas de baja intensidad de uso.

- $\quad$ Áreas de uso rural.

- $\quad$ Áreas de manejo de recursos.

- $\quad$ Áreas de uso industrial.

El plan debía concentrar especialmente la atención en la línea de playa, fijando los estándares para el ancho de los terrenos, la distancia que las edificaciones y sistemas sépticos mantendrían del lago, y el desbroce de vegetación a lo largo de la línea de playa. La intención del Plan de Desarrollo era canalizar las construcciones comerciales y residenciales hacia áreas donde éstas ya existían o donde los impactos ambientales pudieran ser minimizados. Como dice el Plan de Uso de Suelos "no se aprobará ningún proyecto que tenga un ‘impacto adverso’ no deseado”.

\section{Plan Maestro para las Tierras Estatales del Parque Adirondack}

El Plan Maestro se concentra principalmente en la Reserva Forestal de Adirondack, protegida como tierra por siempre virgen por la Constitución del estado. La premisa del Plan Maestro es que el uso de las tierras 
públicas será alentado siempre y cuando no se degraden ni los recursos físicos y biológicos ni los atributos sociales o psicológicos.

La ley que habilita a la Agencia del Parque Adirondack requiere que la Agencia evalúe todas las tierras públicas y las clasifique para su permanente manejo. Los determinantes fundamentales de la clasificación del uso del suelo son las características físicas y biológicas del territorio, y su capacidad asociada para soportar el uso humano. Por ejemplo, las comunidades alpinas son frágiles debido a condiciones físicas y biológicas de altura, y en consecuencia están limitadas a senderos para excursionistas que permiten la protección de la vegetación que los rodea. Los factores sociales y psicológicos tales como la calidad del paisaje o la oportunidad de experimentar la lejanía (remoteness) también son evaluados. Por último, la clasificación reconoce las instalaciones e infraestructura existente, como por ejemplo carreteras o áreas de esquí en funcionamiento.

La piedra fundamental del Plan Maestro la constituyen las zonas naturales y el plan incorpora frases específicas tomadas directamente de la Ley de Zonas Naturales de 1964:

Este documento reconoce una zona natural, en contraste con aquellas áreas donde el hombre y sus propias obras dominan el paisaje, como un área donde la tierra y su comunidad de vida no dependen del ser humano, donde el ser humano es un visitante que no permanece.

Las áreas de la Reserva Forestal se clasificaron comenzando por las “zonas naturales”, como las más protegidas, hasta las de "uso intensivo", que permiten la construcción de lugares de campamento. Las diferentes clasificaciones son:

- Zona natural.

- $\quad$ Primitiva.

- $\quad$ Áreas de canotaje.

- $\quad$ Bosques vírgenes.

- Uso intensivo.

- Áreas históricas.

- $\quad$ Áreas de administración estatal.

Por último, el Plan Maestro requiere que el Departamento de Conservación del Medio Ambiente prepare planes formales de manejo para todas las unidades de tierras públicas al interior del parque. Éstos deben incluir un inventario de los recursos naturales, paisajísticos y culturales, así como el uso público actual proyectado. Los planes también deben proporcionar un 
análisis de los ecosistemas y una evaluación de hasta qué punto el uso público ha sido congruente con la capacidad de estos ecosistemas para sustentar dicho uso. Se debe prestar atención especial a las áreas amenazadas por exceso de uso o donde se requiera rehabilitación. Para garantizar que los planes de manejo se realicen dentro del contexto de un parque que incluye tanto tierras públicas como privadas, éstos deben estar integrados a las características y objetivos de manejo de tierras públicas y privadas que son adyacentes.

\section{Un modelo para el desarrollo sustentable}

Este gran experimento conservacionista continúa hasta hoy. Como la atención y el vocabulario usado por la sociedad han ido evolucionado desde la conservación hacia el desarrollo sustentable, el Parque Adirondack podría servir como modelo de desarrollo sustentable para zonas rurales en otros lugares de Estados Unidos e incluso en el mundo. En el Parque Adirondack los elementos para el desarrollo sustentable deben incluir lo siguiente:

1. Proteger la integridad ecológica de la Reserva Forestal.

2. Garantizar una transición fluida desde las tierras públicas de la Reserva Forestal hacia las tierras privadas adyacentes. Es decir, no queremos que el espacio público sea hermoso y el privado feo. Por el contrario, las tierras privadas deben ser desarrolladas siguiendo las normas de estar "libres de impacto adverso no deseado". Los pueblos y comunidades de los alrededores deben tener una personalidad propia que sea motivo de orgullo para la comunidad que vive allí.

3. Proteger la calidad del agua porque es el recurso más importante del parque. Personalmente, sostengo que la calidad y cantidad del agua es el problema medioambiental de corto plazo más importante del mundo. El parque se da el lujo de contener cuerpos de agua abundantes y de alta calidad. El riesgo está en que debido a su abundancia demos por sentado que su resguardo está asegurado y no los protejamos lo suficiente. Precisamos un mejor entendimiento de la "capacidad de carga" de los cuerpos de agua y de cómo traducirla en una política.

4. Promover actividades económicas que no destruyan ni empobrezcan los recursos naturales de los que dependan dichas actividades u otras.

Para el Parque Adirondack, el logro de estos objetivos requiere una visión y una responsabilidad compartidas. La historia de Adirondack es una de conflictos: conflictos entre inmobiliarias y ambientalistas, conflictos en- 
tre los residentes del parque y los usuarios no residentes, conflictos entre funcionarios del gobierno estatal y del gobierno local. El parque ha tenido éxito gracias a la imaginación visionaria de unos pocos con la necesaria influencia política para hacerlo realidad. Ahora que podemos documentar el éxito del Parque Adirondack, es el momento de tener una visión compartida y una responsabilidad compartida hacia el futuro. Esta responsabilidad debe ser compartida entre los representantes elegidos tanto a nivel estatal como local. A nivel local la responsabilidad debe ser compartida entre ciudadanos, directores de escuelas, directores de caminos, juntas planificadoras, $\mathrm{y}$ todos los participantes en desarrollos inmobiliarios que consideran que lo que mejor sirve a sus intereses es el desarrollar el área de manera que no haya "un efecto adverso no deseado".

Palabras clave: Parque Adirondack, Estados Unidos; conservación del medio ambiente; economía del medio ambiente. 


\section{EL CONTEXTO NACIONAL}

\section{LA EXPERIENCIA DE LA FUNDACIÓN LAHUÉN}

\section{Sergio Vergara*}

A fines de 1990 un grupo de privados consiguió US\$ 160.000 para comprar un predio de cuatrocientas hectáreas de bosque de araucarias en la localidad de Pichares, al oriente de Pucón, IX Región. El predio se sitúa en una altitud entre 1.100 y 1.600 metros sobre el nivel del mar, entre los parques nacionales Villarrica y Huerquehue.

Los fondos provinieron de la Fundación Frank Weeden, que dio US\$ 50.000, Patagonia que entregó US\$ 40.000, Esprit-Chile (controlada por Douglas Tompkins) que aportó US\$ 40.000, y Ancient Forest Internacional, que entre sus asociados y con muchas donaciones individuales logró reunir US\$ 30.000. Obtenidos los fondos, se convocó a un grupo de amigos integrado por Rick Klein, Nicole Mintz, Sergio Grau, Adriana Hoffmann, Manfred Max Neef, Miguel Sandor y Sergio Vergara para organizar una entidad con capacidad suficiente para inscribir a su nombre el predio y garantizar tanto su integridad como su conservación. En abril de 1991 Fundación Lahuén obtuvo su personalidad jurídica, siendo el primer organismo nacional sin fines de lucro cuyo objeto exclusivo era la conservación de ecosistemas forestales privados. Con los fondos reunidos, la Fundación compró el predio al grupo de privados iniciales, el que fue bautizado como "Santuario El Cañi”. Más adelante, en 1993 y gracias al apoyo financiero de la Foundation for Deep Ecology, que entregó US\$ 37.000 con este fin, Fundación Lahuén compró 85 hectáreas adicionales, para completar la actual superficie de la reserva El Cañi de 485 hectáreas.

Los objetivos de la Fundación son:

a) La conservación del bosque nativo a través de la creación de reservas forestales privadas;

b) La compra o adquisición de bosques, especialmente nativos, para mantenerlos bajo protección y conservación, así como la reforestación de sectores dañados;

Sergio Vergara Larraín. Abogado. Fundador de la Fundación Lahuén.

* Extracto de la presentación de Sergio Vergara L. redactado por Leonel Sierralta. 
c) La mantención, protección y conservación de ecosistemas o predios forestales, sean éstos propios o de terceros; y

d) La difusión y promoción de la conservación del bosque nativo, la educación adecuada a este propósito, así como ampliar la conciencia ecológica.

Como un resguardo importante, los estatutos de Fundación Lahuén prohíben vender, enajenar, explotar comercialmente o manejar en forma destructiva los bosques que sean de su dominio o que le sean entregados por terceros para su cuidado o administración.

\section{Reserva El Cañi}

La Fundación Lahuén estableció los siguientes objetivos para la reserva El Cañi:

- $\quad$ Mantener la belleza natural de El Cañi.

- $\quad$ Educar a través de la experiencia.

- $\quad$ Promover la investigación sobre biodiversidad y ecología.

- $\quad$ Procurar su sostenibilidad mediante la creación de incentivos económicos atractivos para la población local, y su autosuficiencia, con el fin de no depender permanente y exclusivamente de la ayuda exterior.

En el interior de la reserva El Cañi existe un cono volcánico, hay una docena de pequeños lagos y un mirador con vistas panorámicas de 360 grados desde el cual se avistan volcanes nevados, picos de granito, grandes lagos y el cordón montañoso que limita con Argentina. El Cañi alberga una variedad importante de especies arbóreas, en especial lenga, araucaria y coigüe, una multitud de fauna silvestre, en que destacan el puma y el gato montés, y una enorme variedad de aves. En la parte superior de la reserva predomina la araucaria.

En abril de 1992, un grupo de amigos de El Cañi, formado por residentes locales y visitantes extranjeros, inauguró una cabaña rústica a los pies de la reserva con agua corriente y electricidad, como punto de llegada y de partida, lugar de encuentro y refugio de emergencia. Más tarde, mediante un proyecto de capacitación e infraestructura financiado por el Fondo de las Américas, se construyó un refugio en la reserva misma, con unos $100 \mathrm{~m}^{2}$ de superficie, que contempló además un espacio cubierto para instalar carpas. Este refugio se utiliza principalmente en invierno y fue refaccionado el año pasado. 
Fundación Lahuén dio inicio a sus programas de educación ambiental en El Cañi durante 1993, teniendo en vista estimular el diálogo y la reflexión sobre la relación entre la humanidad y la naturaleza y comprometer en esta tarea a expertos en diferentes campos para educar sobre la complejidad de los ecosistemas. Los programas contemplaban sumergirse en la naturaleza, a través de caminatas guiadas, camping ecológico y debates. Sólo en el primer año del programa, el Proyecto Educacional El Cañi lideró 38 excursiones en la reserva en las que participaron 62 estudiantes y 247 adultos. Se dieron charlas con exhibición de diapositivas a amplios grupos, orientadas a promover una mayor conciencia sobre la conservación de los bosques y los objetivos del proyecto El Cañi. Sólo durante el primer año participaron en ellas 437 estudiantes y 247 adultos. Finalmente, durante tres años consecutivos el Fondo de las Américas financió proyectos educativos, de capacitación y de infraestructura, con énfasis en la enseñanza, capacitación y participación de la comunidad local.

Con el fin de conservar, educar y cumplir sus objetivos, Fundación Lahuén se decidió a utilizar el gran potencial de la reserva para obtener ingresos a través del ecoturismo. Para ello se estableció que los visitantes debían pagar una entrada al parque y contratar los servicios de un guía entrenado para recorrerlo y mostrarlo a cabalidad, con suficiente información sobre la espectacular flora y fauna de El Cañi y conocimientos para conducir al turista por senderos preestablecidos para llegar a los puntos de mayor interés sin dañar el ecosistema. Inicialmente no se aceptarían visitas sin guías, en un esfuerzo por evitar daños a la belleza natural.

\section{Situación actual}

A la fecha visitan la reserva El Cañi unos setecientos turistas durante el verano, pagando una entrada de \$ 3.000 cada uno, más \$ 3.000 adicionales cuando utilizan guías. Durante esta estación se permite la entrada sin guías, porque existe una buena señalética para llegar a los puntos de mayor interés; además se contrata un guardaparque que colabora con los visitantes. Fuera de los meses de verano visitan la reserva unos cuatrocientos estudiantes de escuelas municipales y privadas.

\section{Acuerdos con la comunidad local}

La gestión de la reserva ha considerado, permanentemente, un delicado equilibrio con la comunidad local. La sustentabilidad está basada en la aceptación y, más que ello, en el compromiso de los vecinos con su tarea de 
conservar, lo que se ha logrado en forma muy satisfactoria. Sin embargo, hay unas quince propiedades contiguas de agricultores pequeños o medianos y todos tienen animales de crianza, especialmente vacunos. Para evitar el pastoreo de ganado dentro de la reserva, se han construido cinco kilómetros de cercos que en los primeros años permitieron el crecimiento de los renovales de lenga, hasta entonces comidos y pisoteados por los animales del vecindario. Ello hizo posible que hoy existan árboles que ya forman una masa juvenil capaz de resistir la depredación animal.

La reserva El Cañi, primera área silvestre protegida de propiedad privada, cuyo propietario es la primera organización sin fines de lucro dedicada exclusivamente a la conservación forestal, ha vivido un constante vaivén de éxitos y fracasos. Sin embargo, constituye un experimento que valió la pena realizar, un proyecto que valió la pena acometer, y una gran enseñanza para muchos.

Palabras clave: Reserva El Cañi, Chile; Fundación Lahuén; bosque nativo; economía del medio ambiente. 


\title{
EL OCÉANO Y LA CONSERVACIÓN EN CHILE: LOS ETERNOS OLVIDADOS*
}

\author{
Juan Carlos Castilla
}

\section{Introducción y regímenes marítimos}

Los océanos (mares) representan aproximadamente el 75\% de la superficie del planeta Tierra y, sin embargo, desde el punto de vista de la conservación, preservación de sus ambientes y biotas y la explotación sustentable de sus recursos, son nuestros eternos olvidados. Esto se debe a varias causas. Una no menor es que los océanos no forman parte directa de lo que normalmente consideramos nuestro hábitat natural: somos "seres terrestres”. Con ello ignoramos las conexiones esenciales entre océano-atmósfera-sistema terrestre, que determinan en último término nuestro hábitat natural. La extensión de los océanos, sus inmensidades y los conocimientos incipientes sobre ellos (es posible que se conozca más de algunos sistemas extra-terrestres que de los océanos) hacen que normalmente les demos la espalda. Esto es especialmente verdad en Chile, donde la expresión: "vivimos de espaldas al Pacífico” no es sólo un dicho sino que una realidad. Adicionalmente, los océanos son nuestros eternos olvidados porque tienen una gran capacidad para absorber, aminorar y “disfrazar”, hasta cierto punto, nuestras agresiones ambientales o extractivas hacia ellos. Muchas personas, comunidades o Estados, aún consideran que los océanos son ilimitados, inmutables y difíciles de perturbar (véanse las raíces de estas antiguas concepciones de Grotius, 1609, en Anad, 1980, y Huxley, 1884). Esto no es verdad. Por ejemplo, la sobre-explotación de los recursos marinos renovables es ya una realidad desde hace más de unos 50 años (Botsford et al., 1997). Más recientemente, los cambios climáticos globales están poniendo de manifiesto importantes modificaciones en los mares; por ejemplo, la aci-

Juan Carlos Castilla. Ph.D. Biología Marina, University of Wales. Profesor titular del Departamento de Ecología, Facultad de Ciencias Biológicas, P. Universidad Católica de Chile. jcastilla@bio.puc.cl.

* Agradezco la invitación del Centro de Estudios Públicos (CEP), y en especial de Leonel Sierralta, para dictar esta charla en el encuentro "Liderazgo del sector privado en la conservación del medio ambiente". Este trabajo fue financiado por el proyecto Fondap-Fondecyt 1501-0001, Center for Advanced Studies in Ecology and Biodiversity. 
dificación de las aguas oceánicas debido al incremento atmosférico de la concentración de $\mathrm{CO}_{2}$ muestra una tendencia ascendente y existen evidencias de ampliación de las zonas de mínimo de oxígeno (Stramma et al., 2008).

Finalmente, los principios de territorialidad marina (oceánica) son muy distintos de aquellos que rigen los de la territorialidad terrestre. Desde el punto de vista histórico las "leyes de los mares" se establecieron por costumbre y en ellos no existe el derecho de propiedad privada (del mismo modo que con el aire). Éste (el derecho de propiedad privada) es un derecho fundamental en los sistemas terrestres. Tres han sido los regímenes territoriales marítimos básicos que se han incorporado primero en leyes costumbristas tradicionales y luego en legislaciones internacionales: a) regímenes de soberanías nacionales: que son similares a una personalidad jurídica por parte de un Estado sobre los océanos; b) regímenes de res nullius: caracterizados por una falta de soberanía o propiedad, la que sin embargo permanece disponible de apropiación por un reclamente; es decir, puede ser objeto de ley soberana; c) regímenes de res communis: referente a un tipo de área, o un objeto móvil, del que no puede haber apropiación de modo que se impida su uso por otros; por lo tanto, una verdadera res communis no puede ser objeto de ley soberana (Anand, 1980; Morell, 1992). La Law of the Sea (LOS) (United Nations Convention on the Law of the Sea) y la Law of the Sea Treaty son los acuerdos internacionales más trascendentes que resultaron de la Tercera Conferencia sobre la Ley del Mar (UNCLOS III: 1972-1982). Allí se definen los derechos y responsabilidades de las naciones respecto del uso de los océanos, estableciéndose guías para el tráfico, los negocios, el ambiente y el manejo de los recursos marinos. La Convención y la LOS entraron en vigencia en 1994 y al presente 155 países y la Unión Europea las han ratificado. Los principales espacios marítimos que son definidos y regulados en estos instrumentos internacionales son: a) Aguas Territoriales (Territorial Waters), comprendidas en las 12 millas náuticas desde la línea de base costera; b) Zona Contigua (Contiguous Zone), comprendida a partir de otras 12 millas náuticas desde el límite marino externo de la TW; c) Zona Económica Exclusiva (Exclusive Economic Zone), que abarca las 200 millas náuticas desde la línea de base costera; d) Aguas Internacionales (International Waters), aguas oceánicas más allá de la Zona Económica Exclusiva. Adicionalmente, un principio territorial marítimo, aun en discusión, es aquel de freedom of the high seas, que es considerado por algunos Estados con un significado de res nullius y por lo tanto fuera de la jurisdicción de alguna nación; mientras que para otros (la mayoría) es considerado como res communis o law of the commons (Castilla y Orrego, 1984, para las especies altamente migratorias). El largo recorrido históri- 
co desde las concepciones de los mares (océanos) como un gran espacio regulado por el principio de freedom of the sea (res nullius; Grotius, 1609) fue finalmente (aunque aún sin un total consenso) regulado a través de la LOS. No obstante, lo que se ha mantenido inalterable mundialmente, y casi sin excepciones, es el concepto fundamental de que aún dentro de las regulaciones espaciales marítimas de la LOS el derecho de propiedad privada sobre el mar no existe. Este hecho tiene una enorme trascendencia para los aspectos que se tratan en este artículo sobre conservación, preservación y uso racional de los espacios y recursos marinos (oceánicos), en particular en Chile y con referencia a la Ley de Pesca y Acuicultura de 1992.

Cuando en una sociedad (estado, nación) existen bienes o recursos que no tienen pertenencia o propiedad particular o individual, sino que son bienes comunitarios (“de los comunes”), se puede producir el fenómeno conocido como la "tragedia de los comunes” (Hardin, 1968), esto es: aquellos bienes o recursos que no le pertenecen a nadie, nadie los cuida y así se pueden producir deterioros como sobre-explotaciones, reducciones poblacionales y usos o manejos inadecuados. Se han descrito dos formas básicas de superar esta tragedia: a) que el Estado (si se trata de un Estado) se haga cargo de esos bienes o recursos en nombre de todos sus ciudadanos ("los comunes”) y los administre en beneficio de ellos a través de leyes, reglamentos, incentivos; b) que dichos bienes o recursos se privaticen a particulares, en parcialidades o en su totalidad, en regímenes de administración privada propiamente tales o en formas de co-administración entre privados y el Estado (también son posibles regímenes mixtos). Estas formas de administración sobre "recursos comunes" ocurren respecto de los "territorios terrestres”, donde, por supuesto, además se da en plenitud el derecho de la propiedad privada. En base a los argumentos esgrimidos arriba, se deduce que los espacios o territorios marinos, en oposición a los terrestres, deben o pueden ser objetos de la "tragedia de los comunes". Históricamente, la conservación y administración racional de los ambientes marinos (oceánicos) no ha pasado por la privatización a particulares. Así, este trabajo, inserto en el Seminario Internacional "El Sector Privado y la Conservación Ambiental: Biodiversidad y Áreas Protegidas”, parecería no tener mucho sentido, ya que en los mares no existe la figura legal de privatización. Sin embargo, en él precisamente se destaca el hecho de que Chile, a través de una legislación pesquera moderna, ha enfrentado la problemática de la "tragedia de los comunes” en los espacios marinos costeros usando fórmulas creativas que han promovido el co-manejo pesquero en especies bentónicas o de fondo, mariscos y algas, en el seno de comunidades de pescadores 
artesanales y por ende la utilización más racional de estos recursos marinos (Castilla y Defeo, 2001; McClanahan y Castilla, 2007). Respecto de la conservación y preservación de territorios, ecosistemas y biodiversidad marina, en este trabajo se plantea y discute la idea generalizada de que existen muchos menos resguardos legales y precauciones que lo que se tiene para los territorios terrestres. En Chile, una parte no menor de esto se debe a que la legislación que regula la conservación y preservación marina es muy dispersa y es menos específica que la relacionada con la de los territorios terrestres (Fernández y Castilla, 2005).

\section{Resumen sobre la legislación chilena en conservación marina y terrestre}

\subsection{Legislación general, sistema nacional de áreas protegidas y los sistemas marinos}

Fernández y Castilla (2005) realizaron un análisis sobre la problemática de conservación marina en Chile, incluyendo perspectivas históricas, las lecciones aprendidas y los desafíos del futuro (además, véase Castilla, 1976, 1986, 1996). El año 1982 en Chile se decretó la Ley Nº 18.362 sobre Áreas Silvestres, donde se definieron las regulaciones sobre conservación, preservación y categorías territoriales, principalmente terrestres del país. En el año 1994, la Ley de Bases del Medio Ambiente Nº 19.300 incorporó nuevos instrumentos y reglamentos específicos. Sin embargo, en ninguna de estas dos legislaciones, centrales para la conservación y preservación de ambientes y biota de Chile, se da especial énfasis a los territorios marítimos. Por otra parte, en 1992, la Ley General de Pesca y Acuicultura (LGPA) No 18.892 sí incluyó instrumentos específicos de conservación marina, como son los Parques Marinos. Aparte de lo anterior existen varias disposiciones en la Armada de Chile y del Ministerio de Educación (por ejemplo, que regula los Santuarios de la Naturaleza) y otras que hacen que la legislación nacional para ambientes marinos sea excesivamente dispersa y compleja. Además, en Chile, destaca la inexistencia de una institucionalidad específica para la conservación de estos sistemas. Éste no es el caso para los territorios terrestres, donde no sólo existe legislación de conservación mucho más específica, sino que una institucionalidad de larga data, como es la Corporación Nacional Forestal (CONAF). No obstante lo anterior Fernández y Castilla (2005) destacan la existencia en el país de 26 áreas marinas que pueden considerarse con algún estado de protección (en 5-6 diferentes categorías). Estos autores usan la nomenclatura de Áreas Marinas Protegidas Privadas, para referirse a sitios marinos bajo protección por parte de alguna institu- 
ción privada (una universidad, por ejemplo), bajo la figura de una "concesión marina” otorgada por el Estado por un número de años. Finalmente, la Comisión Nacional de Medio Ambiente, como parte de la Estrategia Nacional de Biodiversidad (Saball et al., 2006) adicionalmente ha seleccionado 26 áreas marinas a lo largo del país y las ha propuesto como áreas específicas de conservación marina, como parte del objetivo de preservar un 10\% de cada uno de los ecosistemas representativos del país para 2012. En el recuento anterior sobre áreas marinas protegidas no se contemplan los cientos de Áreas de Explotación y Manejo de Recursos Bentónicos (AMERB), incluidas en la LGPA, que suman más de $1.000 \mathrm{~km}^{2}$ de espacios marítimos costeros, que no tienen como finalidad la conservación en sí, sino que un manejo sustentable de los recursos artesanales bentónicos (véase Gelcich et al., 2008).

\subsection{Ley General de Pesca y Acuicultura y el co-manejo en el mar costero}

La Ley General de Pesca y Acuicultura, con su texto refundido, coordinado y sistematizado, fue publicada en enero de 1992 y contiene los lineamentos generales de cómo Chile enfrentó en la década de los 90, en forma creativa, los problemas de administración de los recursos marinos y sus ambientes. Una de las definiciones claves en esta ley es la distinción entre la actividad pesquera industrial y la artesanal: espacios en que ellas pueden operar, características y tamaños de las flotas. Además, la LGPA creó los Registros Pesqueros Artesanales e Industriales obligatorios y la inscripción de los pescadores por recurso pesquero. Del mismo modo, se establecieron regulaciones para los tipos y grados de explotación de los recursos y las modalidades de manejo. Sin embargo, y para los propósitos de este trabajo, desde el punto de vista del manejo y la conservación, en la LGPA existen tres figuras que le dan un carácter especial y de avanzada:

a). Zonación oceánica espacialmente explícita. La LGPA reserva para uso exclusivo de flotas pesqueras artesanales una franja de mar territorial de cinco millas marinas, medidas desde las líneas de base normales, a partir del límite norte de la República y hasta el paralelo $41^{\circ} 28$ 6' S. y alrededor de las islas oceánicas; del mismo modo que la pesca en las aguas interiores. Esto determina una zonación oceánica espacialmente explícita de aproximadamente $27.000 \mathrm{~km}^{2}$ para Chile continental, que ha permitido separar a las flotas pesqueras artesanal e industrial, determinar mejor los esfuerzos de pesca e introducir mecanismos de controles espaciales en las distribuciones de las flotas. Por ejemplo, la introducción de un Sistema de 
Posicionamiento Automático de Naves Pesqueras, aprobado en 1998 (Decreto Supremo 139) y puesto en ejecución obligatoria en 2002. Esta disposición está enfocada principalmente a las actividades de pesca extractiva de peces (pelágicos, demersales y de orilla) donde antes de la puesta en vigencia de la LGPA existía una abierta competencia entre las flotas artesanal e industrial. Más allá de las 5 millas marinas puede operar la flota industrial y en casos de penetraciones de ésta a las 5 millas artesanales, se requieren permisos especiales.

b) Áreas de Manejo y Explotación de Recursos Bentónicos (AMERB). En Chile, antes de 1992 la extracción de recursos pesqueros artesanales bentónicos (pesquería de pequeña escala, principalmente por buceo; véase Bustamante y Castilla, 1987) operaba a través de un sistema pesquero de libre acceso (Castilla, 1994; Defeo y Castilla, 2005). Hacia el final de los años 80 quedaron patentes los problemas de sobre-explotación de estos recursos bentónicos, con los consecuentes daños sociales y económicos para miles de pescadores y el país. Se requería de nuevas regulaciones legales. La LGPA recogió estos desafíos de manejo de la pesca artesanal de pequeña escala, basándose en la experiencia del régimen de libre acceso y en estudios ecológicos y pesqueros realizados en Chile entre 1980 y 1990 (Castilla, 1994). El régimen de pesca para los pescadores artesanales de recursos bentónicos someros fue drásticamente modificado, asignándoseles derechos exclusivos de pesca comunitarios, a niveles de caletas pesqueras y de organizaciones de pescadores, en la forma de asignaciones de Áreas de Manejo y Explotación de Recursos Bentónicos (AMERB). Esto en base al concepto de co-manejo pesquero entre asociaciones de pescadores y el Estado, vía la adjudicación de derechos exclusivos de pesca, por un número de años y en base a cobros por hectáreas: un equivalente a los “Territorial User Rights for Fisheries” TURFS (Castilla, 1994; Gelcich et al., 2006; Castilla y Gelcich, 2006, 2008). Los resultados de este sistema, en operación efectiva en Chile por a lo menos once años, han sido resumidos recientemente por McClanahan y Castilla, 2007, y sus proyecciones para otros sistemas pesqueros del mundo por McClanahan et al. (en prensa). El gobierno de Chile estima que este sistema de manejo pesquero artesanal, para recursos bentónicos, ha sido un éxito, en términos que se han recuperado (o estabilizado) algunas poblaciones de recursos anteriormente sobreexplotados. Una prueba de ello es la continua asignación de estos espacios territoriales marinos de usos exclusivos a las comunidades de pescadores: a la fecha las AMERB sobrepasan las 300 (véase Castilla y Gelcich 2006). 
c) Ley General de Pesca y Acuicultura y los Parques Marinos. Como ya se describió, la LGPA contiene herramientas no sólo de manejo pesquero (las más), sino que además de conservación y preservación de los recursos y ambientes marinos. No es común que una ley de pesca contenga ambas herramientas y ésta es una dimensión, poco destacada de la LGPA de Chile, que la hace novedosa (a pesar de que la combinación de las herramientas de manejo y de conservación aún debe perfeccionarse). En la LGPA las áreas de conservación son definidas como Parques Marinos, con los objetivos de preservar unidades ecológicas de interés para la ciencia y cautelar áreas que aseguren la mantención y diversidad de especies hidrobiológicas, como también aquellas asociadas a su hábitat.

\section{Sistemas territoriales terrestres y marinos en Chile y estados de conservación}

La Tabla $\mathrm{N}^{\circ} 1$ muestra los estados de conservación del territorio terrestre (incluyendo humedales) y marítimos chilenos. En tierra existen 32 parques, 15 monumentos y 48 reservas terrestres, que comprenden un total de $141.253 \mathrm{~km}^{2}$ (aproximadamente un 19\% territorio terrestre continental de Chile). A esto se le deben agregar aproximadamente $10.000 \mathrm{~km}^{2}$ de áreas terrestres bajo estado de conservación por privados. Para los territorios marítimos existen sólo 20 sitios en estado de conservación: seis áreas protegidas, seis parques y ocho áreas de investigación, con $823 \mathrm{~km}^{2}$ (aproximadamente un 0,7\% del Mar Territorial de Chile). En este último porcentaje no se consideran territorios marítimos como las AMERB bajo regímenes de manejo por pescadores artesanales y las concesiones de acuicultura, bajo regímenes de manejo por privados, también en concesión del Estado.

\section{Estimaciones sobre costos y beneficios para el país de estas áreas de conservación y número de personal para sus administraciones (guardapar- ques)}

La Tabla $N^{\circ} 2$ muestra las áreas totales de conservación en Chile para los territorios terrestres y marítimos y un estimado de los números de guardaparques encargados de sus administraciones. Los guardaparques para las áreas de conservación terrestre son $c a .450$ personas y para las marítimas de ca. 10. Los costos estimados por año para la operación de estos sistemas (sólo considerando los guardaparques contratados) fluctúa entre 13 y 24 millones de dólares para los sitios terrestres (Asmüssen \& Simonetti, 2007) y entre 2 y 2,5 millones de dólares para los marítimos (esti- 


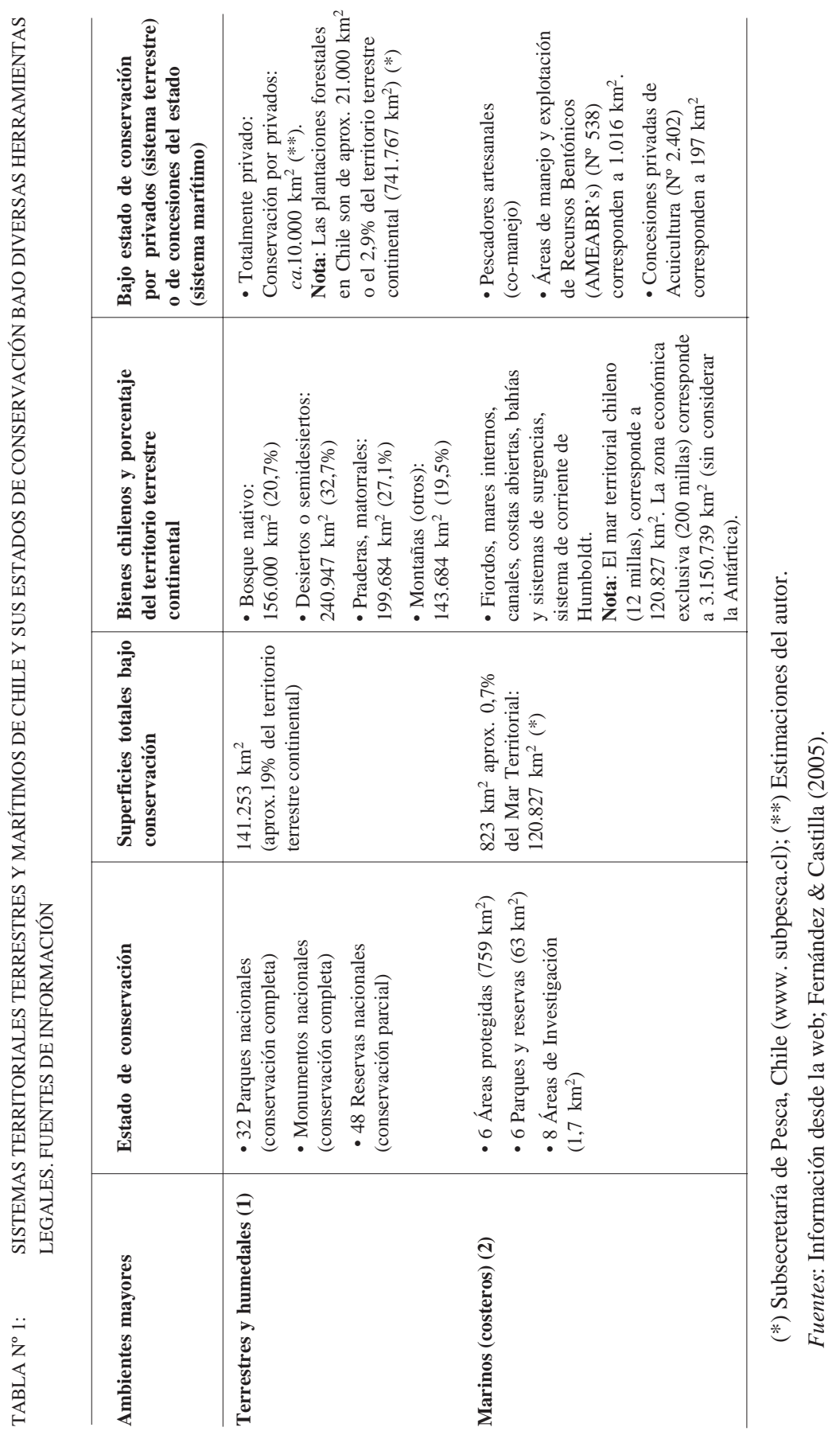




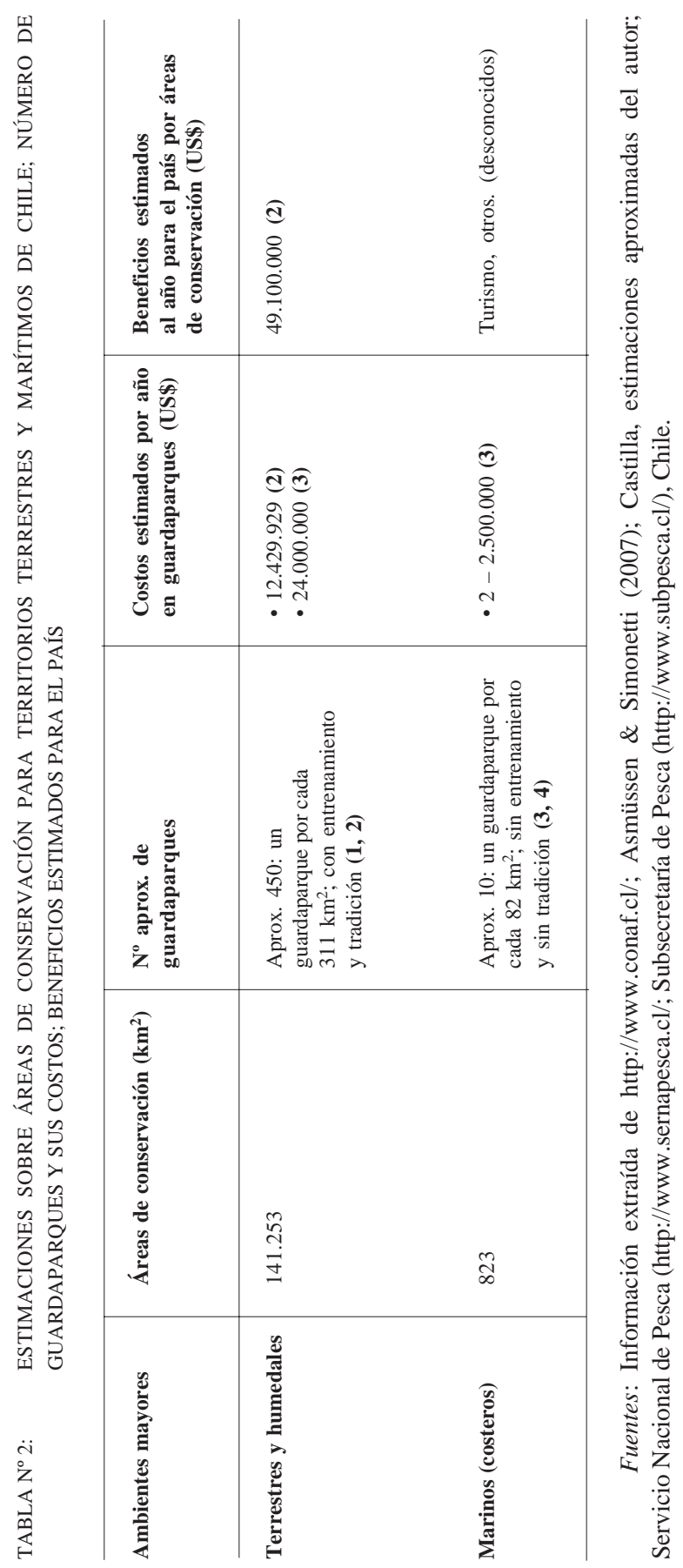


maciones del autor). Los beneficios económicos estimados por año que generan los sitios de conservación terrestre sobrepasan los 49 millones de dólares (Asmüssen \& Simonetti, 2007), mientras que para los sitios marinos no existen estimaciones.

\section{Discusión}

En el trabajo se destacan las divisiones reconocidas internacionalmente respecto de las áreas marítimas en los océanos del mundo y los hitos legales más resaltantes en que han cristalizado dichas divisiones. Además, se remarca la no existencia del derecho de propiedad en los territorios marítimos, en contraposición a lo que ocurre en los territorios terrestres. Una consecuencia de lo anterior es la tendencia de que en el mar se observe con mayor frecuencia la conocida "tragedia de los comunes" (Hardin, 1968). Nada de lo anterior justifica, sin embargo, los diferentes énfasis y preocupaciones del Estado en relación con la conservación y la preservación que resultan muy disminuidas en los mares en comparación con la tierra.

La legislación chilena respecto a la conservación marina es frondosa, dispersa y no está institucionalizada (Fernández y Castilla, 2005). Las leyes nacionales sobre Áreas Silvestres, de Bases del Medio Ambiente y General de Pesca y Acuicultura son los tres instrumentos más importantes al respecto. Sin embargo, a diferencia de la tierra, donde existe una institucionalización bien asentada, la Comisión Nacional Forestal (Conaf), para el mar ello es inexistente o a lo más incipiente (legalmente representada por el Servicio Nacional de Pesca, Sernapesca). Sin duda estos dos elementos conspiran contra el establecimiento en Chile de un número suficiente de áreas marinas protegidas y más aún, de una red espacial bien estructurada (Castilla, 1996; Castilla, 2002). En Chile existen sólo 823 km² de áreas marinas en estado de conservación propiamente tales; en comparación con los más de 150.000 km² (del Estado y privados) para los sistemas terrestres (Tabla $N^{\circ} 1$ ). En el país las inversiones en conservación (sólo tomando en cuenta los costos directos de los guardaparques de áreas en conservación) son hasta un orden de magnitud mayores para los sistemas en tierra que para los marinos (Tabla $\mathrm{N}^{\mathrm{O}}$ 2). Todo lo anterior justifica el título de este trabajo. En verdad, a nivel mundial y también en Chile le seguimos dando la espalda al mar. La conservación y preservación marina, del mismo modo que el uso racional y sostenido de sus recursos, están fuertemente disminuidos y deteriorados. Sin embargo, en este sentido las acciones de manejo racional de recursos de pescadores artesanales en Chile, tales como zonaciones oceánicas espacialmente explícitas cinco millas náuticas en Chile) y las Áreas de Manejo y 
Explotación de Recursos Bentónicos de la LGPA, que incluyen derechos exclusivos de pesca para estos pescadores, son ejemplos a nivel mundial respecto de herramientas de co-manejo novedosas en el uso sustentable de recursos marinos (Defeo y Castilla, 2005; Castilla y Gelcich, 2006) y de cómo se hace para dejar de darle la espalda al mar. Más aún, cuando en el caso de las AMERB chilenas estas medidas de administración, con objetivos específicos de co-manejo de recursos, adicionalmente están rindiendo frutos también en la conservación de la biodiversidad marina (Gelcich et al., 2008)

\section{REFERENCIAS}

Anad, R. P. (1980): Law of the Sea: Caracas and Beyond. Martinus Nuhoff Publishers, pp. 399.

Asmüssen, M. V. \& J. A. Simonetti (2007): “Can a Developing Country like Chile Invest in Biodiversity Conservation?” En Environmental Conservation, 34: 183-185.

Botsford, L. W., J. C. Castilla \& C. H. Peterson (1997): “The Management of Fisheries and Marine Ecosystems”. En Science, 277: 509-15.

Bustamante, R. \& J. C. Castilla (1987): “The Shellfisheries in Chile: An Analysis of 26 Year of Landings”. En Biología Pesquera, 16; 79-97, Chile.

Castilla, J. C. (1976): "Parques y Reservas Marinas Chilenas: Necesidad de Creación, Probables Localizaciones y Criterios Básicos”. En Medio Ambiente, 2: 70-80.

(1986): “¿Sigue Existiendo la Necesidad de Establecer Parques y Reservas Marítimas en Chile?”. En Ambiente y Desarrollo, II (2): 53-63.

(1994): "The Chilean Small-Scale Benthic Shellfisheries and the Institutionalization of New Management Practices”. En Ecology International Bulletin, 21: 47-63.

(1996): "La Futura Red Chilena de Parques y Reservas Marinas y los Conceptos de Conservación, Preservación y Manejo en la Legislación Nacional”. En Revista Chilena de Historia Natural, 69: 253-270.

(2002): "Los Parques Marinos en Chile: Conservación, Manejo y la Relación entre Investigación e Industria”. En Ambiente y Desarrollo, 17: 137-141.

Castilla, J. C. \& O. Defeo (2001): "Latin American Benthic Shellfisheries: Emphasis on Comanagement and Experimental Practices”. En Reviews in Fish Biology and Fisheries, 11: 1-30.

Castilla, J. C. \& S. Gelcich (2006): “Chile: Experience with Management and Exploitation Areas for Coastal Fisheries as Building Blocks for Large-Scale Marine Management”. En The World Bank, Scaling Up Marine Management: The Role of Marine Protected Areas. Washington D.C.: The World Bank Publications, pp. 45-57.

(2008): "Management of the Loco (Concholepas concholepas) as a Driver for Self-governance of Small-Scale Benthic Fisheries in Chile”. En R. Townsend, R. Shotton \& H. Uchida (eds.), Case Studies in Fisheries Self-governance. FAO Fisheries Technical Paper No 504. Rome, FAO, pp. 441-451. 
Castilla, J. C., S. Gelcich, S. \& O. Defeo (2007): “Successes, Lessons, and Projections from Experience in Marine Benthic Invertebrate Artisanal Fisheries in Chile”, capítulo 2. En T. McClanahan \& J. C. Castilla (eds.), Fisheries Management: Progress toward Sustainability. Blackwell publishing, pp. 25-42.

Castilla, J. C. \& F. Orrego (1984): "Highly Migratory Species and the Coordination of Fishery Policies within Certain Exclusive Economic Zones: The South Pacific”. En Ocean Management, 9 (1-2): 21-34.

Defeo, O. \& J. C. Castilla (2005): "More than One Bag for the World Fishery Crisis and Keys for Co-Management Successes in Selected Artisanal Latin American Shellfisheries". En Reviews in Fish Biology and Fisheries, 15: 265-283.

Defeo, O., T. McClanahan \& J. C. Castilla (2007): “A Brief History of Fisheries Management with Emphasis on Societal Participatory Roles”, capítulo 1. En T. McClanahan \& J. C. Castilla (eds), Fisheries Management: Progress toward Sustainability. Blackwell Publishing, pp. 3-21.

Fernández, M. \& J. C. Castilla (2005): "Marine Conservation in Chile: Historical Perspective, Lessons, and Challenges”. En Conservation Biology, 19 (6): 17521762.

Gelcich, S., G. Edwards-Jones, M. J. Kaiser \& J. C. Castilla (2006): “Co-Management Policy Can Reduce Resilience in Traditionally Managed Marine Ecosystems”. En Ecosystems, 9: 951-966.

Gelcich, S., N. Godoy, L. Prado \& J. C. Castilla (2008): “Add-on Conservation Benefits of Marine Territorial User Rights Fishery Policies in Central Chile”. En Ecological Applications, 18: 273-281.

Hardin, G. (1968): “The Tragedy of the Commons”. En Science, 162: 1243-1248.

Huxley, T. (1884): “Inaugural Address”. En Fish Exhib. Lit., 4: 1-22.

Ley de Pesca y Acuicultura 1992. Ministerio de Economía, Fomento y Reconstrucción, Subsecretaría de Pesca, Valparaíso, gobierno de Chile.

McClanahan. T. \& J. C. Castilla, editores (2007): Fisheries Management: Progress towards Sustainability. Blackwell publishing.

McClanahan, T. R., J. C. Castilla, A. T. White \& O. Defeo (en prensa): "Healing Smallscale Fisheries by Facilitating Complex Socio-Ecological Systems”. Por aparecer en Reviews in Fish Biology and Fisheries.

Morell, J. B. (1992): The Law of the Sea: An Historical Analysis of the 1982 Treaty and its Rejection by the United States. McFarland, pp. 482.

Saball, P., Arroyo, M. K., J. C. Castilla, C. Estades, J. M. Ladrón de Guevara, S. Larraín, C. Moreno, F. Rivas, J. Rovira, A. Sánchez \& L. Sierralta (2006): "Biodiversidad de Chile. Patrimonio y Desafíos”. Santiago, Chile: Comisión Nacional del Medio Ambiente, pp. 584-593.

Stramma, L., G. C. Johnson, J. Sprintall \& V. Mohrholz (2008): Expanding OxygenMinimum Zones in the Tropical Oceans”. En Science, 320: 655-658.

Palabras clave: política chilena de recursos marinos y conservación; ecosistemas y biodiversidad marina; economía del medio ambiente. 


\section{PLANTACIONES FORESTALES Y SUSTENTABILIDAD}

\section{Fernando Raga y Aldo Cerda}

\section{Nota aclaratoria}

El presente trabajo busca dimensionar los elementos concretos del desafío de un mundo sustentable para la población existente y futura, a partir del uso de sus recursos naturales, en particular aquellos vinculados a lo comúnmente denominado “forestal” (léase, árboles, biodiversidad de flora, fauna, genes y ecosistemas, suelo, agua, clima y otros). Es decir, partimos nuestro análisis del mundo en que vivimos, tratando de identificar una ruta sostenible en el largo plazo, y no tomando como punto de partida situaciones hipotéticas donde existan menos personas, imperativos morales diferentes o distinta situación de escasez de recursos naturales o medioambientales.

\section{El contexto}

En la actualidad el mundo dispone de un patrimonio de 3,87 billones de hectáreas de bosques, que representan el 30\% de la superficie continental. De éstos, 187 millones son bosques plantados (menos del 5\%), y de ellos, un $48 \%$ es de uso industrial y un $52 \%$ se considera superficie con fines de restauración ${ }^{1}$.

La tasa de plantación mundial se estima en unos 4,5 millones de ha anuales, y del total de bosques plantados, FAO estima que unas 25 millones de hectáreas corresponden a plantaciones de rápido crecimiento. Las plantaciones forestales suministran hoy alrededor del 35\% de la madera que el mundo demanda en forma industrial y se prevé que su participación aumentará al 40\% del consumo industrial de madera hacia el 2020.

La población actual del mundo supera los 6 billones de habitantes, $\mathrm{y}$ se espera que se estabilice en menos de 10 billones a mediados de este

FERnAndo RAGa C. Ingeniero Civil Industrial, Universidad de Chile. Vicepresidente de la Corporación Chilena de la Madera (Corma).

Aldo Cerda M. Economista del Medio Ambiente y Recursos Naturales, University College, London. Profesor de la Facultad de Ciencias Físicas y Matemáticas, Universidad de Chile.

\footnotetext{
${ }^{1}$ FAO: "Forest Resource Assessment”, 2000, en www.fao.org.
} 
siglo $^{2}$. Ella requiere satisfacer sus necesidades materiales y espirituales, y se parte de una situación base en que una proporción apreciable de ella vive en condiciones deplorables ( $21 \%$ de la población mundial vive con menos de 1 US\$ al día ${ }^{3}$ ). Por ende, existe un imperativo moral de favorecer la mejor forma de satisfacer estas necesidades, priorizando la mejoría en las condiciones de vida de los sectores más postergados, y ello sin desmejorar el endowment de recursos naturales y ambientales del planeta.

El imperativo enunciado anteriormente conlleva un doble desafío, dado que la presencia y actividad antrópica en la Tierra tiene un indiscutible impacto medioambiental, que se ha traducido en muchos casos en deterioro del entorno y pérdida de la biodiversidad. Así, un segundo objetivo prioritario es mejorar las condiciones de vida del ser humano, no sólo sin desmejorar las condiciones ambientales, sino también promoviendo la restauración de los ecosistemas más valiosos en peligro.

La vida humana en la tierra es consustancial a la existencia de los bosques. Estos proveen una multiplicidad de bienes y servicios a la sociedad (la mayoría de los cuales no tienen sustitutos), alojan parte importante de la biodiversidad del planeta e interactúan tanto con los suelos, enriqueciéndolos y protegiéndolos, como con la atmósfera, moderando los microclimas y participando en el ciclo hídrico ${ }^{4}$.

Claramente, son las demandas de la humanidad sobre los ecosistemas naturales, entre ellas la de madera, las que generan las discusiones sobre sustentabilidad. De modo que todo planteamiento sobre la misma que ignore dichas demandas, no sólo no responde al ámbito de ésta (social, económico o ambiental), sino que en la práctica no será realista y difícilmente pasará de una discusión teórica, no aportando verdaderas soluciones a los problemas del mundo real.

En vista de lo anterior, el desafío que nos auto-imponemos es discutir formas en cómo lograr suministrar las necesidades de madera de la población, logrando a la vez un máximo nivel de conservación de los ecosistemas naturales, es decir, cómo hacerlo en forma eco-eficiente, entendiendo por eco-eficiencia la producción de bienes y servicios con el menor impacto posible en términos de uso y degradación de los recursos naturales y medioambientales.

\footnotetext{
${ }^{2}$ UNDP: Human Development Report, varios años.

${ }^{3}$ World Bank: World Development Report, 2005.

${ }^{4}$ Pearce, D. W.: Economic Values and the Natural World, 1993.
} 


\section{La madera: un producto fundamental para la vida humana en la Tierra}

\subsection{Consumo y sustituibilidad}

Nuevamente, tomando como base que no podemos excluir del análisis o ignorar en éste la existencia de la humanidad y sus necesidades en la Tierra, emerge como ineludible analizar la situación de la demanda por madera, una de las más importantes materias primas que ésta utiliza. Su uso tiene consecuencias socioeconómicas y medioambientales enormes, y su disponibilidad y consumo son cruciales para el desenvolvimiento de la vida humana en la Tierra.

Actualmente, el consumo global de madera es del orden de 3,45 billones de $\mathrm{m}^{3}$ /año, de los cuales aproximadamente un 53\% se destina en forma directa a uso combustible (si después se añaden los subproductos industriales, el consumo energético de la madera supera el 65\%). Las proyecciones de FAO indican que el consumo al año 2010 llegaría a 3,8 billones de $\mathrm{m}^{3}$. El volumen de madera utilizado en el mundo es tan grande, en sus más de diez mil formas (productos) distintas, que resulta ser la materia prima de mayor consumo global, triplicando el de cemento, 1.150 millones de toneladas; cuadruplicando el de acero, 734 millones de toneladas; y siendo mayor en veinte veces al de plásticos, con 104 millones de toneladas ${ }^{5}$.

Dado que el volumen total de madera utilizado supera al de sus principales sustitutos cercanos sumados, ésta, en la práctica, no puede ser sustituida, no sólo por su enorme volumen (aún descontando el efecto del reciclaje y de la gestión de “residuo mínimo”), sino porque cualquier sustituto genera enormes costos ambientales por mayor consumo de energía, mayores niveles de contaminación tanto en el proceso productivo como en el uso de los mismos (life cycle analysis), y porque provienen de fuentes no renovables. Para un mayor detalle, véase Recuadro $\mathrm{N}^{\circ} 2.1$.

Así, dado que ya hoy en buena parte del mundo se ha llegado a los límites físicos del reciclaje, debemos partir como situación base del hecho de que la madera es un insumo fundamental para la especie humana, y que sus volúmenes requeridos son y serán sustanciales. El problema se centra, entonces, en cómo lograr producir estos volúmenes de madera del modo más eficiente desde el punto de vista socio-económico (minimizando el sacrificio de bienestar humano) y socio-ambiental (minimizando el uso de recursos naturales y los impactos negativos sobre el medio ambiente local y global).

\footnotetext{
${ }^{5}$ FAO: “Agricultura Mundial hacia el Año 2015-30”, en http://www.fao.org/ documents/show_cdr.asp?url_file=/docrep/004/y3557s/y3557s10.htm.
} 


\section{RECUADRO N ${ }^{\circ}$ 2.1:}

\section{VENTAJAS AMBIENTALES DEL USO DE LA MADERA}

La madera es asombrosamente versátil. Se estima que este producto ha sido utilizado en más de 10 mil formas diferentes (Sutton, conferencia en Nueva Zelandia, 1993). Es el producto de mayor consumo per cápita (véase Cuadro $\mathrm{N}^{\circ}$ B 2.1.1.)

\section{CUADRO No B. 2.1.1.}

Grs.

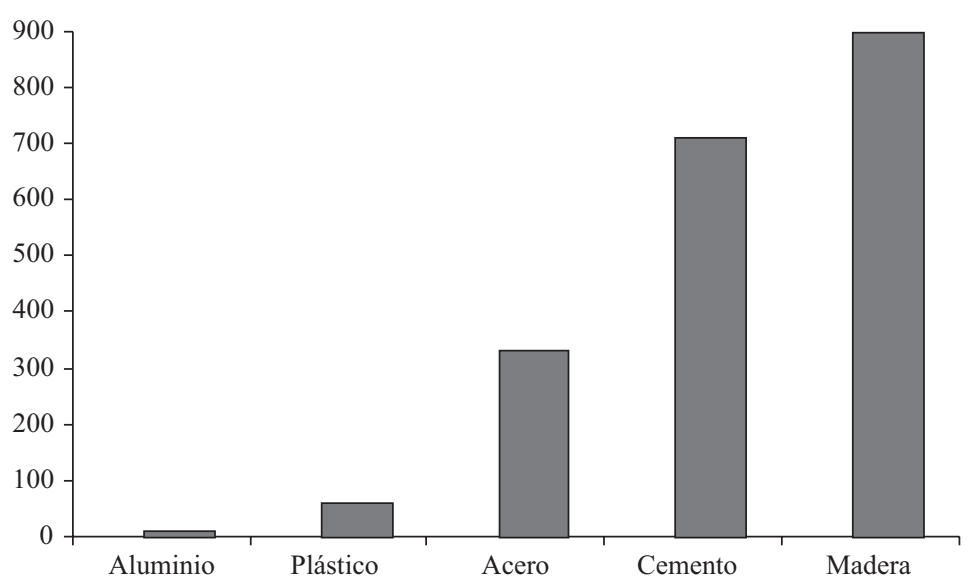

(Fuente: Sutton, 1999)

Existen sustitutos para la mayoría de los productos provenientes de la madera. Si se quisiera disminuir su uso, debería recurrirse a ellos. Y las consecuencias ambientales serían muy serias, pues todos ellos requieren cantidades enormemente superiores de energía para ser producidos, o plantean otros graves impactos negativos en el entorno. Veamos algunos ejemplos.

Reemplazar postes de madera por acero requiere 9 veces más energía. Suelos de madera por concreto, 21 veces. Muros de contrachapado por ladrillo, 30 veces (Fuente: Koch, 1992). Considerando los procesos de extracción, fabricación y transporte, la producción de madera requiere menor energía que la de sus sustitutos. Producir una tonelada de aluminio consume 70 veces más energía que la producción de una tonelada de madera. Por otra parte, la producción de acero y concreto requieren 17 y 3 veces más energía, respectivamente, que la producción de cantidad equivalente de madera (Fuente: Adams, 1994). 
Existen diversos estudios que se han efectuado en referencia al consumo de energía y emisiones de distintos materiales. El Cuadro № B.2.1.2 muestra algunos ejemplos, desarrollados por Honey \& Buchanan (1992)

Sustituir el uso combustible de madera por combustibles alternativos plantea también graves problemas. Si se pensara en reemplazo a gran escala por energía nuclear, aparecería un problema de inversión probablemente insuperable - el principal consumo de madera como combustible se genera en países y sectores de bajos recursos-, y un problema significativo de disposición de residuos radioactivos.

\section{CUADRO B. 2.1.2: ENERGÍA REQUERIDA Y EMISIÓN DE CARBONO PARA PRODUCIR ALGUNOS MATERIALES DE CONSTRUCCIÓN}

$\begin{array}{lrr}\text { Materiales de construcción } & \mathrm{GJ} / \mathrm{t} & \mathrm{GJ} / \mathrm{tm}^{3} \\ & & \\ \text { Madera tratada } & 2,4 & 1,2 \\ \text { Madera laminada } & 9,0 & 4,5 \\ \text { Acero estructural } & 59,0 & 448,0 \\ \text { Cemento reforzado } & 3,1 & 7,3 \\ \text { Alumino } & 145,0 & 362,0\end{array}$

\begin{tabular}{lcr}
\hline Tipo de construcción & $\begin{array}{c}\text { Costo de energía } \\
\left(\mathrm{kg} \mathrm{C} / \mathrm{m}^{2}\right)\end{array}$ & $\begin{array}{r}\text { Carbono lib } \\
\left(\mathrm{GJ} / \mathrm{m}^{2}\right)\end{array}$ \\
Cemento & & 111,92 \\
Acero & 5,61 & 131,01 \\
Madera & 6,64 & 71,22
\end{tabular}

Los combustibles fósiles emiten a la atmósfera carbono de las épocas prehistóricas, agravando el efecto invernadero, en tanto que el cultivo de bosques para leña captura de la atmósfera el carbono que emitirá al quemarse, por lo que no empeora los balances.

En cuanto a emisiones, el Cuadro $\mathrm{N}^{\circ}$ B2.1.2 muestra que las emisiones de carbono liberadas por la construcción en acero y cemento son muy superiores a las de la construcción de madera; en tanto que un estudio de la Universidad de Washington comprobó que la construcción en aluminio emite 2,7 veces más carbono que la madera.

La madera tiene la gran ventaja ambiental sobre la mayoría de sus sustitutos de ser un recurso renovable. Los bosques pueden plantarse o regenerarse indefinidamente, con adecuadas prácticas silvícolas, marcando una diferencia sustancial con los metales, productos arenosos, plásticos y combustibles fósiles.

A lo anterior deben agregarse las contribuciones ambientales de los bosques bien establecidos y manejados, como el control de la erosión, recuperación de suelos y captura de carbono de la atmósfera. 


\subsection{Dinámica de la demanda: crecimiento, pero con límites}

Dada la alta correlación que se mantuvo por un largo período entre el crecimiento de la población y el consumo de madera (véase Gráfico № 2.2.1), diversos grupos han expresado a lo largo del tiempo su preocupación de que una “explosión demográfica” se tradujera en una demanda “espejo” por madera que presione en forma no sustentable a los bosques. Dado lo anterior, lo razonable es revisar primeramente las proyecciones de crecimiento poblacional.

Las últimas proyecciones de FAO, basadas en antecedentes de UNDP, muestran tres escenarios hipotéticos (Gráfico No 2.2.2). Aun cuando el rango que se ofrece es muy amplio y la proyección denominada "alta" podría considerarse preocupante, las últimas proyecciones indican que la tendencia va incluso un poco más abajo que la proyección media (Gráfico $\mathrm{N}^{0}$ 2.2.3). Así, el mundo continuaría incrementando su población hasta algo más de 8,5 billones de personas, para luego estabilizarse y comenzar a descender ${ }^{6}$. De hecho, hoy más de la mitad de la población del planeta vive en

\section{GRÁFICO No 2.2.1: PROYECCIÓN DE CRECIMIENTO DE LA POBLACIÓN Y CONSUMO DE MADERA AL AÑO 2010}

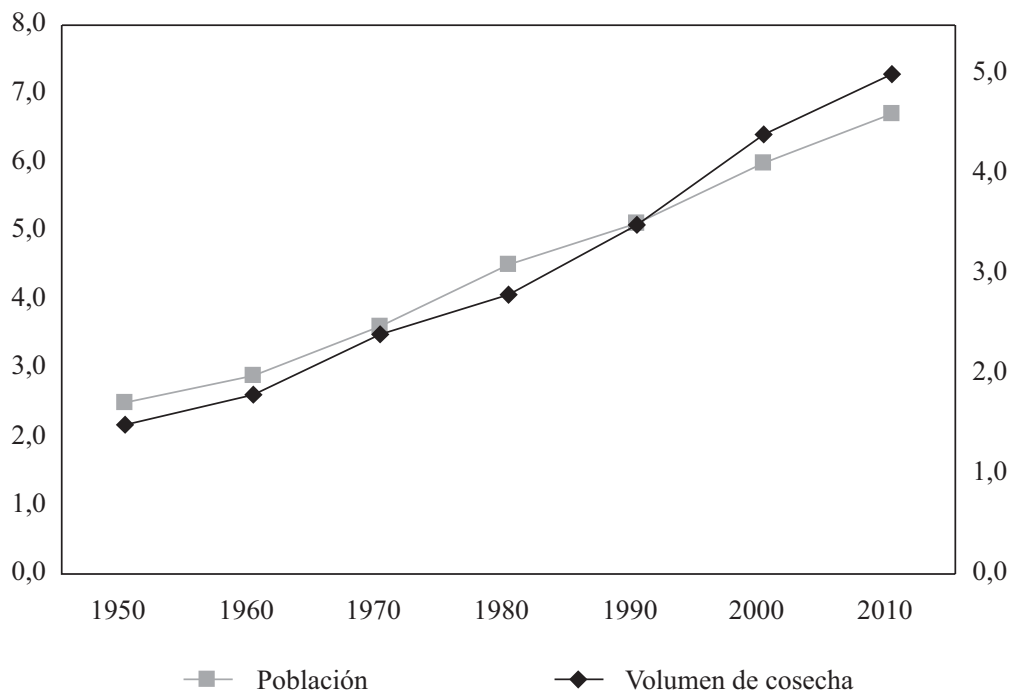

Fuente: FAO, 1991.

${ }^{6}$ Watenberg, Ben J.: Fewer: How the New Demography of Depopulation Will Shape our Future, 2004. 


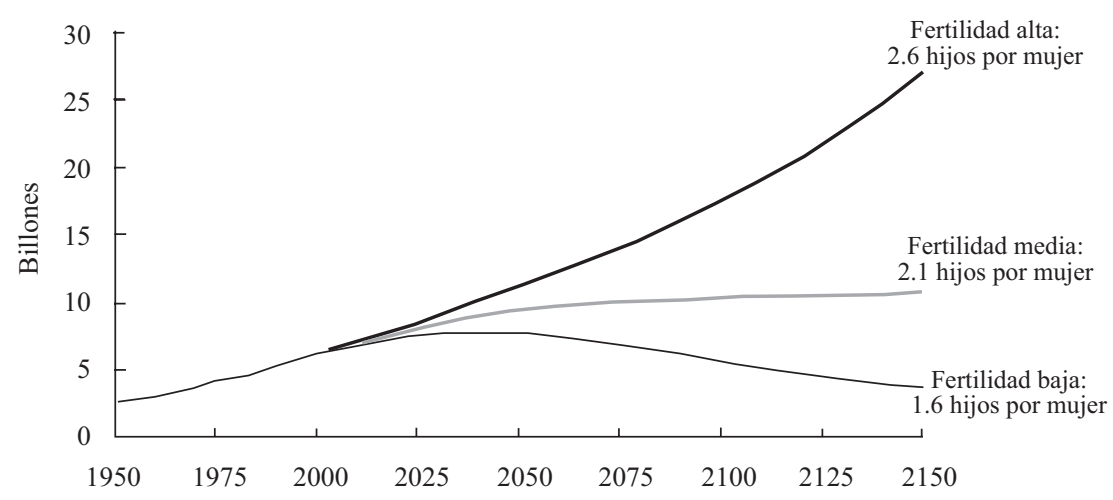

Fuente: Naciones Unidas, 1998.

GRÁFICO No 2.2.3: PROYECCIÓN DE CRECIMIENTO DE LA POBLACIÓN AL 2050

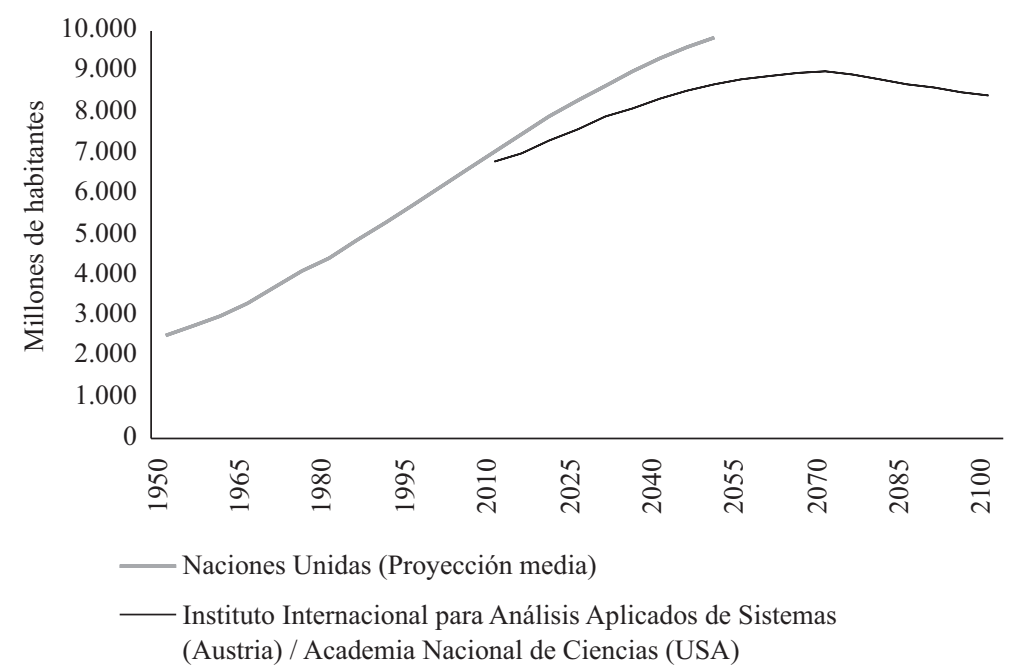

países cuya tasa de fertilidad es inferior a la de reemplazo, de 2,1 hijos por mujer (incluyendo Chile desde el año pasado). De modo que si se mantuviera la correlación de consumo de madera con población y considerando una base actual de 6,2 billones y un equilibrio de 8,5 billones, la demanda por madera crecería como máximo un 37\% respecto de la línea base actual.

Despejada la preocupación del crecimiento demográfico sin límites, un segundo temor podría surgir del hecho que un aumento en el ingreso 
medio de la población expandiera la demanda por mayor consumo per cápi$t a$. Sin embargo, la evidencia empírica muestra que las proyecciones de 1990 no se han cumplido y en la última década, mientras la población y el ingreso medio han aumentado sistemáticamente, la demanda por madera se ha mantenido relativamente estable (véanse Gráficos $N^{\text {os. }} 2.2 .4$ y 2.2.5). De hecho, las últimas proyecciones de FAO indican, por ejemplo, que en 2010 aún no se recuperarán los volúmenes de demanda de madera aserrada de 1990.

¿Qué razones explican lo anterior? La causa principal es el efecto del desarrollo tecnológico, que hoy permite a) reciclar madera no sólo en papeles, sino en diversos tipos de tableros; b) soluciones de ingeniería para productos de madera de igual funcionalidad que utilizan mucha menos fibra por unidad de producto; c) los rendimientos de los aserraderos y otras industrias de madera han aumentado sustancialmente (en el caso chileno, más de un $50 \%$ en la última década), y d) los avances en enchapes, recubrimientos y pinturas permiten generar soluciones a partir de maderas que antes eran consideradas sólo residuos. Entonces, dado que el efecto de la tecnología está más que compensando el crecimiento de la población y del ingreso de ésta, la proyección de aumento de consumo de madera cuando la población mundial llegue a su máximo, deberá ser inferior al 37\% ceteris paribus expresado anteriormente. Un rango máximo de aumento de $20 \%$

GRÁFICO No 2.2.4: PRODUCCIÓN MUNDIAL DE ROLLIZOS INDUSTRIALES

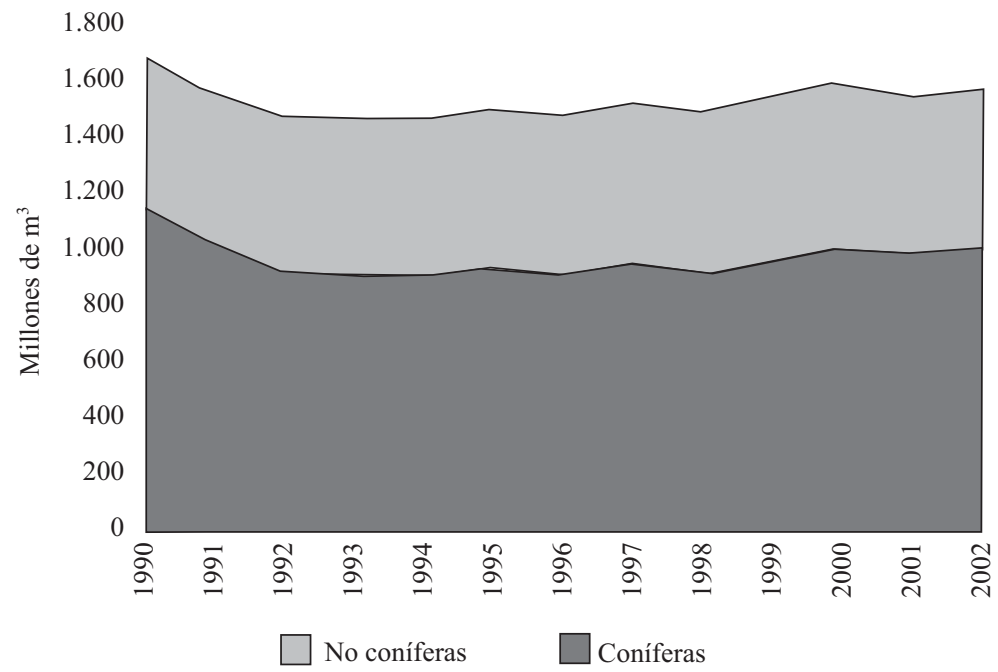

Fuentes: FAO: Faostat, Estadísticas Mundiales, 2003. 


\section{GRÁFICO No 2.2.5: PROYECCIÓN DE CONSUMO GLOBAL DE MADERA ASERRADA}

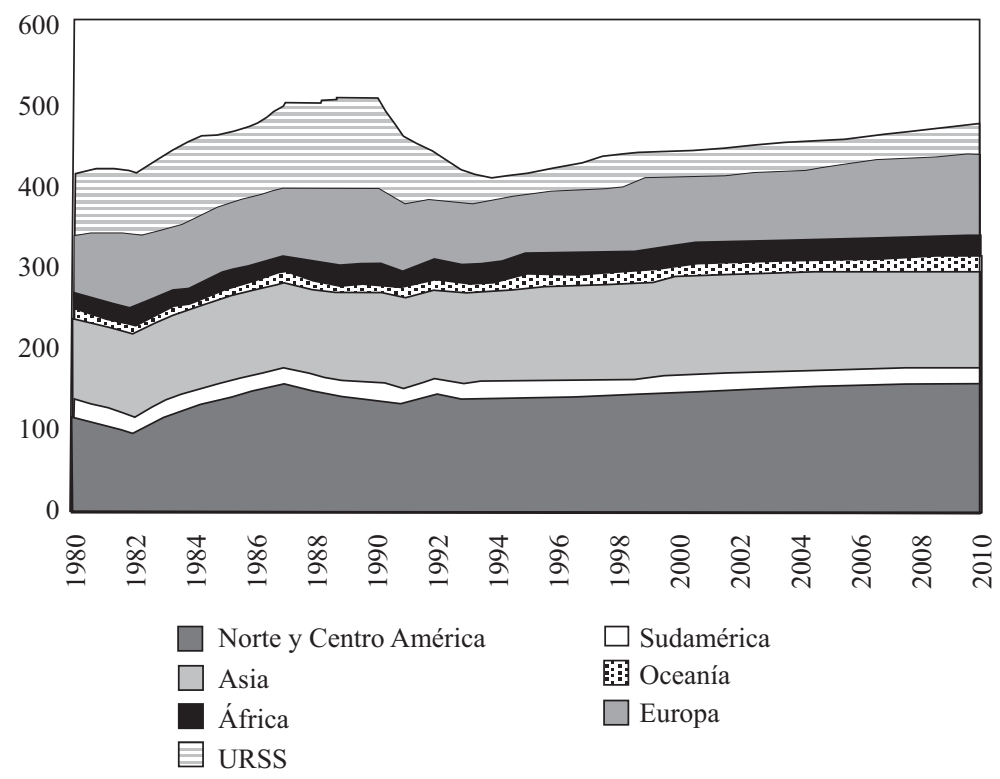

Fuente: FAO.

parece razonable, con lo que la demanda máxima no superaría los 4,2 billones de $\mathrm{m}^{3}$. En el caso que la demanda creciera a la misma tasa que la población (revirtiendo lo sucedido en la última década), esta alcanzaría un límite de 4,8 billones de $\mathrm{m}^{3}$ /año.

\section{Sustentabilidad y eco-eficiencia en la producción de madera}

\subsection{Diversidad y especialización: complementariedad antes que competencia $^{7}$}

Una de las principales discusiones ambientales en las que se ha envuelto a los cultivos forestales, es el tema de la protección de la biodiversidad. Nadie, ni en la comunidad científica o en la sociedad general discute hoy que la biodiversidad es importante y que debe ser conservada. Es

${ }^{7}$ Concepto desarrollado por Wink Sutton en "Plantation Forests Protect our Biodiversity”, mayo 1995. Traducido y publicado en revista CORMA, diciembre 1996. 
fundamental, sin embargo, expresar la razón de su importancia para actuar en consecuencia.

La conservación de la biodiversidad tiene como principal razón permitir que las generaciones futuras no encuentren un mundo con una menor gama de especies que la que tenemos hoy. Pero ¿para qué ha servido la biodiversidad que tenemos hoy? Básicamente, para permitirnos disponer de una amplia gama de opciones para seleccionar especies para nuestra alimentación, para producir energía, construir nuestras viviendas, obtener fibras textiles, o combatir otras especies que son disfuncionales a nuestra supervivencia (enfermedades). Pero de esa gama de opciones, el ser humano utiliza en forma extraordinariamente selectiva las especies más eficientes para un determinado propósito. Por ejemplo, se estima que hay unas 50.000 especies de plantas comestibles en la tierra; pero el grueso de la alimentación proviene sólo de unas pocas especies. Cerca del 70\% de todas las necesidades de alimento son abastecidas por sólo nueve especies de plantas, una de pájaros y tres de animales. Es decir, de la amplia gama que la biodiversidad permite, escogemos las especies más eficientes para determinados propósitos, haciendo un uso especializado. Esta especialización, a su vez, dado que es la más eficiente, es también la que menos recursos naturales utiliza, y por lo tanto la que mejor permite conservar áreas silvestres sin necesidad de intervenirlas con fines productivos.

En la era de la caza y la recolección, se requerían 100 hectáreas de bosque natural para alimentar a una persona durante un año, con alrededor de 200 variedades de comidas. Es fácil imaginar lo que sucedería hoy con el planeta, si se pretendiera alimentar de este modo a más de 6 billones de personas. La cuestión no es por ende, si los cultivos intensivos tienen más impactos sobre el medio ambiente que un manejo mixto: la verdadera cuestión es si el mix de una superficie limitada (y como vemos, en el caso de los bosques es menos del $5 \%$ ), combinada con grandes extensiones conservadas tiene un impacto global mayor sobre los recursos y el medio ambiente, que un escenario en el que todos los recursos son manejados de la misma forma para dicha provisión de bienes y servicios. La naturaleza misma nos da la respuesta: la biodiversidad es especialización en sí misma, donde cada organismo, gen y ecosistema cumple funciones preferentes y otras secundarias. Negarlo es pedir implícitamente que los bosques y las especies se uniformicen.

Así, en definitiva, la especialización de especies de alta productividad ha permitido lograr altas producciones en extensiones relativamente pequeñas de tierra, a través de la agricultura y la ganadería, lo que hace 
posible preservar buena parte del planeta, al producir grandes cantidades de alimentos en forma muy eficiente. De este modo, la especialización de pocas especies permite conservar efectiva y eficientemente la biodiversidad, la misma que retribuye lo anterior con mayor resiliencia al ecosistema global. La aparente paradoja no es tal, y lo que ha sido planteado como una contraposición entre biodiversidad y especialización (crianza o cultivo selectivo, monocultivo) es en realidad un falso dilema.

\subsection{Especialización en los bosques: funciones y usos}

Aun cuando el concepto de sustentabilidad es ampliamente comprendido, su interpretación operacional encuentra más de cien definiciones distintas $^{8}$. A fin de progresar en el desarrollo de recomendaciones de política pública, parece lógico entender la necesidad de conservar los patrimonios ambientales y la base de biodiversidad como condición realista de heredar un patrimonio natural similar al actual a las futuras generaciones. Aplicando lo anterior a los bosques, ello significa generar la capacidad de satisfacer las necesidades de desarrollo de la población, sin disminuir la capacidad multifuncional de dichos bosques.

Las múltiples funciones de los bosques generan distintas fuentes de valor para la sociedad, desde un uso directo y concreto, como es el caso de la madera, hasta la mantención de la resiliencia de ecosistemas complejos, o el valor de existencia, que son funciones indirectas y, en el último caso, intangibles y de no-uso. La Tabla $\mathrm{N}^{\circ} 3.2$ ilustra lo anterior.

Como muestra la Tabla $\mathrm{N}^{\circ}$ 3.2, las múltiples funciones de los bosques generan un amplio rango de demandas sobre ellos (reservorio de biodiversidad; mantención de la productividad económica; respeto a la equidad inter-generacional; respuesta a necesidades sociales y culturales; protección de suelos y los cursos, fuentes y masas de agua; respeto de los valores tradicionales de los pueblos indígenas y de las comunidades rurales; oportunidades de recreación, etc.). Desde una perspectiva de manejo integral de los bosques, las opciones dependen de la diversidad de los mismos: reconocer que todos los bosques son distintos, implica también reconocer que no es esperable que sean igualmente aptos para proveer en la misma forma distintos bienes y servicios, tangibles o intangibles. Todos los bosques pueden proveer madera, pero resulta obvio que las últimas hectáreas de ruil del país deberían ser destinadas a asegurar la preservación de su especie antes que a un uso productivo. Del mismo

\footnotetext{
${ }^{8}$ Pearce, D. W.: “The Economics of Sustainable Development”, 1997.
} 


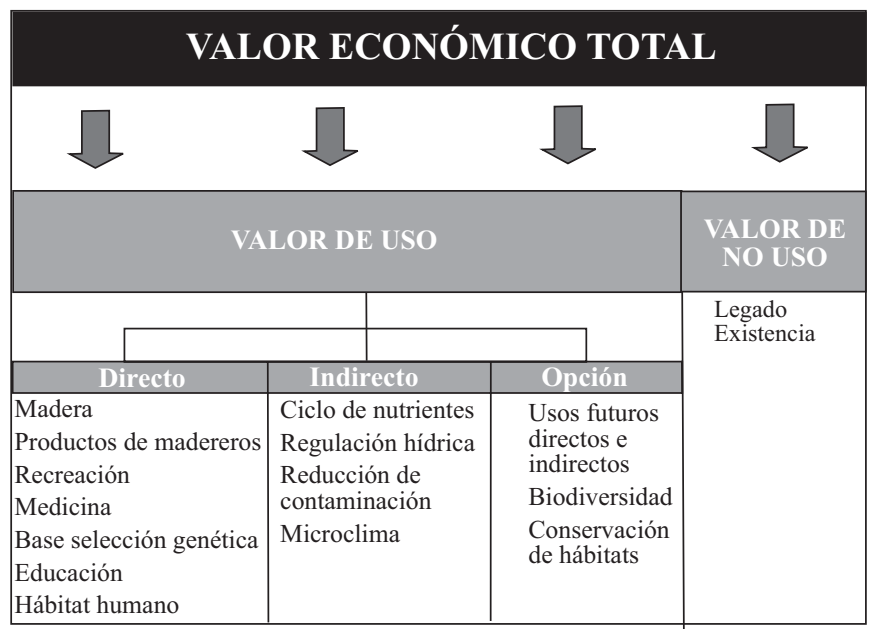

Fuente: Pearce, D. W.: Economic Values of the Natural World, 1993.

modo, cuando la conservación de especies, ecosistemas, suelos, agua y valores culturales se encuentra asegurada, no es razonable esperar que una hectárea adicional de bosque tenga el mismo manejo que cuando son sólo unas pocas las disponibles. Así, en la búsqueda de la eco-eficiencia, se debe asignar el manejo de los bosques según el uso para el que tengan más aptitudes, ya que se logra un mucho mejor desempeño del conjunto, tal como fue demostrado por Vincent y Binkley hace más de una década ${ }^{9}$.

Priorizar usos no significa en ningún caso que otros usos complementarios no sean posibles, y mucho menos que la multifuncionalidad inherente a los bosques desaparezca. De este modo, puede buscarse la sustentabilidad de los bosques tratando que cada uno de ellos provea todos los usos simultáneamente; pero, por lo expuesto más arriba, vemos que esta solución es mucho menos eficiente y requiere la intervención de muchos más bosques que ir aplicando un criterio de especialización. Por ejemplo, los parques nacionales, las reservas forestales y las áreas silvestres protegidas en cada país no son otra cosa que la especialización de bosques en usos de preservación. Se han elegido allí los bosques que tienen mayores "aptitudes” para proveer el servicio “preservación de la biodiversidad, de valores

${ }^{9}$ Vincent, J. y C. Binkley (1993): "Multiple-Use Forestry”, 1993, pp. 370376. 
culturales y del paisaje”, y en la mayoría de ellos no se produce madera, por considerarse que afectarían la forma en como ese uso prioritario es ofrecido. En tal caso, la producción de madera se debe desplazar a otros bosques, y lo lógico es que sean los más aptos para ello, y en lo posible de valor ambiental inferior a aquellos que se destinaron a preservación. Este concepto de tender a especializar la producción de madera, contribuye también a bajar su costo, y con ello la ayuda a competir con otros productos sustitutos de costo ambiental mucho más alto (consumo de energía, contaminación productiva, uso de recursos no renovables), mejorando entonces de forma sustantiva la sustentabilidad global.

La sustentabilidad de los bosques, entonces, podrá alcanzarse a través de un manejo "equilibrado" en sus usos, pero también y cada vez más por medio de combinaciones de bosques que en su conjunto atienden los múltiples usos, pero que individualmente prioricen su uso a aquel para el que sean más aptos. De este modo, una cierta área tendrá bosques que principalmente protegerán sus sectores con pendientes, suelos frágiles y cursos de agua; pero donde también se conservará biodiversidad, se podrán obtener subproductos, y eventualmente producirán madera, si las técnicas silvícolas permiten hacerlo sin desvirtuar su objetivo prioritario. Asimismo habrá sectores, probablemente los más antiguos y biológicamente ricos, o que contengan paisajes únicos, etc., que se destinarán principalmente a preservar la biodiversidad y el paisaje (pero también protegerán los suelos y las aguas, etc.). Del mismo modo, habrá sectores prioritariamente dedicados a producir madera, aunque también protegerán los suelos y producirán oxígeno, entre otras funciones secundarias. En el caso de los bosques de producción, lo esencial es no perder la capacidad y el potencial del suelo para atender otros usos que en el futuro puedan priorizarse, dentro de la multifuncionalidad de los bosques.

En un contexto como el anterior, las plantaciones forestales de alta productividad no son sino un caso específico de priorización de usos, pues se establecen fundamentalmente (aunque no exclusivamente) para producir madera. Pero también, aunque no es su uso prioritario, producen importantes bienes y servicios ambientales, como se verá más adelante.

\subsection{Sustentabilidad: distintos ámbitos, distintas soluciones}

El manejo forestal de los bosques en el mundo puede verse como un continuo de distintas intensidades de manejo, desde bosques virtualmente 
intactos hasta cultivos altamente intensivos. Entre las distintas opciones, se aprecian en la actualidad dos tendencias principales, que pretenden acercarnos a un manejo forestal sustentable (MFS), pero que curiosamente son en apariencia opuestas. Una promueve un manejo menos intensivo, en la línea de la corriente que se ha llamado new forestry, y otra hacia un manejo altamente intensivo en la producción de madera, cuyo ejemplo extremo es el cultivo intensivo de plantaciones forestales (tree farming)

Señalamos que las tendencias referidas son "en apariencia” opuestas, pues, observando en mayor detalle, se aprecia que sus diferencias provienen del nivel espacial al que se pretende aplicar el concepto de sustentabilidad. En el primer caso, se trata de aplicar el concepto a un nivel "micro", tratando de que cada bosque satisfaga todos o una gran parte de los objetivos que pueden establecerse, apuntando a que el manejo forestal imite a la naturaleza (situación muy propia de Europa continental, donde gran parte de los bosques naturales desaparecieron en el curso histórico).

En el segundo caso, se considera una definición implícita o explícita de áreas más amplias (una cuenca, una región, incluso un país), a las que se aplica el concepto de sustentabilidad de modo que se cumplan todos los objetivos a nivel del área total, pero que distintos bosques se especialicen en el objetivo (o grupo de ellos) en el que presentan mayores ventajas naturales, ambientales y socioeconómicas.

A través de un trabajo conjunto, WWF y World Bank desarrollaron el ambicioso proyecto en el marco de su Alianza Forestal (véase Recuadro 3.1). Una de las principales conclusiones de la Fase I del trabajo indica que "El análisis sugiere que una tendencia hacia la intensificación del manejo forestal podría tener un significativo impacto en el abastecimiento mundial futuro de la madera para uso industrial (IWR) [...] IWR podría ser producida a partir de aproximadamente $20 \%$ del área forestal actual ${ }^{\prime 10}$. El 20\% a que se refiere el párrafo indicado, estaría compuesto por un $17 \%$ de bosques nativos secundarios intensivamente manejados, que producirían un $45 \%$ del abastecimiento mundial; un $3 \%$ de plantaciones forestales productivas, que producirían otro $45 \%$ del volumen, mientras el resto ( $10 \%$ del volumen) se obtendría a partir de manejo múltiple del resto del área boscosa, que ascendería al $80 \%$ de la superficie, y estaría bajo distintas categorías de conservación (desde absoluta preservación hasta manejo comunitario multi-objetivo).

\footnotetext{
${ }^{10}$ Spears, John: “Global Vision Research Project”, 2000.
} 


\section{RECUADRO 3.1}

PRoyecto de InVESTIGACiÓN DE Visión GLOBAL

RESUMEN DE LAS PRINCIPALES CONCLUSIONES DE LA FASE 1, Y SUS

IMPLICANCIAS PARA POSTERIORES INVESTIGACIONES / DOCUMENTO

INFORMATIVO PARA EL ENCUENTRO DEL COMITÉ DE GESTIÓN DE PROYECTOS

\section{A) Resumen}

En junio de 1999, la alianza Banco Mundial / WWF se reunió con el Consejo de Relaciones Exteriores y un grupo de investigadores en conservación y políticas, para el inicio de un Proyecto de Investigación de Visión Global acerca de las perspectivas de largo plazo de los bosques del mundo. En la reunión se discutió la hipótesis de que una tendencia global en curso hacia la intensificación de la silvicultura y la productividad agrícola podría previsiblemente en el futuro, contribuir a revertir la deforestación. Se acordó que la Fase 1 generaría siete documentos de discusión por parte de experimentados analistas, para explorar los potenciales impactos sociales, ambientales y económicos de esta tendencia, tanto positivos como negativos. El presente documento, resume algunos de los temas claves y aspectos que emergen de esta primera fase y sus posibles implicancias para posteriores investigaciones. Fue preparado para su consideración por un Comité de Gestión de Proyectos en una reunión efectuada en Washington D.C. el 20 y 21 de enero del 2000.

(ii) Los análisis sugieren que una tendencia a la intensificación de la silvicultura podría tener un impacto significativo en el abastecimiento global futuro de rollizos industriales de madera. Plausiblemente podría conducir a un escenario tal que en el año 2050 la demanda global por rollizo industrial podría abastecerse a partir del $20 \%$ de la superficie actual de bosque.

(iii) Desde la perspectiva tanto social como de conservación, esto podría tener implicancias positivas, ya que, en la medida que las actuales amenazas a los bosques puedan ser contenidas, haría posible manejar el 80 por ciento de los bosques mundiales para el beneficio de las comunidades locales, la preservación de su medio ambiente local y global, y otros beneficios. Estos incluyen la preservación de la biodiversidad, protección del recurso agua, potencial de captura de carbono, así como oportunidades recreacionales.

(iv) Una de las principales amenazas a los bosques tropicales es la usurpación del suelo para fines agrícolas. Análisis preliminares sugieren que el continuo aumento en la productividad agrícola reducirá en el largo plazo la superficie global de tierra cultivable. Considerándolo junto a otros factores como el potencial de similares aumentos en la productividad forestal y en la eficiencia en el uso de la madera, así como el incremento de los ingresos per cápita y la urbanización, se vislumbran verdaderas posibilidades de que la deforestación pueda revertirse, 
los bosques recuperarse y, para el año 2050, tener un aumento neto en la superficie global de bosques.

(v) A pesar de estos mensajes positivos, el hecho es que hoy en día los bosques enfrentan serias amenazas en diversos ámbitos y están decayendo tanto en superficie como en calidad. Las principales deficiencias se identifican en las estrategias prevalecientes de conservación y desarrollo particularmente para Áreas Protegidas. Las implicancias negativas de las tendencias de intensificación hacia el bienestar de las comunidades indígenas, son un tema de especial preocupación. Las actuales políticas de áreas preservadas no cuentan con el apoyo adecuado, tanto en recursos que aseguren su gestión efectiva, como por políticas gubernamentales necesarias para controlar la tala ilegal y otras grandes amenazas a las Áreas Protegidas. Muchas de las ya designadas Áreas de Protección se han convertido en "parques de papel”. Las actuales prácticas para el comercio de rollizos se encuentran, en muchas situaciones, causando daño ecológico, no siendo sostenibles y causando importantes perjuicios a las comunidades indígenas que dependen del bosque para subsistir. ¿Ayudará el aumento de la concentración de silvicultura intensiva a resolver estos temas, o simplemente los empeorará?

\section{B) Anexo 3 del documento:}

POSIBLE SITUACIÓN GLOBAL DE LOS BOSQUES EN EL AÑO 2050

Área global aproximada de bosques 3,0 billones de ha.

Oferta y demanda global de IRW, 3,0 billones de $\mathrm{m}^{3}$

(Este modelo simplificado excluye suministro de IRW proveniente de recursos no forestales que pudieran ser significativos).

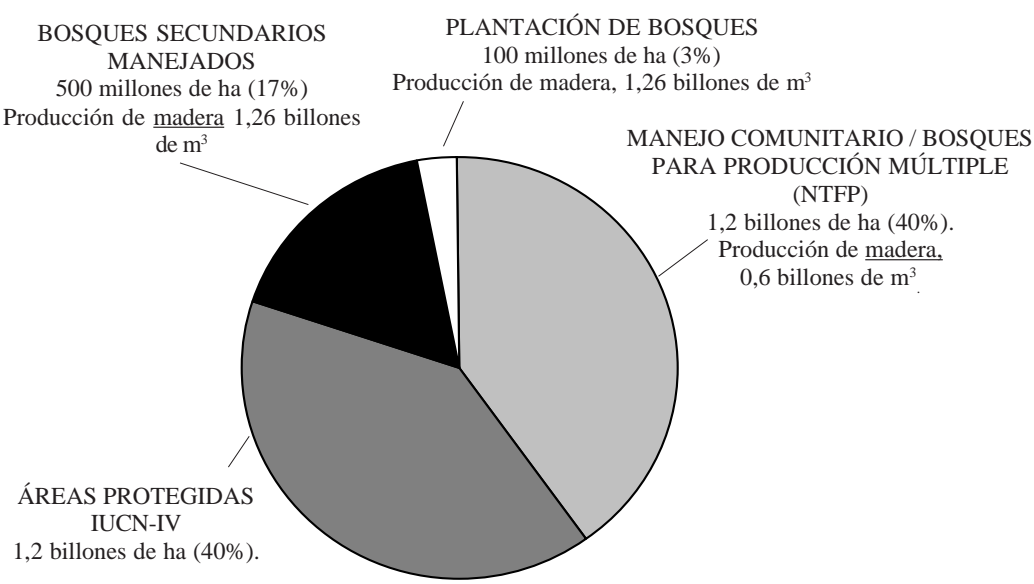

Fuente: Spears, J.: “Global Vision Research Project”, 2000; WWF, Banco Mundial. 
El anterior trabajo permite comprender exhaustivamente la forma en que una tendencia a la intensificación del manejo no sólo puede ser compatible con la sustentabilidad del recurso forestal mundial, sino que además la plantea en una óptica realista respecto a las tendencias mundiales de uso del suelo, al liberar de presiones productivas a un $80 \%$ de los bosques naturales del mundo, en virtud de concentrar la producción de madera en superficies relativamente pequeñas y de alta productividad. El aporte de la superficie de plantaciones resulta clave en este equilibrio, ya que permitiría generar el 45\% del volumen con sólo un 3\% de la superficie total.

Resulta común la crítica de quienes abogan por el concepto de "sustentabilidad micro” hacia las plantaciones, calificándolas como no sustentables, por su simplicidad funcional y su relativamente escasa biodiversidad. Resulta obvio que desde una perspectiva más amplia y en el contexto de "sustentabilidad macro", las plantaciones se revelan como un aporte fundamental para conservar vastas superficies de bosques naturales, con características de biodiversidad y paisaje mucho más valiosas que lo que podría lograrse en las plantaciones mismas al aplicarles restricciones tipo new forestry. Con esto último, se desnaturaliza su gran aporte a la sustentabilidad macro, que es precisamente su habilidad de producir grandes volúmenes de madera en pequeñas superficies. El concepto de "sustentabilidad macro" permite lograr un resultado balanceado y eco-eficiente, combinando en áreas agregadas diversos tipos de bosques dedicados a los usos prioritarios para los que tengan más aptitudes, tal como se discutió más arriba.

Por otra parte, la "sustentabilidad micro", que apunta al manejo múltiple de cada bosque, aunque aparentemente trata de resolver el problema global a través de la suma de las partes, con la idea subyacente de que "si cada parte es sostenible, su suma deberá serlo”, en la práctica limita la posibilidad de obtener alta eficiencia productiva en pequeñas superficies. Con ello, para lograr los balances de madera requeridos se necesitaría una o combinaciones de las siguientes acciones: a) intervenir una superficie mucho mayor de bosques naturales (reduciendo el área que debiera tener una opción de uso menos extractiva por consideraciones de fragilidad, unicidad o rareza); b) reducir el consumo de madera per cápita, y/o c) reducir la población mundial.

Ninguna de las opciones anteriores parece compatible con criterios de conservación y realismo práctico: intervenir grandes superficies de bosques naturales presentará grandes obstáculos de costos (se considera que hoy un 40\% de la superficie global de bosques no están disponibles para la producción maderera, por falta de accesos, altos costos de extracción, indefiniciones legales y otras restricciones), a la vez que enfrentará una enorme 
resistencia de segmentos del mundo ambientalista y de la opinión pública. Aun cuando fuera posible superar esos obstáculos, sería difícil imaginar que tuviera efectos beneficiosos desde el punto de vista de la conservación de la biodiversidad.

Baste imaginar que, para suministrar 4,2 billones de $\mathrm{m}^{3}$ al año, se requeriría intervenir (bajo el concepto de corta sostenida en bosques naturales, tipo new forestry), 3 billones de hectáreas de bosques (más de tres cuartas partes de los bosques del mundo). A lo anterior hay que agregar que, al ser la producción con el modelo tipo new forestry sustancialmente más cara, lo que generaría fuertes incentivos hacia la sustitución de la madera por otros materiales, con consecuencias ambientales muy negativas, tal como se estableció en la sección 2.

En lo que respecta a moderar el consumo de madera per cápita, ya existe una tendencia, tal como se analizó previamente, pero también se demostró que su reemplazo no es física ni ambientalmente viable o recomendable. En cuanto a la población mundial, si bien se extinguieron los fundamentos para el temor a una explosión demográfica incontrolada, no parece realista que el mundo pueda volver a tener 3 billones de habitantes o menos en el futuro previsible (como se requeriría en algunos escenarios de "sostenibilidad micro” aplicada a escala global), de no mediar un cataclismo planetario de enormes proporciones.

Todo lo anterior apunta en el sentido de que la vía más razonable para apoyar la sustentabilidad planetaria de los bosques es lograr generar las producciones necesarias en las mínimas superficies, dejando la vasta mayoría para producir preferentemente bienes y servicios socio-ambientales. La lógica de la existencia de las plantaciones forestales, como se ha visto, está inserta en ese equilibrio global, que envuelve también los recursos forestales y de biodiversidad que se conservan en virtud de la existencia de éstas. Por lo tanto, como discutiremos a continuación, los análisis de las plantaciones deben efectuarse necesariamente en este ámbito amplio y comprehensivo.

\section{Sustentabilidad de plantaciones forestales}

\section{1. Ámbito para evaluar la sustentabilidad. Externalidades positivas}

A partir de lo anteriormente analizado, se concluye que gran parte de la discusión que se sostiene acerca de la sustentabilidad de las plantaciones forestales tiene su origen en análisis reduccionistas. La mayoría de ellos se focalizan en las plantaciones mismas, como si éstas debieran ser autosu- 
ficientes en materia ambiental, y sin considerar que son un elemento de un todo más amplio, complementándose con otros (concepto de sustentabilidad "macro", véase sección 3). Se critica en muchos casos su escasa biodiversidad o su monótono paisaje, en circunstancias que su existencia permite la conservación de superficies de bosques naturales con rica biodiversidad y valiosos paisajes, en una proporción entre diez y veinte veces mayor por cada hectárea de plantaciones (analizar las plantaciones en esta óptica, sería lo mismo que esperar que un miembro u órgano del cuerpo humano desempeñara las funciones del cuerpo completo). No es función esencial de las plantaciones algo que está fuera de su objetivo prioritario que es el de producir madera. Así como no se pide a una fábrica que tenga la estética de una iglesia gótica, ni a un cultivo de trigo o lechugas que se constituya en hábitat de todo tipo de fauna, los cultivos forestales prioritariamente productivos hacen su mayor contribución a la sustentabilidad siendo eficientes en su propósito prioritario. De este modo, y adecuadamente combinadas con bosques que tengan funciones prioritarias de conservación, se permite alcanzar la sustentabilidad en forma eco-eficiente. Las plantaciones forestales son, entonces, no un sustituto, sino un complemento de los bosques naturales; particularmente en aquellas funciones para las cuales estos últimos tienen ventajas.

Sin embargo, a nuestro juicio sí existen requisitos que las plantaciones forestales deben satisfacer para cumplir su rol complementario en la sustentabilidad global. En primer lugar, deben conservar, a lo menos, el potencial productivo del suelo que ocupan y, en lo posible, mejorarlo (cosa que sucede en la mayoría de los casos, bajo adecuadas condiciones de silvicultura y cosecha). En segundo lugar, deben efectivamente complementar los roles de las otras categorías de bosques, respetando su existencia en las proporciones que corresponda ${ }^{11}$.

Asimismo, independientemente de que las plantaciones forestales deben ser evaluadas dentro del contexto de los otros bosques y en relación a las necesidades humanas por madera, generan en sí mismas importantes beneficios ambientales y sociales complementarios (externalidades).

a) Captura de carbono: las plantaciones, por su rápido crecimiento, presentan altas tasas de captura de carbono, transformándose en sumideros netos. Dado que ellas se cosechan antes que el bosque entre en equilibrio de captura y emisión, y que una parte importante de su volumen va a pro-

${ }^{11}$ La discusión acerca de cuánto conservar y preservar excede los propósitos de este documento. Para estos efectos, aceptemos que las proporciones son definidas por la sociedad. Una referencia puede encontrarse en Cerda, Aldo: "Sector Forestal: Una Propuesta de regulación sustentable para el Bosque Nativo”, (2004). 
ductos de larga duración, contribuyen en forma más efectiva que bosques de lento crecimiento a mitigar el efecto invernadero.

b) Recuperación de suelos: las especies utilizadas para cultivos forestales son, en muchos casos, suficientemente rústicas y vigorosas como para colonizar suelos degradados por la agricultura o ganadería, sectores arenosos o con diversos grados de pérdida de material orgánico, iniciando un proceso sistemático de recuperación del suelo (lo que constituye en muchos casos un pre-requisito de su viabilidad económica).

c) Regulación hidrológica: la cobertura boscosa de plantaciones cumple la función de regulación de aguas, tal como lo haría cualquier bosque. Las forestaciones que se han establecido a orillas de fuentes, cursos o masas de agua han contribuido decisivamente a evitar sedimentaciones, mejorar la calidad de las aguas y regular caudales.

d) Control de la erosión: las plantaciones forestales, como todo bosque, protegen los suelos contra la erosión. Pese a que algunos sostienen que las hierbas y pastos bajos también lo hacen, las masas radiculares de los bosques son más efectivas para mantener la estructura del suelo. Asimismo, las copas de los árboles de rápido crecimiento presentan mayor aptitud para amortiguar la fuerza de las precipitaciones-lluvia respecto a otras coberturas. Un elemento adicional de las plantaciones en este caso proviene de su capacidad de ser establecidas donde no hay bosque, particularmente en suelos donde ya hay procesos avanzados de erosión.

e) Mejoramiento del paisaje: la mayor parte de las plantaciones en el mundo se han establecido en terrenos erosionados o abandonados por la agricultura, por lo que ellas realizan un aporte positivo al paisaje, particularmente en sectores previamente desprovistos de otras formas de vegetación.

f) Contribución a la vida silvestre: sin pretender competir con las aptitudes de los bosques naturales para ello, las plantaciones forestales constituyen un hábitat alternativo para muchas especies de aves, insectos, reptiles y mamíferos, siendo un uso del suelo definitivamente superior en este aspecto que el agrícola, el ganadero y, por supuesto, el urbano (razonamiento similar al del punto anterior). Resulta poco equitativo que se compare siempre a las plantaciones con los bosques naturales en esta materia, y no con la mayoría de los otros usos del suelo, respecto a los cuales son definitivamente superiores.

g) Reducción de la migración campo-ciudad: en muchos casos se ha criticado a las plantaciones forestales por desplazar pequeños campesinos a la urbe. En general, el proceso de migración de campesinos a los centros urbanos es inherente al proceso de desarrollo y tecnificación del agro, y este fenómeno ocurre existan o no plantaciones forestales. Desde el punto de vista ambiental, esto no es necesariamente negativo, ya que los 
campesinos en condición de pobreza, en muchos casos cultivan la tierra en forma no sustentable, tendiendo a su degradación y erosión. Pero, por otra parte, el desarrollo de plantaciones forestales genera la aparición o incrementa el valor de la industria forestal local, fortaleciendo los villorrios y las urbes de menor tamaño. Esta actividad económica local reduce el flujo de campesinos a las grandes urbes aquejadas por graves problemas ambientales de congestión y contaminación, así como por problemas sociales de marginalidad, evitando así que estos problemas se incrementen.

\subsection{Respuestas a inquietudes básicas respecto del futuro de las plantaciones}

Quienes ven con escepticismo el fenómeno del desarrollo de las plantaciones, plantean diversas preocupaciones sobre la evolución futura de éstas y sus posibles impactos. En esta sección discutiremos algunas de ellas.

a) “La intensidad del manejo de las plantaciones terminará por agotar la tierra y su cultivo no podrá sostenerse por un número indefinido de rotaciones"

No existe evidencia científica que indique que con una silvicultura apropiada las plantaciones forestales no puedan sostener su producción indefinidamente, tal como ha sucedido con la agricultura y fruticultura bien realizadas $^{12}$. Más bien, las nuevas tecnologías han ido incrementando cada vez más los rendimientos, rotación tras rotación. La agricultura se practica en la Tierra hace más de diez mil años, y si bien hay episodios de serias consecuencias negativas debido a prácticas no sustentables, también hay notables ejemplos de zonas que continúan produciendo con mayores rendimientos que antes, después de muchos siglos de cultivo. El avance del conocimiento y la tecnología permiten hoy un mayor control de las variables asociadas a los cultivos, haciendo posible prever y compensar los posibles efectos ambientales negativos. En el extremo, la tecnología está en condiciones de sostener agricultura con nutrición artificial, utilizando el suelo sólo como un sustrato de establecimiento, y en ocasiones, incluso sin él (como es el caso de la agricultura hidropónica).

Las plantaciones forestales someten al suelo a menos exigencias de demanda de nutrientes que los cultivos agrícolas (por ejemplo, el pino radia-

${ }^{12}$ FAO: “Towards Sustainable Forest Management”, p. 22; FAO: "Bibliografía Anotada sobre los efectos ambientales, sociales y económicos de los Eucaliptos” (Compilación de trabajos para el período 1985-1994 y para el período 1995-1999). 
ta consume una cantidad equivalente de nutrientes en una rotación a lo que un cultivo de trigo requiere en un año ${ }^{13}$ ). Si se tiene cuidado de agregar a los suelos los elementos, particularmente minerales, cuya presencia se debilite de una rotación a otra, y se efectúan prácticas de cosecha de bajo impacto en los suelos, protegiéndolos de la erosión, es posible sostener el cultivo forestal indefinidamente.

b) "Las plantaciones extenderán sus superficies indefinidamente, reemplazando bosques nativos y ecosistemas naturales”

Hemos demostrado en el punto 2.2 que la proyección de crecimiento de la población del planeta es limitada y que también lo es la proyección de demanda por madera. Es esta última la variable que determina el crecimiento de la superficie de plantaciones, por lo que su proyección también está limitada. En el Cuadro $N^{\circ}$ 4.2.b mostraremos el requerimiento de superficie de plantaciones para abastecer distintas proyecciones de consumo.

CUADRO N 4.2.B: ABASTECIMIENTO DE DEMANDA MÁXIMA DE MADERA, AL ALCANZAR POBLACIÓN MÁXIMA DE 8,5 BILLONES

\begin{tabular}{|c|c|c|c|c|c|}
\hline & $\begin{array}{l}\text { Demanda } \\
\text { máxima, } \\
\text { bm³/año }\end{array}$ & $\begin{array}{c}\text { Producción } \\
\text { otros bosques } \\
\text { bm³ªño }\end{array}$ & \begin{tabular}{l}
\multicolumn{1}{c}{ Saldo a } \\
producir por \\
plantaciones \\
bm³/año $^{3}$
\end{tabular} & $\begin{array}{c}\text { Superficie de } \\
\text { plantaciones (3) } \\
\text { MMHas }\end{array}$ & $\begin{array}{c}\text { \% sobre } \\
\text { el total } \\
\text { de bosques }\end{array}$ \\
\hline $\begin{array}{l}\text { Proyección propia } \\
\text { escenario bajo (1) }\end{array}$ & 4,2 & 2,0 & 2,2 & 110 & $2,9 \%$ \\
\hline $\begin{array}{l}\text { Proyección propia } \\
\text { escenario alto (1) }\end{array}$ & 4,8 & 2,0 & 2,8 & 140 & $3,7 \%$ \\
\hline $\begin{array}{l}\text { Proyección Sedjo et al. } \\
\text { escenario bajo (2) }\end{array}$ & 5,3 & 2,0 & 3,3 & 162 & $4,3 \%$ \\
\hline $\begin{array}{l}\text { Proyección Sedjo et al. } \\
\text { escenario alto (2) }\end{array}$ & 6,1 & 2,0 & 4,1 & 205 & $5,4 \%$ \\
\hline
\end{tabular}

(1) Proyección propia: El escenario “Bajo” considera que la demanda crecerá menos que la población. Ésta se incrementará de 6,2 a 8,5 billones (37\%); mientras la demanda por madera considera un aumento de $20 \%$ sobre la base de 3,5 billones $\mathrm{m}^{3} / \mathrm{año}$. El escenario “Alto” considera que la demanda crecerá al mismo ritmo que la población, es decir, 37\% sobre 3,5 billones $\mathrm{m}^{3}$.

(2) Proyección Sohngen, Mendelsohn y Sedjo, 1999: crecimiento de la demanda de 50 a 75\% (proyecciones "Baja” y “Alta” respectivamente), aplicadas sobre una base de 3,5 billones de $\mathrm{m}^{3}$ /año de consumo.

(3) Productividad: considera una productividad promedio de $20 \mathrm{~m}^{3} / \mathrm{ha}$-año.

${ }^{13}$ Forestal Millalemu - Universidad del Bío Bío, 1989. 
Tal como se desprende del Cuadro $N^{\circ}$ 4.2.b, la superficie máxima de plantaciones forestales podría alcanzar a algo más de 200 millones de ha, suponiendo que la demanda se incremente un $75 \%$ antes de entrar en régimen. Hay varias razones para pensar que ésta es una cota superior: se calculó con la proyección más alta de demanda, que significaría que ésta crecería a una tasa prácticamente el doble del incremento esperado para la población hasta el 2050 y se estimó un rendimiento medio de las plantaciones de rápido crecimiento de $20 \mathrm{~m}^{3} /$ ha-año, situación que la tecnología puede incrementar sustancialmente, requiriendo menor superficie.

Queda claro que no existe fundamento para pensar que la superficie de plantaciones crecerá indefinidamente. Tampoco puede pensarse que una superficie del orden del 5\% puede ser una amenaza para el 95\% restante: no hay posibilidad alguna que represente un peligro de sustituir globalmente los bosques naturales.

De todos modos y pese a su escasa superficie a escala global, si las plantaciones se establecen en altas concentraciones, podrían afectar ecosistemas locales valiosos, lo que se puede evitar tomando precauciones de conservación para esos casos (pero estas precauciones básicas no pueden conducir a generalizaciones que minen su necesario desarrollo).

c) “Las prácticas de viverización, mejoramiento genético y cultivo de las plantaciones podría generar alguna enfermedad que atacara letalmente a los bosques nativos"

El temor a posibles pestes generadas que afecten sin control a los bosques nativos parece corresponder a un evento extremadamente improbable: en diez milenios de agricultura monocultural nunca se ha reportado una situación de este tipo que revista gravedad. Del mismo modo, entre las causales significativas de pérdida de bosques en el mundo, no se ha registrado nunca algo similar (en particular, desde el desarrollo de las plantaciones en Nueva Zelandia y Chile, no se ha observado ninguna situación de este tipo).

Una mutación de algún tipo de hongo o insecto podría causar una plaga seria para los bosques, pero dicha mutación puede producirse tanto en los bosques nativos como en las plantaciones, y no hay razón para pensar que pueda originarse en las plantaciones. De hecho, las especies utilizadas en las plantaciones industriales son nativas en otros lugares del planeta. A veces se menciona el caso del Phitoptora ramorum, especie de hongo que ha producido serios estragos en diversas especies del noroeste 
de Estados Unidos, popularmente conocido como “sudden oak death”, infectando los viveros y luego los ejemplares adultos; pero hasta donde se ha investigado, su origen está vinculado a especies ornamentales de jardín (rododendros) y no tiene relación alguna con plantaciones industriales.

d) "Habría que "mejorar" (sic) la sustentabilidad de plantaciones con una mayor biodiversidad (cultivo menos intensivo, intercalación de especies nativas, etc.)”

Llevando el argumento en contrario al extremo: si una sola hectárea del planeta pudiera producir toda la madera y el alimento del mundo, dejando todo el resto de la inmensidad virgen, conservada y en equilibrio, pero al “costo” de que esta hectárea fuera totalmente artificial y exigiera gran esfuerzo para mantenerla, ¿no valdría la pena?

Si insistimos en modificar esta hectárea ultraproductiva, el costo de oportunidad de la misma sería volcar enormes demandas productivas sobre el resto y amenazar su conservación. ¿Por qué hacerlo? No vemos lógica en ello. Esto es un claro ejemplo (extremo por cierto) del equilibrio entre cultivos y áreas silvestres. La mejor forma de proteger estas últimas es que los cultivos sean cada vez más productivos y utilicen menos tierra para lograr lo mismo. Y de hecho, pese al incremento de la población, eso es lo que ha ido sucediendo.

\subsection{Buenas prácticas para el establecimiento y manejo de plantaciones}

Hemos planteado que las plantaciones forestales son una solución para el equilibrio entre producción y conservación en el planeta. Sin embargo, como en cualquier cultivo, las prácticas para su desarrollo pueden ser adecuadas o inadecuadas. Muchas de las críticas que se hacen a las plantaciones se refieren en realidad a prácticas de su cultivo que pueden ser mejoradas, o a situaciones inherentes a cualquier cambio de uso del suelo.

a) Erosión en los suelos: este aspecto es inherente a las malas prácticas de cosecha, que pueden darse tanto en especies nativas, como en agricultura y plantaciones. Hoy existe tecnología que permite efectuar las faenas de cosecha con bajo impacto para el suelo. Si se toman las debidas precauciones, utilizando las técnicas adecuadas para las condiciones de pendiente, pluviometría y fragilidad del suelo, además de una pronta reforestación, este aspecto se evita o minimiza. 
b) Sustitución de bosques de alto valor y fragmentación de ecosistemas: si bien hemos visto que el gran aporte de las plantaciones es liberar de presión productiva a la vasta mayoría de la superficie de bosques nativos, es posible que en lugares de alta concentración de plantaciones existan ecosistemas de alto valor que, en caso de no tomar las debidas precauciones, puedan ser reemplazados por éstas. Nuevamente, este no es un problema inherente a las plantaciones: los ecosistemas ambientalmente valiosos pueden ser reemplazados también por usos agrícolas, ganaderos, industriales o urbanos.

De modo que, con una adecuada identificación de las áreas valiosas y una política explícita de conservación de éstas, el riesgo disminuye o se controla totalmente. En cuanto a la fragmentación de ecosistemas valiosos, esto también puede precaverse por la vía de planes de conectividad y corredores de biodiversidad, los que deben incluirse en los planes de manejo y/o en los programas de mejoramiento continuo impulsados por la certificación de manejo forestal sustentable ${ }^{14}$.

c) Impactos sobre comunidades indígenas: la discusión sobre propiedad de territorios ancestrales es un tema político y no silvicultural o biológico, y en ningún caso es algo inherente a las plantaciones. En tierras supuestamente indígenas no sólo hay plantaciones, sino bosques naturales, superficies ganaderas y agrícolas, ciudades, industrias y caminos. En el caso de Chile, las plantaciones forestales están en su vasta mayoría establecidas en terrenos de propiedad privada, por lo que en el caso de reclamaciones se trata de disputas legales y en ningún caso tienen que ver con el uso específico del suelo en plantaciones. Por otra parte, los sistemas de certificación establecen condiciones de buena relación de los establecimientos de plantaciones con comunidades indígenas y vecindad en general.

d) Cambios en el régimen hidrológico: el establecimiento de plantaciones tiene efectos en el régimen hidrológico. En muchos casos, se utilizan plantaciones para reforestar cuencas previamente deforestadas, con objeto de mejorar la regulación de la cuenca. En otros casos, en áreas previamente deforestadas, se nota un mayor consumo de agua por parte de las plantaciones que se establecen. En general, las plantaciones de alto rendimiento se establecen en zonas de alta pluviometría, por lo que su consumo de agua en general no afecta negativamente el balance global, y normalmente no es muy distinto al de las masas boscosas naturales propias del lugar, que

${ }^{14}$ FSC (www.fsc.org), PEFC (www.pefcorg.); Certfor (www.certfor.org) entre otros. 
precisamente crecen en esas zonas por requerir también alto consumo de agua. Sin embargo, en ocasiones pueden producir externalidades negativas a sectores agrícolas aledaños, al disminuir sus disponibilidades de aguas subterráneas. Por ello, se recomienda el monitoreo de este tipo de efectos en el caso de establecimiento de altas concentraciones de plantaciones, aspecto que se incluye en los requerimientos de los principales sistemas de certificación. Dicho monitoreo permite tomar medidas para mitigar los efectos y/o compensar las eventuales externalidades negativas para los vecinos.

En síntesis, así como cualquier actividad humana (en salud, educación, política, producción u otras), las prácticas inadecuadas en plantaciones pueden producir consecuencias negativas, las que no son inherentes a las plantaciones mismas, sino a la ejecución de actividades silviculturales en forma inadecuada. El aporte de las plantaciones a la sustentabilidad puede concretarse plenamente, impulsando el mejoramiento de las prácticas silvícolas, ambientales y sociales asociadas a su manejo. Y esto puede lograrse en gran medida promoviendo la certificación de las plantaciones a través de los principales estándares a nivel mundial.

\section{Conclusiones}

En conclusión, en el análisis de la sustentabilidad de las plantaciones forestales, es indispensable adoptar una perspectiva holística y comprehensiva que no se focalice sólo en ellas, sino en su complementariedad con las grandes superficies de bosques naturales ricos en biodiversidad y paisajes que logran conservarse gracias a su formidable eficiencia en producción de madera. Las plantaciones forestales bien ejecutadas y manejadas son una respuesta racional, sustentable y eco-eficiente a las crecientes demandas de madera del mundo. Estableciendo dichas plantaciones en condiciones de alto rendimiento y desarrollándolas tecnológicamente para potenciar su capacidad de producir grandes volúmenes de madera en reducidos espacios de tierra, se estará logrando su principal aporte a la sustentabilidad del planeta, que es permitir la conservación de vastas áreas de ecosistemas naturales valiosos; sin perjuicio de su restante variedad de contribuciones ambientales.

Con objeto de asegurar que su manejo sea adecuado y evitar o minimizar los impactos ambientales no deseables que pudieran producir, es importante promover la certificación de las plantaciones. El desarrollo de éstas en el futuro tiene un horizonte limitado, y constituirán, al llegar al equilibrio 
de su crecimiento, una fracción muy minoritaria del total de los bosques, por lo que no revisten amenaza a gran escala para los bosques naturales, sino, más bien, son su necesario complemento en el delicado equilibrio de la sustentabilidad planetaria, que no puede ser tal sin considerar las necesidades y el bienestar del hombre.

\section{REFERENCIAS}

\section{Referencias en sitios web:}

FSC: $w w w . f s c . o r g$.

PEFC: www.pefc.org.

CERTFOR: www.certfor.org.

FAO: www.fao.org.

\section{Otras referencias}

Adams, Larry (1994): “Comparing Wood to Other Materials: There Is No Comparison”. En Wood \& Wood Products, September, p. 94.

Cerda, A. (2003): "Sector Forestal: Una Propuesta de Regulación Sustentable para el Bosque Nativo”. En "Políticas para una Revolución Microeconómica”. Santiago: Instituto Libertad y Desarrollo.

Contreras-Hermosilla, A. (1999): “Towards Sustainable Forest Management: an Examination of the Technical, Economic and Institutional Feasibility of Improving Management of the Global Forest Estate”. FAO/FPIRS/01, p. 22.

FAO (2000): "Forest Resource Assessment”. En www.fao.org. (2002a): “Agricultura Mundial hacia el año 2015-2030”. En http://www.fao.org/ documents/show_cdr.asp?url_file=/docrep/004/y3557s/y3557s10.htm.

(2002b): "Bibliografía Anotada sobre los Efectos Ambientales, Sociales y Económicos de los Eucaliptos”. Compilación de trabajos para el período 19851994 y para el período 1995-1999. FP/16S, FP/17S.

(2003): FAOSTAT, Base de Datos Estadísticos de la FAO.

“Towards Sustainable Forest Management”, FAO/FPIRS/01.

Forestal Millalemu - Universidad del Bío Bío, 1989.

Honey, Brian G. y Andrew H. Buchanan (1992): "Environmental Impacts of the New Zealand Building Industry”. Research Report 92-2, Dept. of Civil Engineering, University of Canterbury, Christchurch, New Zealand.

Koch, Peter (1992): "Wood versus Non-Wood Materials in US Residential Construction: Some Energy Related Global Implications”. En Forest Products Journal 42 (5): 31-42.

Pearce, D. W. (1993): Economic Values of the Natural World. UK: Earthscan. (1997): “The Economics of Sustainable Development”. CSERGE, mimeo.

Spears, John (2000): “Global Vision Research Project”. Summary of Main Findings Emerging from Phase 1, World Bank / WWF Alliance / Council of Foreign Relations. Washington D.C. Jan 15/00. 
Sutton, Wink. (1995): "Plantation Forests Protect our Biodiversity". En New Zealand Forestry, 40(3): 2-5. [Traducido y publicado en revista CORMA, diciembre 1996, Santiago.]

(1999): "Does the World Need Planted Forests?" Trabajo presentado en la "Intersessional expert meeting on the role of planted forests", Santiago, Chile. 6-9 abril 1999.

United Nations, Population Division (1998). "World Population Projections to 2150", NY.

United Nations Development Programme (UNDP): Human Development Report (varios años).

Vincent, J. y C. Binkley (1993): “Multiple-Use Forestry”. En Journal of Land Economics Vol. 69, $\mathrm{N}^{\circ}$ 4: 370-76.

Wattenberg, Ben J. (2004): Fewer: How the New Demography of Depopulation Will Shape our Future. Chicago: Ivan R. Dee.

Will, G. M. Y R. Ballard. (1976): “Radiata Pine. Soil Degrader or Improver?”. En New Zealand Journal of Forestry.

World Bank (2005): World Development Report. World Bank.

Palabras clave: recursos renovables y conservación; plantaciones forestales; economía del medio ambiente. 


\title{
INSTRUMENTOS NO TRADICIONALES PARA LA PROTECCIÓN DE LOS RECURSOS NATURALES EN CHILE
}

\author{
Ricardo Katz, Gabriel del Favero, \\ Leonel Sierralta, Javier Vergara, \\ Guillermo González, Gonzalo Moyano
}

\section{INTRODUCCIÓN}

La “Estrategia Nacional de Biodiversidad”, elaborada el año 2003 en el marco del cumplimiento del Convenio sobre Diversidad Biológica (ENB) ${ }^{1}$, establece como objetivo principal la proposición de acciones que apunten a la supervivencia, en el largo plazo, de la biodiversidad nacional representativa. Para ello, se pretende comenzar con la protección de, al menos, el 10\% de las superficies de cada uno de los ecosistemas relevantes antes del $2010^{2}$.

A sólo dos años del plazo propuesto, se puede constatar que el ritmo de avance hacia ese objetivo es sustancialmente menor al necesario para concretarlo. El Estado no sólo ha sido lento en incorporar nuevas unidades al Sistema Nacional de Áreas Silvestres Protegidas del Estado (SNASPE) ${ }^{3}$, sino que ha sido incapaz de generar las condiciones para encauzar y masificar el espontáneo interés de los privados de participar en la conservación de la biodiversidad, a pesar de que la Ley 19.300 sobre Bases Generales del Medio Ambiente, del año 1994 (LBGMA), impuso explícitamente al Estado la tarea de fomentar e incentivar la creación de Áreas Protegidas Privadas (APP).

RiCARDO Katz. Ingeniero Civil, Universidad de Chile. Master en Ciencias en Administración Ambiental, Universidad de Texas. Investigador asociado y coordinador de la Comisión de Medio Ambiente del CEP.

Gabriel del FÁvero. Abogado. Investigador asociado y secretario de la Comisión de Medio Ambiente del CEP.

Leonel Sierralta. Master en Ecología Forestal, Instituto Agronómico Mediterráneo de Zaragoza (IAMZ). Investigador asociado y miembro de la Comisión de Medio Ambiente del CEP.

Javier Vergara. Miembro de la Comisión de Medio Ambiente del CEP.

Guillermo GonzÁLez. Ingeniero Civil mención en Ingeniería Ambiental, Universidad Católica de Chile. Especialista ambiental, Gestión Ambiental Consultores (GAC).

GonZALo MoyAno. Abogado. Especialista en derecho ambiental, Vergara Abogados.

${ }^{1}$ Ratificado por Chile el año 1994, lo que hace que el Convenio forme parte del ordenamiento jurídico vigente.

${ }^{2}$ Conama: "Estrategia Nacional de Biodiversidad", 2003.

${ }^{3}$ Entre el año 2000 y el 2008 sólo ha incorporado una nueva unidad, el Parque Nacional Corcovado. 
Este poco fecundo proceso ha sido acompañado de una rica discusión en torno a la incorporación de los agentes privados a la conservación de la biodiversidad. En la última década, a través de una cantidad importante de publicaciones y seminarios, se ha ofrecido una amplia gama de propuestas para incentivar la creación de nuevas APP. Este trabajo busca reposicionar en la agenda la urgente necesidad de generar estos incentivos, haciendo hincapié en algunas de las ideas ya expresadas, y entregando nuevas propuestas para hacer más sencillo y eficiente un sistema que permita avanzar hacia la meta trazada en la ENB.

A esta altura se hace necesario indicar algunos supuestos básicos de nuestra propuesta. En primer lugar y, tal como se estableció en la LBGMA, el incentivo privado para la protección de la biodiversidad debe descansar en un régimen mayoritariamente voluntario. Es decir, partimos de la base que, siempre que sea posible, el Estado debe generar un sistema de incentivos con el objetivo de influir en el comportamiento de los agentes privados, evitando imponer restricciones discrecionales y arbitrarias al uso de esas propiedades.

Por otra parte, se debe aclarar que nuestra propuesta se asienta en los objetivos indicados en la ENB, sin buscar evaluarlos o reformularlos desde el punto de vista ecológico. De esta manera, nos hemos enfocado en la conservación de ecosistemas relevantes, dejando de lado la protección orientada a especies de fauna o a unidades de paisaje.

\section{CONDICIONES PARA LA CONSERVACIÓN PRIVADA}

La experiencia internacional ha ido progresivamente identificando algunas condiciones que deben concurrir para posibilitar mecanismos de conservación privada de relevancia ambiental. En este ámbito, la Organización para la Cooperación y el Desarrollo Económico (en sus siglas en inglés OECD) se ha referido extensamente a la incorporación de instrumentos económicos por parte de sus Estados miembros con el objeto de conservar la biodiversidad. Al respecto, esta organización se ha focalizado especialmente en aquellos factores necesarios para la creación de mercados de conservación de la biodiversidad, incluyendo instrumentos para la administración privada de áreas de valor natural.

Resulta especialmente relevante apreciar cómo, al mismo tiempo que los incentivos de mercado operan para reducir la inapropiada presión sobre recursos relacionados con la biodiversidad, también pueden incidir en una mejor administración de éstos. La creación de mercados, en este ámbito, opera a través de la superación de barreras al intercambio comercial, incluyendo el establecimiento y asignación de derechos de propiedad estables y 
bien definidos ${ }^{4}$. Conforme a la OECD, la creación de mercados se basa en la premisa que los titulares de estos derechos de propiedad van a maximizar el valor de sus recursos en el tiempo, permitiendo un uso, conservación y restauración más eficiente de la biodiversidad.

Por otra parte, se ha indicado que a fin de lograr los objetivos relacionados con la protección y uso sustentable de la biodiversidad, los instrumentos económicos generalmente requerirán ser utilizados con otros instrumentos que no son de mercado, tales como estándares, normas, restricciones de acceso, entre otros. Sin embargo, lo relevante es la complementariedad entre todas estas herramientas de gestión ${ }^{5}$.

Se requerirá además una capacidad de diseñar, ejecutar y fiscalizar los instrumentos definidos. Por esta razón, un elemento central para la ejecución de los instrumentos de incentivo consiste en la existencia de un esquema institucional que sea capaz de llevar adelante dichas tareas. Desde esta perspectiva, se requiere que las autoridades cuenten con las competencias que le permitan orientar correcta y eficientemente los instrumentos de incentivo para la conservación. En este sentido, se requiere dotar a las autoridades de los recursos humanos y financieros necesarios para incorporar al sector privado en la conservación. Asimismo, las decisiones en la definición de políticas deben ser tomadas considerando los costos que cada una de éstas tienen para el Estado, incluyendo su fiscalización y monitoreo. Tales opciones deben también tomar en cuenta los costos privados para su implementación.

Finalmente, la OECD también ha puesto hincapié en la necesidad de contar con información que permita identificar los recursos de biodiversidad, su estado de conservación y posibilidades de explotación futura. Ello será relevante para identificar las dificultades existentes y su respuesta frente a los distintos incentivos para la conservación de recursos relevantes.

\section{Situación ACTUAL EN CHILE}

\subsection{Estado de la biodiversidad}

El Sistema Nacional de Áreas Silvestres Protegidas del Estado (SNASPE) actualmente cuenta con 32 Parques Nacionales, 48 Reservas Nacionales y 15 Monumentos Naturales, cubriendo un total de 14 millones de hectáreas, lo que representa el 19\% de la superficie de Chile continental.

\footnotetext{
${ }^{4}$ OECD: "Recommendation of the council on the use of economic instruments in promoting the conservation and sustainable use of biodiversity”, 2004, p. 8. Adoptada por el Consejo de la OECD el 21 de abril de 2004.

${ }^{5}$ Ibid, p. 7.
} 
Pese a la elevada proporción del territorio que se encuentra protegido, el SNASPE presenta una serie de deficiencias.

El 84\% de estas áreas se concentra en las Regiones de Aysén y Magallanes, mientras que los ecosistemas del Chile central, localizados entre las regiones de Coquimbo y del Maule, se encuentran protegidos en menos del 1\% de su área total, a pesar de corresponder a uno de los 25 hotspots identificados a nivel mundial por su valor de biodiversidad global y su alto grado de amenaza ${ }^{6}$. El 60\% de las 85 formaciones vegetacionales identificadas para el país (según la clasificación de Gajardo7) están insuficientemente protegidas o sin protección por el SNASPE. A lo anterior se suma una serie de restricciones operacionales, financieras e institucionales. Por ejemplo, una evaluación de la efectividad de las áreas del SNASPE en la ecorregión valdiviana detectó entre las principales debilidades un marco legal que limita la capacidad fiscalizadora de los guardaparques, un presupuesto insuficiente, vacíos de información e investigación y una institucionalidad ambiental que no garantiza la prevención de amenazas en las áreas protegidas públicas ${ }^{8}$.

Alcanzar la meta de una protección efectiva de al menos el 10\% de las superficies de cada uno de los ecosistemas relevantes, establecida en la ENB, tendría para el Estado costos relevantes asociados a la adquisición y manejo de estas áreas ${ }^{9}$. Por lo tanto, se hace claro que una meta de esta magnitud no se podrá alcanzar en el mediano plazo sino con la incorporación masiva de agentes privados, o bien, con la decisión de inversión estatal que parece no existir.

${ }^{6} \mathrm{Al}$ respecto, véase Pauchard Aníbal y Pablo Villarroel: "Protected Areas in Chile: History, Current Status, and Challenges”, 2002, pp. 318-330; y Myers, Norman et al., "Biodiversity Hotspots for Conservation Priorities", 2000, pp. 853-858.

${ }^{7}$ Véase Gajardo, Rodolfo: La Vegetación Natural de Chile: Clasificación y Distribución Geográfica, 1995, y Luebert, Federico y Pablo Becerra, "Representatividad Vegetacional del Sistema Nacional de Áreas Silvestres Protegidas del Estado (SNASPE) en Chile”, 1998, pp. 62-69.

${ }^{8}$ Tacón, Alberto et al.: Evaluación Rápida de la Efectividad de Manejo en las Áreas Silvestres Protegidas de la Ecorregión Valdiviana, 2005.

${ }^{9}$ Considerando que la gran mayoría de los sitios prioritarios para la conservación identificados ya están en manos privadas. Esta es la situación, por ejemplo, de la totalidad de los sitios prioritarios reconocidos por la Estrategia Nacional de Biodiversidad para la Ecorregión de los Bosques Mediterráneos. Al respecto véase Sepúlveda, Claudia y Pablo Villarroel: "Servicios Ecosistémicos y Financiamiento de la Conservación Privada en Chile", 2006, pp. $12-20$.

De acuerdo a estimaciones realizadas por el Plan de Acción Forestal en 1994, mejorar la superficie protegida a nivel nacional de modo que todas las formaciones vegetacionales del país queden protegidas en un 5\% o más, y que el SNASPE supere algunos problemas de infraestructura y personal, significaría una inversión cercana a los US\$ 100 millones. Al respecto véase Villarroel, Pablo: “Cooperación Público-Privada para la Conservación de la Biodiversidad”, 1998, pp. 65 -72. 
En efecto, esta necesidad ha sido captada y espontáneamente ejecutada por dichos agentes, quienes se han adelantado al Estado y, sin incentivos de ningún tipo, han incorporado a la conservación más de 300 APP que suman cerca de 1 millón 400 mil hectáreas ${ }^{10}$. Estas iniciativas son sumamente diversas respecto de su tamaño, en un rango que va desde unas pocas hasta cientos de miles de hectáreas. También hay grandes diferencias en el uso que se les da: algunas se mantienen en un estado de preservación estricta, mientras otras utilizan de manera sustentable algunos recursos naturales del predio protegido, pasando por una serie de experiencias de ecoturismo y desarrollos inmobiliarios. Igual o más diversos son quienes están detrás de las distintas iniciativas, así como sus motivaciones: desde grupos de personas con mero interés filantrópico, los que a su vez buscan aprovechar un sector de las áreas para uso recreacional, empresas que se comprometen a la conservación de ciertas áreas como parte de medidas de compensación por impactos causados por proyectos sometidos al Sistema de Evaluación de Impacto Ambiental (SEIA) ${ }^{11}$, hasta la industria forestal, que protege más de 400.000 hectáreas $^{12}$, algunas por razones operacionales y otras de forma voluntaria. En el Recuadro se pueden ver algunos casos relevantes de APP.

Por otra parte, existe una serie de situaciones que imponen a propietarios privados la obligación de conservar sus predios (o parte de ellos) de manera no necesariamente voluntaria. Éste es el caso de las Áreas de Preservación Ecológicas definidas por los instrumentos de planificación territorial y que van más allá de las áreas del denominado SNASPE, así como de ciertos sitios Ramsar*. Otro caso lo constituyen los Sitios Prioritarios para la Conservación que han sido identificados por Conama. Éstos, sin un respaldo legal formal, definen áreas que el Estado considera relevante proteger, lo que afecta a las actividades económicas en la zona vía restricciones que se imponen en el SEIA (sistema de evaluación de impacto ambiental).

Finalmente, si se incluyeran todas estas áreas privadas al inventario de áreas protegidas en el país, éste aumentaría de forma relevante. Sin embargo, ninguna de éstas normalmente es incluida en dichos inventarios, lo cual es correcto dado que, si bien algunas pueden cumplir con su objetivo de protección, no cuentan con una protección efectiva que permita asegurarlo.

${ }^{10}$ Maldonado, V. y R. Faúndez: “Asesoría para la Actualización Base de Datos Cartográfica de Áreas Silvestres Protegidas Privadas a Nivel Nacional. Informe Final”, 2005.

${ }^{11}$ La Estrategia Nacional de Biodiversidad de 2003 señala que habría 50.000 ha de terreno bajo protección asociada a compensaciones del SEIA.

12 Eliodoro Matte L., en discurso de presentación de este seminario "Liderazgo del sector privado en la conservación del medio ambiente”, infra, en esta misma edición.

* Se trata de humedales que presentan una alta riqueza de especies, inscritos en la Convención sobre Humedales, firmada en Ramsar, Irán, en 1971. (N. del E.) 


\section{RECUADRO}

\section{ALGUNAS INICIATIVAS PRIVADAS DE CONSERVACIÓN}

La Comunidad Ahuenco, formada por un grupo de 45 personas naturales, consiste en 850 hectáreas cercanas a la sección norte del Parque Nacional Chiloé, en la Región de Los Lagos. Además de recursos relevantes de flora y fauna, en el área se encuentra una colonia de pingüinos. La comunidad es una ONG que forma parte de la Red de Áreas Protegidas Privadas (RAPP), sin reconocimiento formal de su status de conservación. Cada miembro de la comunidad es dueño de una acción en una sociedad inmobiliaria, las que son transables en el mercado y/o heredables. Cada comunero tiene derecho a la construcción de una vivienda de veraneo sobre una reducida porción, manteniéndose la mayoría del predio como parque en común ${ }^{\mathrm{a}}$. El mantenimiento depende exclusivamente del aporte de dichos comuneros.

La Reserva Ecológica Huilo Huilo es un proyecto inmobiliario-turístico que nace a partir del patrimonio forestal de la Compañía Forestal y Maderera Panguipulli. Considera un total de 56 mil hectáreas, ubicadas en la comuna de Panguipulli, Región de Los Lagos, en la ribera sur del Lago Pirihueico y del río Fuy. Combina áreas de conservación con venta de parcelas (menos del 1\% del total del proyecto) y desarrollo turístico. Se conservan bosques de roble y raulí, poco representados en el SNASPE. Corresponde a un sitio prioritario de conservación según clasificación realizada por CONAMA en 2003, pero tampoco cuenta con reconocimiento formal de su status. Asimismo, en esta reserva se han iniciado programas de reproducción y reintroducción del huemul.

El Proyecto Karukinka, ubicado en Tierra del Fuego, región de Magallanes, consiste en un importante proyecto de conservación realizado por una organización financiera internacional (Goldman Sachs), en alianza con una ONG de conservación con base en Estados Unidos (Wildlife Conservation Society). Con una superficie aproximada de 250 mil hectáreas, contiene remanentes de importancia global de bosques primarios de lenga y bosques mixtos lenga-coigüe de Magallanes, y alberga además una variedad de otros ecosistemas que incluyen humedales, ecosistemas andinos, estepa patagónica, todos representativos de la biodiversidad austral $^{\mathrm{b}}$. Se desarrollan proyectos de erradicación de castores y de investigación sobre guanacos. Esta APP tampoco tiene reconocimiento formal como área de conservación.

La conservación de la Laguna Conchalíc, en la Región de Coquimbo, es el resultado del cumplimiento de los compromisos asumidos por Minera Los Pe-

a Corcuera, Elisa: "Primer Congreso de Conservación Privada de Tierras en Chile”, 2003, pp. 46-50.

b Saavedra, Bárbara: "Karukinka, Nuevo modelo para la Conservación de Biodiversidad”, 2006, pp. 21-27.

c Información obtenida de la página web www.pelambres.cl. 
lambres durante la evaluación de sus proyectos en el SEIA. Sus 34 hectáreas de humedales son el punto de descanso de alrededor de 70 especies de aves, gran parte de ellas migratorias del hemisferio norte, ya que por sus singulares características biológicas, constituye un ecosistema altamente diverso, especialmente importante para su nidificación, alimentación y refugio. Está reconocido como Santuario de la Naturaleza y fue designado Sitio Ramsar en 2004, convirtiéndose en el primer humedal del país con esta categoría que se encuentra bajo la protección de una empresa privada.

El Santuario de la Naturaleza Salar de Huasco, Región de Atacama, es una iniciativa en la cual participan la Municipalidad de Pica, CONADI, Minera Doña Inés de Collaguasi y la ONG Centro de Estudios del Desarrollo y que cuenta con apoyo financiero del Banco Mundial. Este humedal altoandino destaca por ser un ecosistema con rica avifauna altiplánica. Es una importante zona de alimentación, nidificación y residencia temporal o permanente de aves. Se caracteriza por mantener una vegetación atípica en la región ${ }^{d}$.

En los humedales costeros de la Región del Bío Bío, la Compañía Siderúrgica Huachipato cuenta con 65 hectáreas de humedales bajo protección voluntaria. Llama la atención que esta área se encuentra adyacente a las instalaciones industriales de la empresa, la cual controla el nivel de las lagunas con el agua del río Bío Bío, con el fin de mantener este ecosistema. El plan de manejo en ejecución incluye un catastro de aves y el seguimiento de su desarrollo, y ha permitido detectar la presencia de cerca de 40 especies de aves. Una vez más, esta APP no tiene reconocimiento formal de su status de conservación.

Una experiencia reciente e innovadora es la que se gestó en Mejillones, Región de Antofagasta, zona que constituye un sitio de nidificación relevante del

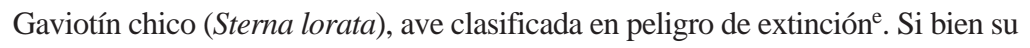
situación ya había generado la necesidad de establecer áreas de conservación en los planes reguladores del sector y de exigir medidas de mitigación a los proyectos ubicados en la zona, recién en el año 2007, con el ingreso simultáneo de una serie de proyectos portuarios y termoeléctricos al SEIA, se implementó un plan de protección de largo plazo, a ejecutarse a través de la "Fundación para la Sustentabilidad del Gaviotín chico”. La creación de esta fundación fue hábilmente coordinada por la municipalidad local, y contó con la participación de las empresas, el gobierno regional, el SAG y la Universidad de Antofagasta. Busca proteger y conservar esta especie a través del desarrollo de capacidades de investigación, generación de nuevos conocimientos en torno a la especie e implementación de medidas técnicas asociadas a dicho objetivo.

Finalmente, el Sendero de Chile ${ }^{\mathrm{f}}$ es un proyecto iniciado el año 2000 como parte de la celebración del bicentenario de la república y que tiene planifi-

${ }^{\mathrm{d}}$ Información obtenida de la página web www.monumentos.cl.

e International Union for Conservation of Nature (IUCN): Libro Rojo de Especies Amenazadas, 2005.

f Infante, Sebastián: “El Sendero de Chile”, 2007. 
cado el desarrollo integral de 23 tramos asociados a destinos diferentes, con 2000 kilómetros comprometidos de sendero. El proyecto incorpora la participación de los privados en su implementación, basado en un novedoso modelo de intercambio de aportes entre los propietarios de las áreas en las cuales se emplaza el recorrido principal del sendero (y sus accesos a atractivos, paraderos y estaciones), y la Fundación Sendero de Chile. El esquema consiste en que dicho propietario cede los derechos de uso y goce de sus terrenos a la fundación, la cual los administra (explotándolo en base al turismo) y a cambio entrega al propietario un porcentaje del ingreso percibido.

\subsection{Esquema normativo actual}

La Ley N 18.362 de 1984, que creó el Sistema Nacional de Áreas Silvestres Protegidas del Estado (SNASPE), incluyó un conjunto de objetivos de conservación tendientes a la mantención de áreas de carácter único o representativas de la diversidad ecológica natural del país ${ }^{13}$. Ya al momento de su dictación existían en el país categorías de protección de la biodiversidad consagradas por un conjunto de textos normativos. Ejemplo de ello es la Ley de Bosques de 1925 (y su modificación de 1931) que establece la existencia de los Parques Nacionales de Turismo, así como algunos instrumentos de planificación que reconocían áreas de restricción, como es el caso del Plan Regulador Intercomunal de Concepción del año 1977. Sin embargo, la Ley $\mathrm{N}^{\circ} 18.362$ no estableció un régimen único de conservación, sino que fue diseñada de forma paralela a la existencia de estos estatutos. Ello generó una diversidad de textos normativos, de diversa jerarquía y ámbito de competencia, que reconocen áreas de protección de distinta índole, sobre la base de diversos criterios. Asimismo, el procedimiento para su dictación y autoridades competentes varía sustancialmente, así como el papel que juega la ciudadanía en su dictación.

En efecto, actualmente el SNASPE se encuentra conformado por diversos Parques Nacionales, Reservas Nacionales y Monumentos Naturales, categorías que coexisten con otros instrumentos de protección como son las Reservas Forestales (DL 1939 de 1977), los Santuarios de la Naturaleza (Ley 17.288), Áreas de Protección Turísticas (Ley 18.378), Zonas Típicas

${ }^{13}$ Se debe indicar que dicha ley no ha entrado en vigencia por cuanto comenzará a regir a partir de la fecha en que entre en plena vigencia la Ley 18.348 de 1984, mediante la cual se crea la Corporación Nacional Forestal (CONAF), como persona jurídica de derecho público, lo cual aún no ha ocurrido. A la fecha, CONAF sigue siendo una corporación de derecho privado. 
(Ley 17.288), Áreas de Valor Natural incluidas en instrumentos de planificación territorial, entre otras.

Por otra parte, la posibilidad que los privados puedan crear áreas silvestres protegidas ha sido reconocida por la Ley 19.300 de Bases Generales del Medio Ambiente. En efecto, el artículo 35 de dicha ley asigna al Estado la función de fomentar e incentivar la creación de este tipo de áreas. Adicionalmente, les ha reconocido igual tratamiento tributario, derechos, obligaciones y cargas que aquellas áreas pertenecientes al SNASPE. Asimismo, establece que la afectación de las áreas protegidas privadas tiene el carácter de voluntaria y que su supervisión se encuentra a cargo del mismo organismo administrador del SNASPE. En cuanto a la desafectación de las áreas protegidas privadas, ésta se producirá por vencimiento del plazo, por incumplimiento de las obligaciones que el propietario asume al solicitar su declaración, o a petición anticipada del propietario.

Parte central de la operación de este sistema descansa en un reglamento que, conforme a la Ley 19.300, debe establecer los requisitos, plazos y limitaciones a que se encuentran las áreas privadas protegidas. A pesar de haberse elaborado dicho reglamento, éste no ha sido promulgado aún, en parte porque debe necesariamente tratar aspectos que son materias de ley.

\subsection{Efectos del esquema actual}

La existencia de diversos regímenes de conservación, cuya administración depende de autoridades tan diversas como el Consejo de Monumentos Nacionales, CONAF, el SAG y los gobiernos regionales, entre otras, lleva a un marco regulatorio complejo, no coordinado, produciendo en muchos casos un escenario de incerteza jurídica y, lo que es más grave, resultando en una amenaza a la misma biodiversidad que se pretende proteger.

Un ejemplo de lo anterior ha sido la reciente discusión respecto a la validez de las áreas de preservación ecológica reconocidas en instrumentos de planificación territorial. El centro de la discusión se ha enfocado en determinar si dichos instrumentos pueden crear áreas de protección o si sólo están facultados para reconocer áreas existentes, debida y formalmente definidas por los organismos competentes. La respuesta no resulta sencilla debido a la ausencia de una regulación clara al respecto por parte de la legislación de urbanismo y construcciones. En medio de dicha discusión se plantean nuevos proyectos de inversión que no tienen claridad jurídica para proponer medidas de compensación, mitigación o reparación en el caso que dichas áreas sean afectadas. 
Por otra parte, si bien existe un número muy importante de iniciativas privadas de conservación, también es cierto que éstas presentan una serie de temas aún por resolver. Las APP no necesariamente están alineadas con las prioridades definidas por la ENB, muchas de ellas contando con una gran belleza escénica pero con una baja relevancia ecológica.

A pesar de algunos esfuerzos, como los que han realizado instituciones como Parques para Chile y el Comité Nacional Pro Defensa de la Flora y Fauna, CODEFF (a través la Red de Áreas Protegidas Privadas), existe una baja coordinación entre las distintas áreas. De esta manera, se desaprovecha la posibilidad de formar conjuntos de redes territoriales que permitan proteger superficies significativas de ecosistemas prioritarios mediante la formación de corredores biológicos que conecten áreas protegidas públicas o privadas entre sí, lo que podría generarse inclusive con áreas de poco tamaño que constituyen la mayor parte de las $\mathrm{APP}^{14}$.

Por otra parte, la mayoría de las APP no cuentan con reconocimiento formal de su estatus de protección, por las dificultades que implica realizarlo. Lo anterior redunda en que éstas quedan expuestas a ser afectadas por proyectos de vialidad, gasoductos, industrias, etc., sin ningún tipo de resguardo ambiental, contrariamente a lo que ocurre con las áreas que conforman el SNASPE. Además, las iniciativas de conservación privada se convierten en un mercado sin regulación de ningún tipo, en relación a su valor ecológico, quedando indiferenciadas aquellas que representan una contribución real a la conservación del patrimonio natural del país. Esta deficiencia tampoco permite asegurar que estas áreas efectivamente tendrán un manejo adecuado y las deja vulnerables frente a un eventual desvinculamiento en el futuro por parte de los mismos propietarios.

\section{LINEAMIENTOS PARA LA CONSERVACIÓN PRIVADA}

Nuestra propuesta busca abordar algunas de las deficiencias antes descritas, de manera de aportar a la discusión y eventual solución del problema, y a que el Estado pueda generar incentivos adecuados para alentar la incorporación de privados a la conservación, permitiendo alcanzar las metas propuestas en la Estrategia Nacional de Biodiversidad. La propuesta consta de tres etapas: la redefinición de las categorías de protección, la priorización de los ecosistemas y la incorporación de nuevas áreas protegidas. Cada una de éstas se describe en detalle a continuación.

${ }^{14}$ En efecto, la mayoría de las APP registradas en Chile tienen tamaños inferiores a las 100 ha. Véase Sepúlveda, Claudia: “Áreas Privadas Protegidas y Territorio: La Conectividad que Falta”, 2002, pp. 119-124. 


\subsection{Redefinición de las categorías de protección}

Teniendo en consideración el marco regulatorio actualmente existente, resulta imprescindible que cualquier política de conservación se encuentre respaldada por un régimen único de conservación de la biodiversidad, que opere sobre la base de criterios uniformes, y en la cual participen autoridades e instituciones atingentes al tema. Se debe evitar el escenario existente actualmente, en donde diversas autoridades, en forma descoordinada, declaran categorías de protección diversas, que no dialogan entre sí, y que generan un importante grado de incerteza jurídica. Además, dichas declaratorias habitualmente afectan propiedades de particulares, que ven cercenados sus derechos sobre esas propiedades sin que exista una compensación de por medio.

La generación de un mecanismo coherente debe ser la base de un sistema que permita homogeneizar las categorías de protección, permitiendo que las actuales competencias de diversos organismos que tienen facultad para declarar diferentes áreas de protección se integren, a fin de incluir, bajo un cierto número de categorías, las consideraciones y criterios de biodiversidad que hoy se encuentran dispersos. Para ello, y conforme se ha indicado precedentemente, el Estado debiera redefinir las categorías de conservación actualmente existentes, permitiendo que todos los instrumentos de protección respondan a criterios comunes. Además, se debiera aprovechar una instancia como ésta para actualizar los conceptos actualmente utilizados para definir las distintas categorías, provenientes de la Convención de Washington, realizada en la década de los 40 . Si bien este trabajo no pretende ofrecer un nuevo listado de categorías, creemos deberán considerarse las categorías propuestas por la IUCN (International Union for Conservation of Nature) $)^{15}$.

\subsection{Priorización de los ecosistemas}

Como siguiente paso, el Estado deberá coordinar la priorización de las áreas a conservar, a través de un sistema basado en variables científicas, pero que también incorpore la participación ciudadana. El Libro Rojo de los Sitios Prioritarios para la Conservación ${ }^{16}$ y los listados regionales consti-

${ }^{15} \mathrm{Al}$ respecto, véase el documento de la UNEP: "Directrices para las Categorías de Manejo de Áreas Protegidas”, disponible en la página web: http://www.unep-wcmc.org/ protected_areas/categories/esp/index.html.

${ }^{16}$ Muñoz, M., J. Yáñez y H. Núñez: Libro Rojo de los Sitios Prioritarios para la Conservación de la Diversidad Biológica en Chile, 1997. 
tuyen un avance en esta dirección, pero se hace necesario aunar los criterios y elaborar un listado priorizado a nivel nacional, mediante un mecanismo transparente y participativo. Dicha priorización debe responder al objetivo de la Estrategia Nacional de la Biodiversidad de dar protección al 10\% de la superficie de cada uno de los ecosistemas relevantes. Por lo tanto, esto supone también la definición clara de lo que deba entenderse por “ecosistema"17.

Como resultado del proceso debería generarse un acuerdo políticociudadano-científico respecto de los sistemas que se busca conservar. Se podrá determinar cuáles de ellos ya se encuentran suficientemente representados en el SNASPE y cuál es el déficit que debe ser incorporado al nuevo sistema de áreas protegidas que incluya al SNASPE y a las APP (al cual denominaremos Sistema Nacional de Áreas Protegidas, SNASP). Como ya se ha señalado, es de esperar que una proporción muy importante de dichos sistemas estén ubicados dentro de predios privados, por lo que nuestra propuesta se focaliza en la incorporación de éstos al SNASP.

Cabe señalar que esta priorización permitirá además determinar las áreas que se encuentran sobrerrepresentadas en el SNASPE, algunas de las cuales podrían desafectarse y así generar recursos para la conservación de las otras áreas. Por otra parte, al igual que las normas de calidad ambiental, la definición de áreas debería revisarse periódicamente para efectos de redefinir prioridades.

\subsection{Incorporación de nuevas áreas protegidas}

Se estima que la mayor parte de las áreas que se definirán como prioritarias para conservación corresponderán a propiedades privadas, razón por la cual se deberán desarrollar mecanismos de incentivos para su conservación, orientados a los propietarios de dichas áreas.

Mucho se ha escrito en Chile respecto de este tipo de incentivos; se han presentado propuestas que van desde beneficios tributarios hasta subsidios directos, pasando por asistencia técnica ${ }^{18}$. Sin embargo, no se ha ofrecido una propuesta clara que permita abordar el siguiente hecho: en

${ }^{17}$ Debe señalarse que la última clasificación relevante realizada corresponde a la de los "pisos de vegetación" (desarrollada en Federico Leubert y Patricio Pliscoff, Sinopsis bioclimática y vegetacional de Chile, 2006).

${ }^{18} \mathrm{Al}$ respecto véase Sepúlveda, Claudia: “Incentivos para la Creación y Manejo de Áreas Silvestres Protegidas Privadas en Chile”, 1997, pp. 38-46; Geisse, Guillermo y Claudia Sepúlveda: "Iniciativas Privadas y Política Pública de Conservación Ambiental”, 2000, pp. 6-13; Villarroel, Pablo: “Los Gestores Privados y su Papel en la Conservación de la Biodiversidad”, 2004, pp. 65-74. 
Chile ya existe una gran cantidad de áreas protegidas privadas, sin mediar incentivos de ningún tipo, lo que es reflejo de la elevada disposición a conservar de ciertos actores privados.

Por lo tanto, entregar incentivos por igual a todos los propietarios de predios que se busque conservar no resultaría en una asignación eficiente de recursos, debiendo buscarse incentivos diferenciados que capturen las diferentes disposiciones privadas hacia la conservación. No obstante, lo anterior sólo es posible cuando, para un mismo ecosistema, se cuenta con múltiples oferentes privados $\mathrm{y}$, por ende, existe competencia y posibilidad de capturar esas diferentes disposiciones. En consecuencia, nuestra propuesta consta de dos casos generales que se presentan a continuación.

\subsubsection{Caso de múltiples oferentes privados}

\subsubsection{Licitaciones como mecanismo para la conservación}

En el caso de ecosistemas que se deseen incorporar al SNASP, de acuerdo a los criterios mencionados en el punto 4.2, y que se encuentren presentes en predios privados de propietarios distintos, nuestra propuesta es que existan incentivos diferenciados y que sean los privados quienes propongan cuánto desean recibir a cambio de conservar la biodiversidad existente en su propiedad.

La manera más eficiente de llevar esto a cabo es a través de licitaciones, en las cuales a los propietarios de las áreas que se busca conservar se les dé la posibilidad de presentar una propuesta para conservar un área específica a cambio de un subsidio directo, entregado anualmente, que provenga desde un fondo al que denominaremos Fondo para la Conservación de la Biodiversidad. De esta forma, aquellos con mayor disposición a conservar esperarán un subsidio menor que quienes no tienen interés de hacerlo, por lo que un sistema de licitación apelará a la competencia entre los actores y permitirá capturar la disposición intrínseca de algunos de éstos ${ }^{19}$. Una vez recibidas todas las propuestas, se deberían elegir las más costoefectivas hasta alcanzar la representatividad requerida de cada ecosistema. En el caso de que la licitación se declare desierta, se deberá pasar al caso que se describe más adelante.

Son varios temas los que se deben afinar para poder poner en práctica un sistema de este tipo. El más obvio tiene que ver con el origen de los

${ }^{19}$ Es esperable que muchas de las APP existentes, que no cuentan con una declaración formal pero que buscan obtenerla, exijan bajos subsidios para incorporarse al SNASP, pues ello no les implicaría cambios relevantes con relación a su actividad actual. 
recursos necesarios para el fondo que entregará las compensaciones a los propietarios. Una parte debería provenir directamente del Fisco, pero el fondo podría ser complementado por aportes de los mismos privados ${ }^{20}$, por ejemplo, de los proyectos que se someten al SEIA y que deben compensar ciertos impactos.

De acuerdo a lo establecido en el Reglamento del SEIA, las compensaciones deben realizarse en "moneda verde" y en el lugar donde los impactos ocurran ${ }^{21}$. Por lo tanto, ante la necesidad de compensar un cierto impacto, el titular del proyecto podría hacer un aporte, destinado específicamente a incorporar al sistema áreas prioritarias ubicadas en el sector de su proyecto (una alternativa sería que el titular adquiriera el o los predios donde se encuentre el ecosistema en cuestión y que luego él se presente a la licitación). De esta manera, iniciativas de este tipo, que hoy no necesariamente están alineadas con las prioridades de conservación, pasarían a formar parte de un sistema integrado de áreas protegidas.

También puede considerarse la posibilidad de que otras empresas hagan aportes para financiar el fondo general o específicamente para la conservación de ecosistemas seleccionados por ellos, lo que podría resultarles atractivo como acciones de responsabilidad social empresarial. En el caso de las empresas, las donaciones podrían además estar afectas a rebajas tributarias análogas a las que existen para las donaciones culturales. Este tipo de aportes también podría provenir de personas naturales interesadas.

Por otra parte, deberá desarrollarse un mecanismo objetivo para determinar el costo-efectividad de las distintas ofertas, en base a indicadores lo más objetivos posible. En este aspecto, el sistema de licitación tiene una gran ventaja: al momento de realizarse una convocatoria para un ecosistema específico, las ofertas se recibirán y evaluarán simultáneamente, lo que permite analizar los efectos sinérgicos entre ellas. Bien podría ocurrir que dos propiedades relativamente pequeñas por sí solas no sean ecológicamente atractivas, pero que en conjunto sí lo sean. Este tipo de situaciones deben ser incorporadas al análisis, buscando el mejor conjunto de ofertas al más bajo costo.

Además, debe examinarse cómo asegurar la conservación efectiva y adecuada de la propiedad. Para ello, las bases de la licitación de cada sector

${ }^{20}$ En efecto, la misma Estrategia Nacional de Biodiversidad establece en su Línea Estratégica $\mathrm{N}^{\circ} 8$ que se deben "definir las condiciones necesarias para establecer un fondo para la conservación de la biodiversidad”.

${ }^{21}$ El artículo 60 del Decreto Supremo N ${ }^{\circ}$ 95/2001 de Minsegreps, establece que "los recursos naturales o elementos del medio ambiente" deberán ser reemplazados o sustituidos por "otros de similares características, clase, naturaleza y calidad". 
específico deberán establecer el grado de conservación requerido del ecosistema respectivo: preservación estricta o si puede efectuarse algún nivel de uso.

Los concursantes deberían presentar una propuesta técnica (Plan de Manejo), en el caso que se soliciten usos consuntivos, debido al mayor grado de intervención asociado. Por ello, deberían generar líneas base, que determinen la situación inicial y el estado del área en cuestión, así como proponer sistemas de monitoreo de impacto. Alternativamente, los organismos del Estado relacionados (CONAF, SAG, etc.) podrían generar planes de manejo estándar para ecosistemas y tipos de usos específicos, los que podrían ser directamente incorporados a las bases ${ }^{22}$.

Una vez firmado el contrato de conservación, los subsidios anuales deberán estar condicionados a la verificación del cumplimiento de las condiciones establecidas en el Plan de Manejo respectivo, para de esta manera generar un incentivo permanente al manejo adecuado de las áreas seleccionadas.

Finalmente, cabe señalar que se ha optado por subsidios directos pues los beneficios tributarios (la alternativa muchas veces señalada) normalmente son poco atractivos dado el bajo valor que tienen las propiedades rurales, a diferencia de lo que ocurre en Estados Unidos, donde los impuestos territoriales suelen ser muy elevados y su rebaja representa uno de los principales incentivos para proyectos de conservación de tierras priva$\operatorname{das}^{23}$. Debe señalarse que para la implementación de beneficios de este tipo, se hace necesaria la modificación de la Ley 19.300, pues su artículo 35 limita las compensaciones a los propietarios de las APP a beneficios tributarios.

\subsubsection{Contrato de conservación}

Se debe precisar de forma general los términos del contrato a firmarse entre el Estado y el propietario del terreno, el que impondrá una serie de restricciones al uso de la propiedad a cambio de una compensación en dinero. Este contrato podría asimilarse a las obligaciones que se contraen al constituir una servidumbre de conservación o "conservation easement”. De

22 Véase Sepúlveda, Claudia et al. "Aportes al Reglamento para Áreas Protegidas Privadas”, 2003, pp. 32-42. Una discusión que va más allá del alcance de este artículo corresponde al conflicto de intereses que presentan los organismos mencionados entre su labor de fomento productivo y de conservación, por lo que no necesariamente serían los más indicados para el desarrollo o aprobación de dichos planes de manejo.

${ }^{23}$ Véase Sepúlveda, Claudia: “Áreas privadas Protegidas y Territorio: La Conectividad que Falta”, 2002, p. 122. 
esta forma, el propietario del terreno voluntariamente restringe o limita el tipo y cantidad de desarrollo que puede ser llevado a cabo sobre su terre$\mathrm{no}^{24}$.

Este tipo de servidumbre de conservación es un instrumento de gran flexibilidad, capaz de adaptarse a las necesidades locales de cada propietario y cada terreno. Es también una opción de menor costo respecto de la adquisición de las propiedades, que suele variar entre el 30\% y el 70\% del valor de ésta, dependiendo de las restricciones acordadas ${ }^{25}$.

Cabe hacer presente que este mecanismo de servidumbre, que se ha aplicado en otros países (como EE.UU.), es muy distinto del mecanismo de servidumbre que existe en el derecho chileno, por la posibilidad que una sola persona pacte la servidumbre, mientras en el derecho chileno se requiere la concurrencia de dos predios, constituyéndose así un derecho de un predio sobre el otro ${ }^{26}$. En Chile, cuando ambas propiedades caen en una misma mano, legalmente termina la servidumbre. No obstante lo anterior, la servidumbre, bajo los criterios del derecho chileno, puede constituirse de todas formas en un instrumento privado de conservación, pero con limitaciones en cuanto a que se mantiene en la medida que no se confunda el dominio de las propiedades.

Las compensaciones deberían entregarse anualmente, por el período de tiempo que dure el contrato. El contrato no debe poder rescindirse en todo el plazo de conservación estipulado, salvo por el incumplimiento de alguna de las partes, debiendo constar la restricción en la respectiva inscripción en el Conservador de Bienes Raíces ${ }^{27}$. Deberán tomarse las precauciones necesarias para compatibilizar estos contratos con la revisión periódica de las áreas prioritarias para la conservación.

\subsubsection{Declaración de autoridad}

Una vez que la autoridad haya finalizado el proceso de licitación, mediante la designación del oferente con la mejor oferta, y una vez que se haya suscrito el contrato de conservación respectivo, el privado debería

${ }^{24}$ Villarroel, Pablo: “Cooperación Público-Privada para la Conservación de la Biodiversidad”, 1998.

${ }^{25}$ Corcuera, Elisa: "Conservación de Tierras Privadas en Chile y el Mundo: ¿Coincidencia o Tendencia?”, 2000, pp. 36-43.

${ }^{26} \mathrm{Al}$ respecto, véase Ubilla, Jaime: "La Conservación Privada de la Biodiversidad y el Derecho Real de Conservación”, 2004.

${ }^{27}$ La posibilidad de hacer inscripciones al margen el Conservador de Bienes Raíces por razones ambientales puede tener utilidad en este tema como en otros. A modo de ejemplo, se pueden señalar las restricciones que pueden existir fruto de la contaminación de un sitio. 
solicitar al Estado la declaración de la categoría de conservación voluntaria que le permita un reconocimiento erga omnes respecto a su status jurídico reconocido por el Estado como área que forma parte del SNASP ${ }^{28}$. Ello posibilitará su protección con relación a obras que pretendan emplazarse en sus cercanías, o en el terreno mismo, sean éstas desarrolladas por el propio propietario o por terceros, sean públicos o privados.

\subsubsection{Caso de un solo oferente privado o licitación declarada desierta}

En caso que exista un solo oferente privado para un determinado ecosistema, el esquema de licitación antes descrito no resulta factible, pues no existiría competencia. En ese caso, la manera de asegurar su conservación consiste en que el Estado realice una declaración de ciertas zonas privadas bajo un esquema conservación. Para hacer efectiva la declaración, el Estado deberá ofrecer al propietario la entrega anual de una cierta compensación (monto a determinar por peritos, de forma similar a la Ley Eléctrica), por la conservación y administración del área, o derechamente deberá adquirir la propiedad, en el caso que el propietario no esté interesado en desarrollar un proyecto de conservación.

Este sistema debería además contemplar un plazo máximo (de cinco años, por ejemplo) después del cual, si el Estado no ha hecho efectiva la declaración y compensación antes descritas, las propiedades originalmente identificadas deben quedar desafectadas ${ }^{29}$. Esto busca que la declaración no constituya un acto meramente formal, sino que se realicen las acciones necesarias para brindar protección efectiva a los ecosistemas relevantes.

\section{FunCIONAMIENTO DEL ESQUEMA EN EL MARCO DE UNA NUEVA INSTITUCIONALIDAD AMBIENTAL}

Junto con la existencia de los incentivos económicos adecuados, el funcionamiento de un sistema como el propuesto requiere de un esquema que permita una correcta y eficiente administración del régimen de conser-

${ }^{28}$ El efecto erga omnes permitiría que el contrato suscrito genere efectos más allá de quienes concurrieron a su celebración, produciendo efectos respecto a terceros.

${ }^{29}$ Ello se asemejaría al sistema consagrado por la Ley General de Urbanismo y Construcciones respecto a la declaratoria de utilidad pública de ciertas áreas para la futura construcción de obras viales. Conforme al artículo 59 de dicha ley, los plazos de caducidad para las declaratorias de utilidad pública de los terrenos del área urbana, son de diez años para las vías expresas, y de cinco años para las vías troncales y colectoras y los parques intercomunales y comunales. El plazo de caducidad de las declaratorias de utilidad pública de los terrenos ubicados en áreas de extensión urbana, son de diez años, pudiendo prorrogarse por una vez por igual lapso. 
vación de áreas protegidas. Para ello, resulta de especial relevancia establecer una institucionalidad relacionada con la conservación de la biodiversidad, y en particular respecto a la conservación privada.

Con el objeto de lograr lo anterior, y tal como lo han señalado estudios internacionales, se requiere contar con la capacidad de diseño, implementación y fiscalización del régimen de conservación propuesto. Desde esta perspectiva, la institucionalidad debe contar con la capacidad de generar y canalizar la información sobre biodiversidad que debe ser conservada y administrada, con el objeto de otorgar a dichos recursos los mecanismos de protección necesarios. A su vez, la autoridad deberá construir el necesario respaldo político para estas iniciativas, procurando contar con un sistema transparente y participativo.

En el marco de la nueva institucionalidad ambiental actualmente en discusión, el régimen de conservación de la biodiversidad debiera encontrarse bajo la administración del Ministerio de Medio Ambiente, a través de una eventual Subsecretaría de Recursos Naturales o un Servicio Nacional de Parques y Áreas Protegidas. Dicha entidad debería velar por el correcto funcionamiento de la conservación pública y privada de la biodiversidad, centralizando la información sobre recursos ambientalmente relevantes del país, estableciendo políticas y objetivos generales de alcance nacional. Esta entidad podría servir de promotor de las licitaciones de conservación propuestas, constituyendo la contraparte de los privados en esta materia. De este modo, es evidente que el rediseño institucional que actualmente se encuentra analizando la autoridad es una oportunidad para crear los instrumentos en esta dirección.

Sin perjuicio de lo anterior, parece razonable que, en función de sus atribuciones constitucionales respecto del desarrollo territorial armónico y equitativo de las regiones, los gobiernos regionales participen en la definición de aquellas áreas que deben ser destinadas a ciertos grados de protección ambiental. Si bien pueden existir categorías de protección a nivel nacional, las regiones debieran ser partícipes de la declaración de áreas de relevancia ambiental regional, pero obviamente dentro del marco ya señalado. Por lo anterior, la nueva institucionalidad también debería tener esto en consideración.

Se debe tener presente que el enfoque del régimen propuesto no hubiese requerido la existencia de un ente ministerial para su implementación, bastando un ente coordinador como el desempeñado por CONAMA, pero obviamente la propuesta gubernamental va en la dirección ya señalada. 


\section{ConClusiones}

Este artículo propone un sistema que capture la disposición voluntaria a conservar por parte de ciertos actores privados. Con ello, se busca optimizar el uso de los recursos públicos, generando incentivos para la conservación privada de la biodiversidad.

Parte central de nuestra propuesta descansa en la necesidad de reformular las categorías de protección ambiental, a fin de posibilitar un esquema de conservación que otorgue mayor certeza jurídica, superando la actual multiplicidad de categorías de protección actualmente existentes. Ello, a fin de posibilitar mayor claridad respecto a las autoridades que participan en la definición de zonas de conservación de la biodiversidad, y acerca de los criterios utilizados.

Adicionalmente, la priorización de sitios debe basarse en una definición de áreas a nivel nacional y regional, conforme a una evaluación ambiental estratégica que considere aspectos sociales y económicos. Los procedimientos de definición y asignación de áreas deben considerar procedimientos claros (como la dictación de normas) y transparentes, posibilitando la participación ciudadana.

Con el objeto de alcanzar las metas de conservación de la ENB, se deberá distinguir entre aquellos ecosistemas con múltiples oferentes privados, de aquellos con un solo oferente. En los primeros, el sistema propuesto apunta a la voluntariedad y competencia para fomentar la conservación. En el caso de los ecosistemas con un solo oferente (o cuando la licitación se declare desierta), nuestra propuesta asigna al Estado una responsabilidad respecto a estas áreas, debiendo compensar al propietario, o alternativamente adquirir el predio.

El esquema propuesto permitiría establecer un régimen que defina con mayor claridad las áreas del territorio destinadas a la conservación. Lo anterior permitiría que se constituya un sistema que genere mayor certeza respecto a las áreas de protección de la biodiversidad en el largo plazo y que permita a los privados contar con un sistema que genere los incentivos adecuados para conservar dichas áreas.

Finalmente, se debe aprovechar la reforma a la institucionalidad ambiental en curso para implementar un sistema que permita cumplir con las metas de conservación definidas. En definitiva, esta propuesta pretende potenciar, de manera eficiente, el interés privado en la conservación, para dar cumplimiento a las metas fijadas en la ENB. 


\section{BiBLIOGRAFÍA}

Conama: “Estrategia Nacional de Biodiversidad”. Santiago, 2003.

Corcuera, Elisa: "Conservación de Tierras Privadas en Chile y el Mundo: ¿Coincidencia o Tendencia?”. En Ambiente y Desarrollo, Vol. XV (4), 2000, pp. 36-43.

"Primer Congreso de Conservación Privada de Tierras en Chile". En Ambiente y Desarrollo, Vol. XIX (1), 2003, pp. 46-50.

Gajardo, Rodolfo: La Vegetación Natural de Chile: Clasificación y Distribución Geográfica. Santiago: Ed. Universitaria, 2a edición, 1995.

Geisse, Guillermo y Claudia Sepúlveda: "Iniciativas Privadas y Política Pública de Conservación Ambiental”. En Ambiente y Desarrollo, Vol. XVI (3), 2000, pp. 613.

Infante, Sebastián: “El Sendero de Chile”, 2007 (documento inédito).

International Union for Conservation of Nature (IUCN): Libro Rojo de Especies Amenazadas. IUCN, 2005.

Lindberg, Kreg: The Sale of Biodiversity to Nature Tourists. París: OCDE, 2003.

Luebert, Federico y Pablo Becerra: "Representatividad Vegetacional del Sistema Nacional de Áreas Silvestres Protegidas del Estado (SNASPE) en Chile”. En Ambiente y Desarrollo, Vol. XIV (2), 1998, pp. 62-69.

Luebert, Federico y Patricio Pliscoff: Sinopsis Bioclimática y Vegetacional de Chile. Santiago. Editorial Universitaria, 2006.

Maldonado, V. y R. Faúndez: “Asesoría para la Actualización Base de Datos Cartográfica de Áreas Silvestres Protegidas Privadas a Nivel Nacional. Informe Final”. Programa de Biodiversidad Codeff/Conama, Santiago, diciembre 2005.

Matte L., Eliodoro: Discurso de presentación del seminario "Liderazgo del sector privado en la conservación del medio ambiente”. Infra, en esta misma edición de Estudios Públicos.

Muñoz, M., J. Yáñez y H. Núñez: Libro Rojo de los Sitios Prioritarios para la Conservación de la Diversidad Biológica en Chile. Santiago: Conaf, 1997.

Myers, Norman, et al.: "Biodiversity Hotspots for Conservation Priorities". En Nature, 403, 2000, pp. 853-858.

OECD: "Recommendation of the Council on the Use of Economic Instruments in Promoting the Conservation and Sustainable Use of Biodiversity”. Adoptada por el Consejo de la OECD el 21 de abril de 2004.

OECD, Programa de la OECD para el Medio Ambiente: "Harnessing Markets for Biodiversity: Towards Conservation and Sustainable Use”, 2003.

Pauchard, Aníbal y Pablo Villarroel L.: "Protected Areas in Chile: History, Current Status, and Challenges”. En Natural Areas Journal, Vol. 22 (4), 2002, pp. 318-330.

Saavedra, Bárbara: “Karukinka, Nuevo Modelo para la Conservación de Biodiversidad”. En Ambiente y Desarrollo, Vol. 22 (1), 2006, pp. 21-27.

Sepúlveda, Claudia: "Incentivos para la Creación y Manejo de Áreas Silvestres Protegidas Privadas en Chile”. En Ambiente y Desarrollo, Vol. XIII (3), 1997, pp. 38-46. “Áreas Privadas Protegidas y Territorio: La Conectividad que Falta”. En Ambiente y Desarrollo, Vol. XVIII (2-3-4), 2002, pp. 119-124.

Sepúlveda, Claudia, et al.: "Aportes al Reglamento para Áreas Protegidas Privadas”. En Ambiente y Desarrollo, Vol. XIX (1), 2003, pp. 32-42. 
Sepúlveda, Claudia y Pablo Villarroel: "Servicios Ecosistémicos y Financiamiento de la Conservación Privada en Chile”. En Ambiente y Desarrollo, Vol. 22 (1), 2006, pp. 12-20.

Simpson, David: “Conserving Biodiversity through Markets: A Better Approach”. En Perc Policy Series, 2004.

Tacón, Alberto, et al.: Evaluación Rápida de la Efectividad de Manejo en las Áreas Silvestres Protegidas de la Ecorregión Valdiviana. Santiago: WWF-Conaf, 2005.

Ubilla, Jaime: "La Conservación Privada de la Biodiversidad y el Derecho Real de Conservación”. En Revista de Derecho Ambiental, Centro de Derecho Ambiental, Universidad de Chile, 2004.

UNEP: “Directrices para las Categorías de Manejo de Áreas Protegidas”, disponible en la página web: http://www.unep-wcmc.org/protected_areas/categories/esp/index.html.

Villarroel, Pablo: "Cooperación Público-Privada para la Conservación de la Biodiversidad". En Ambiente y Desarrollo, Vol. XIV (4), diciembre de 1998, pp. 65 -72.

"Los Gestores Privados y su Papel en la Conservación de la Biodiversidad”. En Ambiente y Desarrollo, Vol. XX (1), 2004, pp. 65-74.

Western Governors Association: "Purchase of Development Rights: Conserving Lands, Preserving Western Livelihoods”. 2001.

Palabras clave: política chilena de conservación del medio ambiente y protección de la biodiversidad; sector privado y conservación del medio ambiente; economía del medio ambiente. 